\title{
Development of Novel Strategies for Enhancing the Cycle Life of Lithium Solid Polymer Electrolyte Batteries
}

Grant No. DE-FG02-93ER14387

By

Digby D. Macdonald*, Mirna Urquidi-Macdonald***, Harry Allcock**, and George Engelhard*

Students Contributors (Alphabetical Order): N. Bomberger***, L. Gao*, and D. Olmeijer**

The Pennsylvania State University

***203C Earth-Engineering Science Building. Mumesm@engr.psu.edu

*201 Stiedle Building.Ddm2@psu.edu

**103 Chandlee Lab.

University Park, PA 16802

Submitted to:

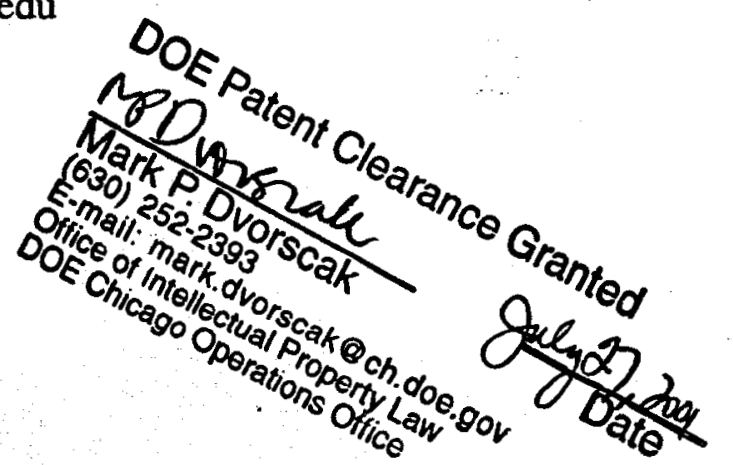

Dr. Paul Maupin

Department of Energy/Division of Chemical Sciences

Office of Basic Energy Sciences, ER 142

19901 Germantown Road

Germantown, MD 20874-1290

April 2001 


\section{DISCLAIMER}

This report was prepared as an account of work sponsored by an agency of the United States Government. Neither the United States Government nor any agency thereof, nor any of their employees, makes any warranty, express or implied, or assumes any legal liability or responsibility for the accuracy, completeness, or usefulness of any information, apparatus, product, or process disclosed, or represents that its use would not infringe privately owned rights. Reference berein to any specific commercial product, process, or service by trade name, trademark, manufacturer, or otherwise does not necessarily constitute or imply its endorsement, recommendation, or favoring by the United States Government or any agency thereof. The views and opinions of authors expressed herein do not necessarily state or reflect those of the United States Government or any agency thereof. 


\section{DISCLAIMER}

Portions of this document may be illegible in electronic image products. Images are produced from the best available original document. 
INDEX

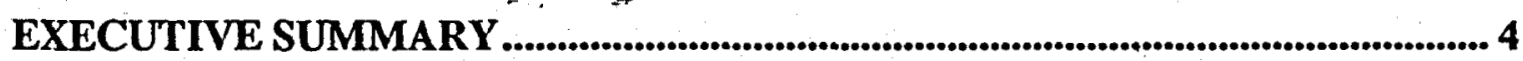

\section{CHAPTER 1. LITHIUM INTERCALATION RECHARGEABLE BATTERIES.... 7}

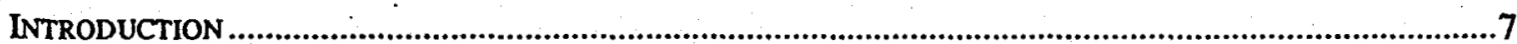

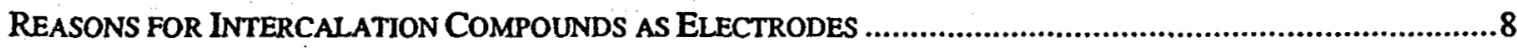

ACTIVE MATERIALS FOR SECONDARY LITHIUM-ION BATTERIES .............................................................

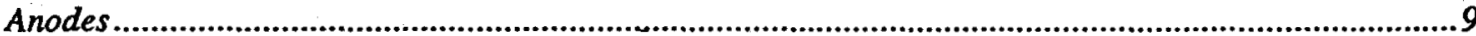

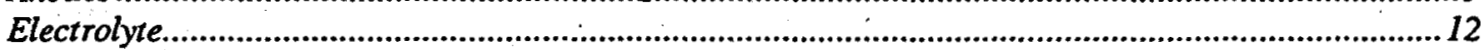

Cathodes

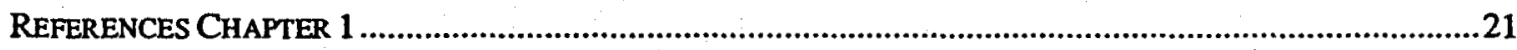

CHAPTER 2. POLYMER SYNTHEIS............................................................. 23

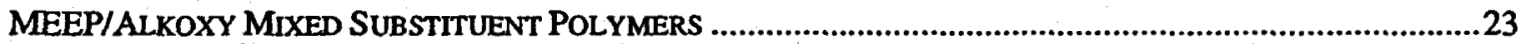

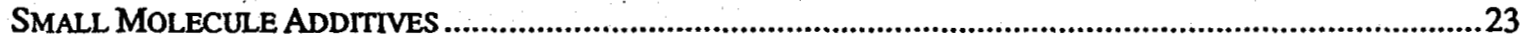

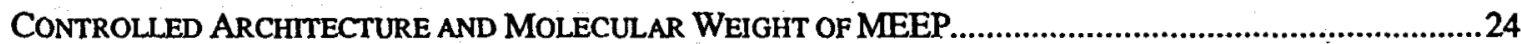

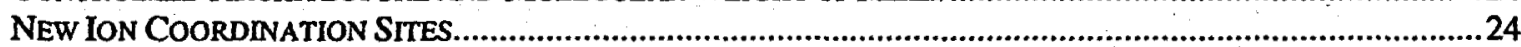

CHAPTER 3. EXPERIMENTAL SET UP .......................................................... 25

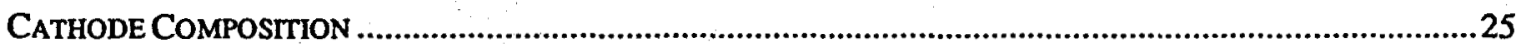

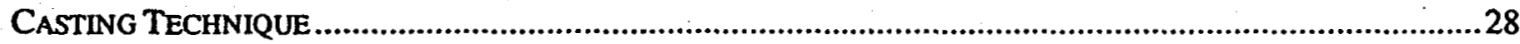

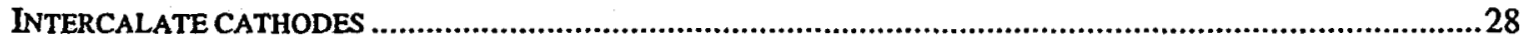

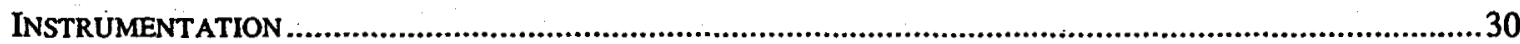

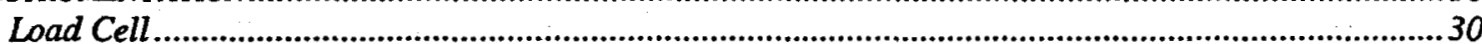

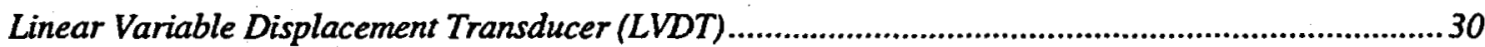

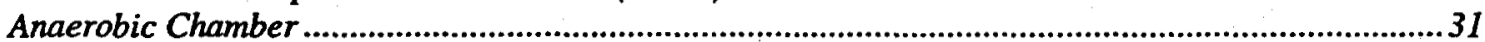

Electrochemical Measuring System.....................................................................................................31

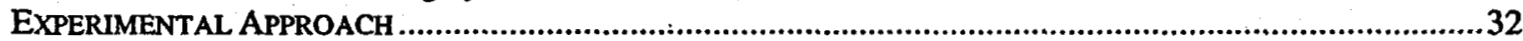

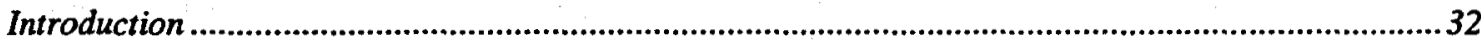

Sample Configuration

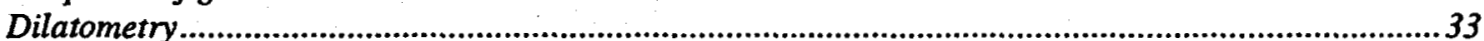

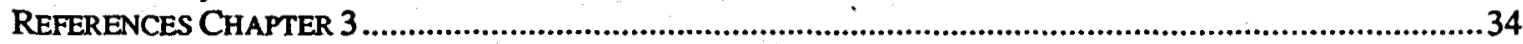

CHAPTER 4. EXPERIMENTAL RESULTS ..................................................... 43

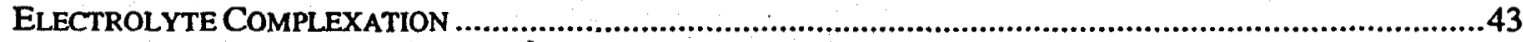

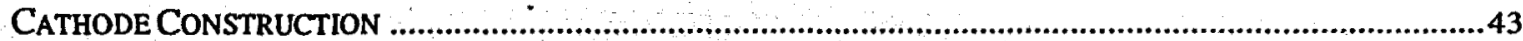

CHARACTERIZATION OF LJ/SPE/IC AND IC/SPE/C' LAMINATE

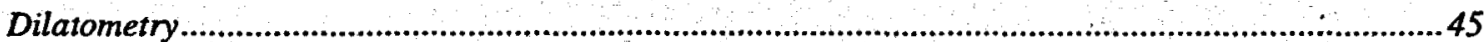

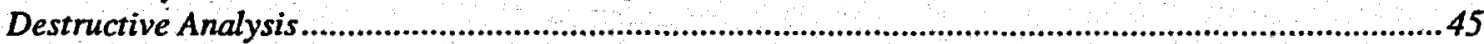

Impedance .

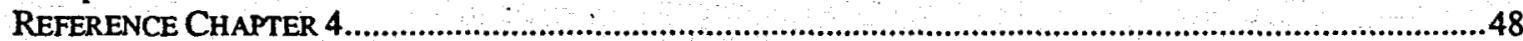

CHAPTER 5. CATHODE/POLYMER INTERFACE MODELING ..................... 54

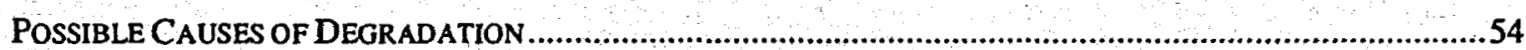

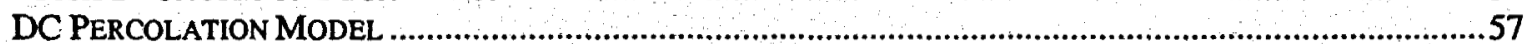

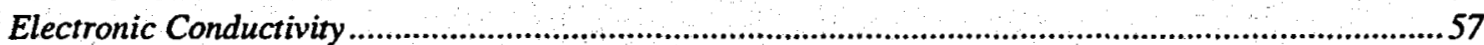

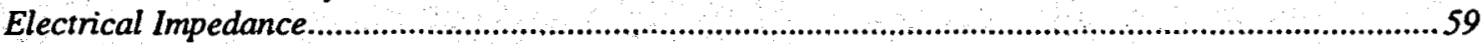

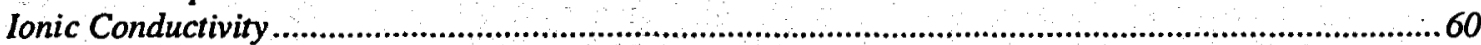

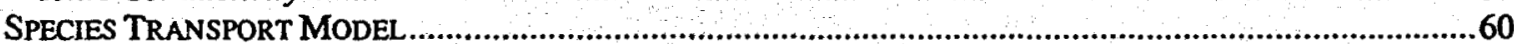

REFERENCES CHAPTER 5

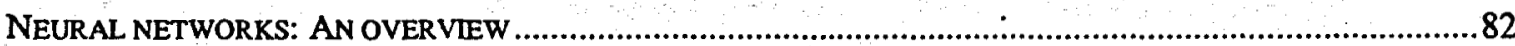

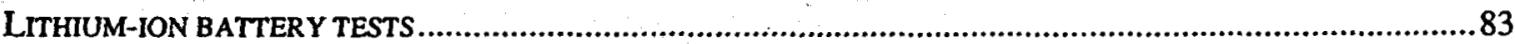

DATA REPRESENTATION ONE

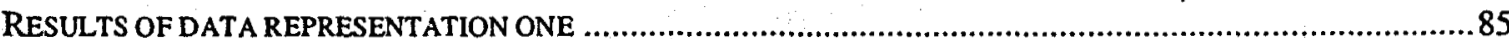


DATA REPRESENTATION TWO

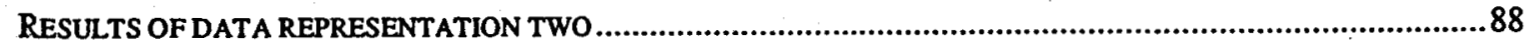

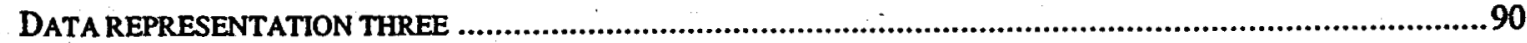

RESULTS FOR DATA REPRESENTATION THREE

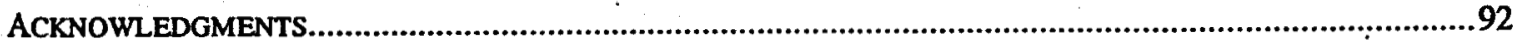

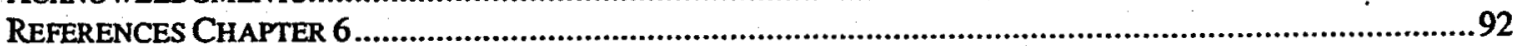

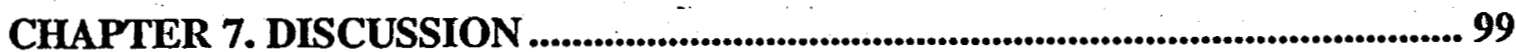

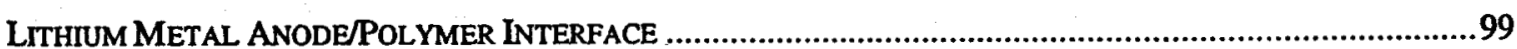

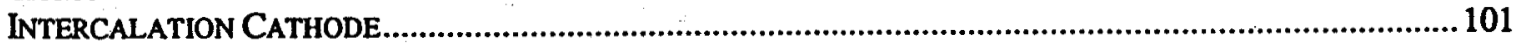

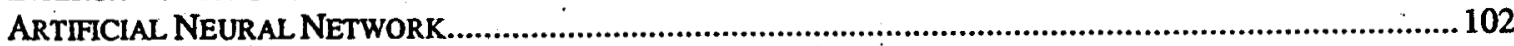

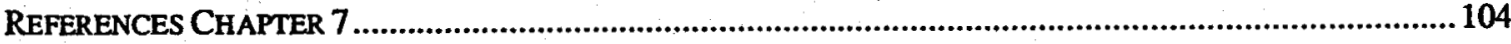

APPENDIX 1. LIST OF PUBLICATIONS AND ABSTRACT ..........................108

APPENDIX 2. PATENTS AND INVENTION DISCLOSURES.....................110

APPENDIX 3. STUDENT'S THESES.............................................111 


\section{Executive Summary}

Lithium/solid polymer electrolyte $(\mathrm{Li} / \mathrm{SPE})$ secondary batteries are under intense development as power sources for portable electronic devices (computers, cellular telephones, etc.), as well as electric vehicles. These batteries offer many advantageous characteristics; including high specific energy, high energy density, very low self-discharge rates, and great flexibility in packaging. However, problems have arisen that, to date, have inhibited the introduction of this technology into the marketplace. These problems include:

- Concern over the safety of metallic lithium, which has resulted in an extensive investigation of lithium intercalated carbon anodes -- the type that are used in liquid electrolyte, "lithium-ion" or "rocking-chair" batteries.

- Low specific power and power density, which severely restrict the use of Li/SPE batteries in applications that require moderate-to-high power levels.

- Low cycle life resulting from irreversible changes that occur in Li/SPE batteries on cyclic charging/discharging. The low cycle life is believed to result from reactions that occur between the $\mathrm{Li}$ and $\mathrm{SPE}$, and from irreversible processes that occur within the intercalation cathode.

The present report summarizes the findings of a four-year program, including a one-year, no-cost extension, to examine processes that occur within $\mathrm{Li} / \mathrm{SPE}$ secondary batteries upon cyclic charging/discharging. The report includes a detailed analysis of the impedance measured on the Li/SPE/IC and IC/SPE/IC systems, which were charge-cycled by applying a high current density $\left(6 \mathrm{~mA} / \mathrm{cm}^{2}\right)$ to accelerate failure. The SPE used was Super-MEEP. (a derivative of methoxyethoxyethoxyphosphazene) with lithium triflate salt as the electrolyte, while the intercalated cathodes (IC) comprised mixtures of $\lambda$ - or $\gamma-\mathrm{MnO}_{2}$, carbon powder, and MEEP (methoxyethoxyethoxyphosphazene) as a binder. Symmetrical laminates of the type Li/SPE/Li and IC(Li)/SPE/C (where the left side was initially loaded with $\mathrm{Li}$ ), and unsymmetrical laminates of the type Li/SPE/IC, were charge cycled over 2 or 4 hours $(1$ or 2 hours in each direction) with impedance measurements taken at constant potential at five cycle intervals. Failure was indicated by a sharp rise in the laminate impedance on further cycling. The results indicate that the cycle life of this specific, Super-MEEP-based unsymmetrical laminate (battery) is due to the failure of the IC, and not to the failure of the lithium/SPE interface. 
Studies on symmetrical Li/SPE/Li laminates, using impedance spectroscopy and sensitive dilatometer, show that cycling results in a significant expansion of the structure over the first few tens of cycles; however, no corresponding increase in the impedance was noted. Destructive examination of the Li/SPE interface after cycling revealed the lack of lithium "powdering", which has been reported for other Li/SPE systems. Nevertheless, the irreversible expansion of the laminate on cycling is attributed to the reaction of lithium with components of the SPE, possibly with residual water. As noted above, no increase in impedance was noted as the symmetrical $\mathrm{Li} / \mathrm{SPE} / \mathrm{Li}$ laminates were cycled, and a model that postulates the interstitial transport of $\mathrm{Li}^{+}$through a reaction product layer at the Li/SPE interface accounted for the impedance data.

The cycle life of the intercalation cathode was found to be very sensitive to the method of fabrication. Thus, as-cast cathodes failed after a few tens of cycles under the severe cycling regimen employed, whereas cathodes that had been hydrostatically pressed after casting cycled for more that 400 cycles without any evidence of capacity loss or increase in impedance. The principal failure mode of the cathode is postulated to be due to cyclic stresses induced by intercalation/deintercalation of $\mathrm{Li}^{+}$from the $\mathrm{MnO}_{2}$ active material, resulting in the rupture of ohmic contacts within the composite structure. Rupture of the ohmic (carbon/carbon and carbon $/ \mathrm{MnO}_{2}$ ) contacts results in an increase in the resistivity of the cathode, which decreases the current penetration depth on subsequent cycles, thereby leading to a loss of capacity and ultimately to a catastrophic increase in resistance, as percolation within the structure is lost. Other mechanisms are also possible, including possibly the reaction of $\mathrm{Li}^{+}$with species in the cathode, resulting in the irreversible loss of mobile lithium ions within the active $\left(\mathrm{MnO}_{2}\right)$ phase (e.g., reaction of $\mathrm{Li}^{+}$with residual water to form mono molecular $\mathrm{LiOH}$, which does not migrate within the $\mathrm{MnO}_{2}$ lattice)

Initial modeling of the intercalation cathode, by solving the transport equations for $\mathrm{Li}^{+}$, $\mathrm{X}^{-}$(counter ion), and $\mathrm{e}^{-}$in the composite structure consisting of an active material $\left(\mathrm{MnO}_{2}\right)$; an electronic conductor (carbon), and a polymer binder/electrolyte (MEEP), was performed, with the objective of simulating processes that occur within the cathode on cycling. One model assumed the irreversible loss of mobile lithium within the active material; a finite capacity of the active material $\left(\mathrm{MnO}_{2}\right)$ to accommodate $\mathrm{Li}^{+}$, together with appropriate boundary conditions; and that the electrons are in quasi-equilibrium. The model indicates that the $\mathrm{Li}^{+}$concentration in the 
composite changes most rapidly closest to the IC/SPE interface and that the penetration depth (the distance over which the $\left[\mathrm{Li}^{+}\right]$changes) is a sensitive function of the transport properties. However, under certain conditions, $\left[\mathrm{Li}^{+}\right]$appears to be relatively constant and the kinetics of charge/discharge are governed by intercalation/deintercalation of $\mathrm{Li}^{+}$into/from the $\mathrm{MnO}_{2}$ active material. Characterization of the penetration depth into both the composite and the active material, as a function of charge/discharge parameters, is of the utmost importance, because these factors ultimately control the capacity of the cathode.

We also explored percolation models -- at the rudimentary level -- to explain the sudden increase in resistance of the cathode that signaled failure. While a percolation model readily accounts for the increase in impedance, the complexity of the relationships between the dependent (resistance) and independent variables (charge/discharge characteristics) is such that quantitative prediction of the cathode resistance and capacity as a function of the cycling parameters could not be made. However, by combining percolation with the intercalation model outlined above, qualitative explanation has been achieved for the charge/discharge and failure behavior of the composite intercalation cathode.

Finally, a pattern recognition neural network (ANN), using a wavelet representation, was developed during this research program, in order to predict the cycle life of a battery from the charge/discharge characteristics. The ANN was trained using extensive data for Li-ion batteries obtained from NASA, because, at the time that the ANN was developed, insufficient data had been collected on the present project. This model, which is not based on any preconceived mechanism, but instead defines patterns between the dependent and independent variables, proved to be capable of predicting the cycle life of a battery from data collected over as little as $10 \%$ of the life. This finding may indicate that processes that eventually cause the battery to fail are manifest early in the battery duty cycle, but that they are generally obscured by the processes of normal battery operation. The development of this model was described in "Great Advances in Science," by the Science Coalition, with the report being presented in September 1998 to the 105th US Congress. The objective of that report was to demonstrate the tremendous benefits accrued from investment in university-based research. 


\section{Chapter 1. Lithium Intercalation Rechargeable Batteries}

\section{Introduction}

The primary objectives of this study were to: (1) Explore the mechanism(s) of failure of $\mathrm{Li}^{+}$intercalation cathodes (IC) on charge cycling; (2) Develop and evaluate new solid polymer electrolytes (SPEs) based on the polyphosphazenes platform; and (3) Develop models for predicting the cycle life of $\mathrm{Li} / \mathrm{SPE} / \mathrm{IC}$ batteries under specified charge/discharge cycling regimens at constant temperature $\left(22^{\circ} \mathrm{C}\right)$ and at variable pressures. The SPEs were based on MEEP (methoxyethoxyethoxyphosphazene) and "super-MEEP" (SMEEP, a derivative of MEEP, which is mechanically more robust), with lithium triflate (lithium trifluorosulfonate) added as the electrolyte.

The ICs were prepared with MEEP as the binder, carbon black as the electronically conducting phase, and $\lambda$ - or $\gamma-\mathrm{MnO}_{2}$ as the active material. Two methods of preparing ICs were employed in the study: (i) Solution casting; and (ii) compression of mixtures of the components in a die at a pressure of $5000 \mathrm{psi}$. The electrolyte separating the two electrodes (ICs, $\mathrm{Pt}$, or $\mathrm{Li}$ ) was Super-MEEP, containing Li triflate as the salt. While cycling the cell galvanostatically at a current density of $6 \mathrm{~mA} / \mathrm{cm}^{2}$, generally for one hour in each direction, the cell volume was monitored using a sensitive linearly variable differential transformer (LVDT). Cycling was periodically interrupted to measure the cell impedance using electrochemical impedance spectroscopy (EIS). A unique feature of this work is that the impedance data were assessed for compliance of the system with the constraints of Linear Systems Theory using the KramersKronig transforms. Initially, symmetrical laminates of the type $\mathrm{Pt} / \mathrm{SPE} / \mathrm{Pt}$ and $\mathrm{Li} / \mathrm{SPE} / \mathrm{Li}$ were explored. The impedance of the Pt/SPE/Pt laminate initially decreased as pressure was applied across the system, which was attributed to a decrease in the contact resistance between the Pt and the SPE. However, as the pressure was further increased, the impedance was found to increase, which was interpreted as reflecting a decrease in the free volume of the SPE. The volume of an unsymmetrical $\mathrm{Li} / \mathrm{SPE} / \mathrm{CC}$ laminate initially increased with cycle number, but then attained a steady state after approximately 500 cycles. The pressure exerted by the laminate against a retaining spring was found to increase with cycle number, but it too eventually reached a steady state. The increase in volume and pressure is attributed to the irreversible reaction of lithium with moisture and/or components of the electrolyte. 
We then studied the cycling performance of the intercalated cathode (IC/SMEEP) interface. This was done by cycling symmetrical laminates of the type IC'/SMEP/IC (where IC' is an intercalation cathode that was preloaded with lithium), and also by cycling unsymmetrical laminates ( $\mathrm{Li} / \mathrm{SMEEP} / \mathrm{IC})$. The ICs that were prepared by solution casting generally failed in a few tens of cycles. However, those ICs that were prepared by compressing mixtures of the components at 5000 psi displayed small changes of impedance in over 500 cycles. The impedance was found to remain essentially constant throughout the entire cycling regimen, and was essentially resistive (non-reactive) at frequencies below $10 \mathrm{kHz}$. No powdering of the $\mathrm{Li}$ electrode and no sudden increase of impedance value, both of which are characteristic of the "failure" of $\mathrm{Li} / \mathrm{SPE}$ batteries and IC'/SMEP/IC laminates (resistance increase only), were detected on post-test examination. The principal experimental finding of this study is that the IC was generally responsible for failure on charge cycling in the types of batteries explored in this work, contrary to previous reports of failure of Li/SPE batteries being due to the anode ("lithium powdering").

Two types of models were developed to account for failure of the intercalation cathodes: (i) A percolation model, which uses empirical equations and can explain DC and AC impedance results, but carries little inside physico-chemical information; and (ii) a deterministic physical model based on solving transport equations in one dimension.

The percolation model was extensively presented in Gao Lei's thesis [1] and is briefly discussed in this report. The deterministic model performed on data produced during this research effort describes the degradation in capacity of an IC, and its subsequent failure, to the irreversible loss of mobile $\mathrm{Li}^{+}$due to reaction with IC tramp components (i.e., water). This reaction (i.e., the formation of $\mathrm{LiOH}$ ) removes $\mathrm{Li}^{+}$from the immediate environment adjacent to the active material and hence is no longer available for intercalation/de-intercalation.

\section{Reasons for Intercalation Compounds as Electrodes}

Intercalation compounds are used as electrodes in secondary lithium ion batteries, because they undergo discharge/recharge cycles more reversibly than alternative materials, and because they reduce the reactivity of the intercalated material with the electrolyte. When a metal such as lithium is used as an electrode in a secondary battery, the repeated cycling causes the lithium to plate onto the electrodes as long dendrites instead of a uniform sheet. These dendrites 
can become electrically disconnected from the rest of the electrode, thus the battery's capacity can be greatly reduced. There are also safety considerations since dendrites increase the lithium metal surface area, thus increasing the area for energetic reactions with the electrolyte to occur. The intercalation compound also reduces the negative effects of reaction of the electrode metal with the electrolyte by isolating the metal ion from the electrolyte in the intercalation compound. These reactions often damage the electrolyte/electrode interface, which is very important for the performance of the battery.

The development of secondary lithium ion batteries -- using cathodic intercalation compounds and without aqueous electrolytes having high energy density and recharge ability -was not successful until a replacement was found for the lithium metal anode [15]. Lithium ions were found to intercalate almost totally reversibly in some cathodic intercalation compounds, but the lithium metal anode caused problems due to dendrite formation [2] and reaction with organic electrolytes to form a passive film [6], as mentioned above. The alternatives that were found for lithium metal anodes were $\mathrm{Li}-\mathrm{C}$ intercalation compounds (with a theoretical stoichiometry of $\mathrm{LiC}_{6}$ ). The reversible intercalation of lithium has been documented with a variety of carbons, such as graphite, carbon fiber, and petroleum coke electrodes [7]. These electrodes prevent lithium dendrite formation upon cycling and are expected to reduce the reactivity of lithium with the electrolyte since the lithium rest potential is lower than the potential at which $\mathrm{Li}-\mathrm{C}$ intercalation occurs. However, reduction of many solvents used in the electrolytes of these batteries occurs at potentials much greater than the lithium rest potential, and the surface chemistry of lithium intercalation carbons in these solvents may be similar to that of lithium metal, requiring other means to prevent such reactions [7].

\section{Active Materials for Secondary Lithium-Ion Batteries}

\section{Anodes}

Ambient temperature secondary lithium cells with lithium metal anodes have limited cycle life, due to reasons mentioned above. Subbaro et al. [1] theorized that this reduced cyclability is due mainly to the reactivity of the lithium anode with the organic electrolyte, and could be improved by replacing the lithium anode with a lithium-rich alloy that would reduce the reactivity of the anode with the electrolyte. They proposed testing the following alloys based on several properties of $\mathrm{Li}-\mathrm{Al}$, $\mathrm{Li}-\mathrm{Si}, \mathrm{Li}-\mathrm{Sn}, \mathrm{Li}-\mathrm{Zn}, \mathrm{Li}-\mathrm{Pb}$, Li-Cd. 
The use of carbon intercalation compounds may be a better way to reduce reactivity with electrolytes, deterioration of the anode/electrolyte interface, and prevent reduced cycle ability. Aurbach et al. [7] investigated the intercalation performance of several different types of carbons in different environments. The carbons they tested were Ketjen black (KB), Antralur, Acetylene black, graphite, and carbonized polyacryonitrile (PAN), which were produced using the binders (4-5 weight \%) ethylene/propylene/diene polymer (EPDM), Teflon PTFE, or polyvinylidene difluoride (PVDF). The anodes were tested in propylene carbonate (PC), tetrahydrofuran (THF), and methyl format $(\mathrm{MF}) / \mathrm{CO}_{2}$ solutions of $1 \mathrm{M} \mathrm{LiAsF}_{6}$.

Aurbach et al. [7] found that the intercalation performance depends on the carbon material, the binder, the electrolyte, and the additives to the electrolyte. The first four charge/discharge cycles for five different carbons in two different electrolytes were explored. The carbons perform much better in $\mathrm{MF} / \mathrm{CO}_{2}$ solvent than $\mathrm{PC}$, and graphite and $\mathrm{PAN}$ have the highest degree and reversibility of intercalation in $\mathrm{MF} / \mathrm{CO}_{2}$. Graphite is greatly affected by the electrolyte used, as can be seen by the zero values for lithium intercalation in PC. The reduction of $\mathrm{Li}-\mathrm{C}$ intercalation with $\mathrm{PC}$ as the solvent is thought to be due to the co-intercalation of PC with the lithium ions in the graphite, thus allowing the PC to react with the graphite and causing deterioration of the structure. The effect of the solvent used on the performance of two different cathodes is shown. As suggested by the author, the presence of $\mathrm{CO}_{2}$ in the electrolyte may improve performance by forming a passive film of $\mathrm{Li}_{2} \mathrm{CO}_{3}$, which prevents the reaction of solution species with the anode, thereby hindering the $\mathrm{Li}-\mathrm{C}$ intercalation reaction.

Among the binders used to produce the carbon cathode, Teflon and PVDF were found to offer both good degree and reversibility of intercalation, while EPDM performed poorly. The optimum amount of binder used was 4-5 weight \%. The superior performance of Teflon and PVDF was believed to be due to their fluorinated carbons, which undergo reactions that stabilize carbon atoms in the lattice and prevent solution particles from infiltrating and reacting to cause deterioration of the anode structure.

Based on their results, Aurbach et al. [7] recommends the use of an anode structure between graphite, which has an ordered structure and a high degree of intercalation, but is greatly affected by the solution used; and carbon black, which is less ordered and has a lower 
degree of intercalation, but is not strongly affected by the electrolyte solution used. PAN also shows a promising degree of intercalation and reversibility when the proper solution is used.

Shi et al. [13] studied the effect of stacking patterns on the reversible capacity of graphite. They studied graphite as a potential intercalation anode, because it is odorless, tasteless, nontoxic, and has excellent lithium intercalation properties, such as high reversible lithium intercalation, good electronic conductivity, and low electrochemical potential vs. $\mathrm{Li} / \mathrm{Li}$. Graphite is made of a planar hexagonal network of carbon atoms, and has two different stacking order phases: hexagonal $(2 \mathrm{H})$ and rhombohedral (3R). A piece of graphite can contain both of these stacking arrangements, along with areas of turbostatic disorder that contain random stacking faults. These stacking faults reduce the specific capacity for lithium intercalation of the graphite, because the faults cause strains and defects that do not allow the layers to shift when lithium is intercalated, as they would for well-ordered, stacked layers. The stacking phases present and the amount of stacking faults depends on the graphite processing, starting materials, atmosphere, and heating conditions.

The $2 \mathrm{H}$ and $3 \mathrm{R}$ phases can be detected by $\mathrm{X}$-ray diffraction (XRD), and Shi et al. [13] devised a structural model and a computer program that could be used with the XRD pattern to calculate the percentage of $3 \mathrm{R}$ phase, $2 \mathrm{H}$ phase, and stacking faults present in the graphite. Based on these values, they calculated a theoretical lithium intercalation capacity, which was then compared to the measured capacity. The calculated capacities were reasonably close to the measured capacities. Notice that the graphites with the highest amount of stacking faults $\left(\mathrm{P}_{2 \mathrm{H}}\right.$ and $P_{3 R}$ ) have the lowest capacities. The letter " $x$ " indicates the percentage of $3 H$ phase present. The authors found that there was no significant difference between the intercalation capacities of the $2 \mathrm{H}$ and $3 \mathrm{R}$ phases, both having a theoretical capacity of $372 \mathrm{mAh} / \mathrm{g}$.

Another form of hard carbon intercalation compound - graphene sheets -- were studied by Xing et al. [14]. Graphene sheets are prepared from hard carbons at temperatures near 1000 ${ }^{\circ} \mathrm{C}$. The authors used different organic materials (sugar, nuts, wood, resin, etc.) prepared in different ways and heated at different temperatures to produce different graphene sheet samples. Graphene sheets have the same hexagonal carbon shapes in planar arrays as crystalline graphite, but the sheets only consist of a few dozen hexagons. X-ray diffraction (XRD) can be used to determine the size of the sheets and the nature of the stacking. The (100) and (110) peaks 
determine the width of the sheets and the (002) peak indicates how many sheets are stacked in a parallel fashion. Sheets that are not in a parallel stack are said to be single sheet regions. According to the falling cards model, the cross-linked single sheet regions form micropores for lithium intercalation. When a parallel sheet region is formed, larger pores develop, because 2 small pores become 1 larger pore. It has been shown that samples with more single-layer regions have the highest lithium intercalation capacity. Large pores and pore openings are thought to allow electrolytes to enter intercalation sites, which react with the compound and occupy sites that could have been used for lithium ions. Thus, hard carbon samples with small pores/openings with maximized pore wall area per unit mass of carbon should be able to intercalate the most lithium.

Xing et al. [14] used small angle X-ray sçattering (SAXS) to determine the average pore size of their different samples in order to determine if there was a correlation between pore opening size and reversible capacity. They found that, for graphene sheets produced from dewatered sugar carbon, reversible capacity decreases as the amount of parallel layer regions increases and pore opening size increases, with a maximum reversible capacity of approximately $600 \mathrm{mAh} / \mathrm{g}$. Two explanations for the higher capacity of single-layer regions are their resistance to reaction with electrolytes due to smaller pore openings (as mentioned above) and their ability to absorb lithium on both sides of their graphene sheets, since they have no parallel neighbor sheets.

Starting materials, and the production processes used, both play a role in determining the structure of the graphene sheets and the resulting intercalation performance. Environmental factors during production, such as the presence of certain gases during pyrolization, are also a factor. The absence of argon and/or the presence of carbon dioxide during pyrolization can cause carbon burn off, which can "burn away" cross links between single-layer regions, allowing sheets to rotate and form parallel regions, thus increasing pore size.

\section{Electrolyte}

The ideal electrolyte has high conductivity, a wide electrochemical operating window, high stability toward lithium, low density, low viscosity, and is compatible with the cathode and separator materials. Some solvents that have been investigated for electrolytes are tetrahydrofuran (THF), 2-methyl tetrahydrofuran (2-MeTHF), methyl formate (MF), and 
propylene carbonate (PC). These organic, non-aqueous electrolytes provide poor cycle ability, because they react strongly with lithium. Also, they have relatively low conductivity compared to aqueous electrolytes, which are avoided due to their reactivity with lithium.

To avoid the problem of reactivity with lithium, Subbaro et al. [1] investigated the use of electrolytes made from mixed solvents. They used 2-MeTHF and THF as base solvents, and ethylene carbonate (EC), PC, and 3-methylsulfolane (3-Mes) as the co-solvents. For these they measured conductivity, stability towards lithium, and lithium cycling efficiency. The results for some of the selected electrolytes are discussed. The electrolytes containing EC performed the best, with the electrolyte made from $10 \% \mathrm{EC}+90 \%$ 2-MeTHF offering the best overall performance. Experimental cells using an electrolyte made from this solvent and $\mathrm{LiAsF}_{6}$ operated for over 300 cycles at $100 \%$ depth of discharge (DOD). FTIR and AC impedance studies suggest that this superior performance is due to the formation of $\mathrm{Li}_{2} \mathrm{CO}_{3}$ film on the surface of the lithium electrode, preventing reactions with the electrolyte that cause deterioration of the surface.

Surampudi et al. [6] studied the cycle life performance and reactivity with lithium of a variety of liquid, organic electrolytes. They tested electrolytes containing $1.5 \mathrm{M} \mathrm{LiAsF}_{6}$ in the following solvents: THF, EC + THF, THF + 2-MeTHF, 2-MeTHF + 2-MeF, EC + 2-MeTHF + 2-MeF, THF + 2-MeTHF, 2-MeF, and dioxolane + 2-MeF. The cycle life performance of these electrolytes were tested in sealed, spiral-wound $1 \mathrm{~A}-\mathrm{h} \mathrm{Li}-\mathrm{TiS}_{2}$ cells. The capacity vs. number of cycles for the electrolytes indicates that the three electrolytes with the best performance were $\mathrm{THF}+2-\mathrm{MeTHF}+2-\mathrm{MeF}, \mathrm{EC}+2-\mathrm{MeTHF}+2-\mathrm{MeF}$, and 2-MeTHF + 2-MeF

Using micro-calorimetry, the reactivity of the different electrolytes with lithium was measured. The electrolytes that give the least heat output when exposed to lithium are the least reactive. The EC + 2-MeTHF + 2-MeF, THF + 2-MeTHF + 2-MeF, and 2-MeTHF + 2-MeF were the least reactive of the reactive electrolytes tested. These are the same electrolyte solvents that were found to have the most cycle ability, indicating that the reactive electrolytes cause a passive film to form on the anode, thus increasing the resistance and reducing the cycle life.

Aurbach et al. [7] studied the effect of different electrolyte solvents on the cycle ability of lithium batteries. The electrolyte solution MF-LiAsF $6(1 \mathrm{M}) / \mathrm{CO}_{2}(6 \mathrm{~atm})$ exhibited the best performance. 
Irish et al. [10] used corrosion potential-time transients to rank the reactivity of three electrolyte solvents: THF, 2 Me-THF, and PC. They found that PC exhibits the greatest reactivity with lithium, and that water impurities in the solvent tend to cause the lithium surface film to break down, exposing bare lithium during intense anodic cycling, thus leading to increased corrosion potentials. Using Raman spectroscopy, they found evidence that the presence of $\mathrm{CO}_{2}$ causes the formation of a carbonate film on the lithium anode surface. This may prevent further reactions with the electrolyte and explain the superior performance of batteries exposed to $\mathrm{CO}_{2}$, as shown by Aurbach et al. [7]

Alternatives to liquid, organic electrolytes are polymer electrolytes. Polymer electrolytes made from poly(ethylene oxide) (PEO) and a lithium salt $\left(\mathrm{LiClO}_{4}, \mathrm{LiCF}_{3} \mathrm{SO}_{3}, \mathrm{LiBF}_{4}\right)$ can be used to produce high energy, rechargeable lithium batteries. One problem with these polymer electrolytes is the high temperature $\left(80-100^{\circ} \mathrm{C}\right)$ that is required for them to have the conductive properties needed to operate properly. At this temperature, the polymer behaves much like a viscous liquid, leading to problems due to mechanical instability, passivation of electrodes, and leakage.

To produce a polymer with a more stable structure at high temperatures, Scrosati et al. [2] produced composite electrolytes by adding an inert filler (small grain size $\beta^{\prime \prime}-\mathrm{Al}_{2} \mathrm{O}_{3}$ ) to polymer complexes (i.e., $(\mathrm{PEO})_{8} \mathrm{LiClO}_{4}$ ). The inert filler allowed them to produce an electrolyte polymer complex that was chemically similar to the original polymer electrolyte, but with improved mechanical properties. The electrolyte still behaves as a liquid at the microscopic level, allowing fast ionic mobility, but the inert filler acts a supporting matrix for the amorphous conductive polymer. They found that if the filler particles used are small $(<5 \mu \mathrm{m})$, the conductivity of the composite electrolyte is comparable to the original polymer electrolyte. The polymer and filler particles have been shown to be non-reactive by Differential Scanning Calorimetry (DSC), which detects only one endothermic peak as the composite electrolyte is heated, which corresponds to the transition of the polymer complex from a crystalline to an amorphous state.

To verify the improved performance of the composite electrolyte, AC complex impedance responses were recorded for cells with a conventional polymer electrolyte and for cells with the composite electrolyte. The fresh cells were tested and then stored for 8 days at 80 ${ }^{\circ} \mathrm{C}$, and then tested again. The conventional polymer electrolyte showed an increase in the size 
of a low-frequency semicircle, which was associated with the electrolyte/anode interface, indicating that the resistance of the interface had, in fact, increased. This may be due to the reaction of the lithium with the electrolyte to form a passive, non-conducting layer. This lithium passivation is common with liquid, organic electrolytes and reduces cycling efficiency. The size of the semicircle associated with the electrolyte/anode interface did not increase appreciably, indicating that the anode was not passivated by the electrolyte. The effect of this on the cycling capacity of the batteries containing these electrolytes. A battery using the conventional polymer electrolyte underwent only 35 cycles at a C/5 discharge rate before failure, but a battery containing the composite electrolyte underwent 70 cycles at a C/5 rate, and 120 more cycles at a C/10 discharge rate.

\section{Cathodes}

Intercalation compounds for secondary lithium batteries have several advantages. The intercalation of lithium into these compounds is a virtually reversible process, providing high cycle ability. Unfortunately, deterioration of the cathode due to various reactions often reduces this cycle life. These cathodes also have a high projected energy density and are relatively inexpensive compared to other prospective materials [3].

Subbaro et al. [1] compared the performance of several different intercalation compounds for cathodes in secondary lithium batteries. The compounds they investigated were $\mathrm{TiS}_{2}, \mathrm{MoS}_{3}$, $\mathrm{V}_{6} \mathrm{O}_{13}$, and $\mathrm{NbSe}_{3}$. The results for their comparisons are discussed. TiS 2 performed the best with respect to realizable specific energy and cycle life. $\mathrm{MoS}_{3}$ and $\mathrm{V}_{6} \mathrm{O}_{13}$ were not able to reach their high theoretical specific energy, and they exhibited low cycle life.

The authors also found that the $\mathrm{TiS}_{2}$, which was prepared using the vapor transfer method, had a higher Faradaic utilization than the commercially available $\mathrm{TiS}_{2}$. This was probably due to the purity and stoichiometry of the samples. Several different binders were used for producing their cathodes, and they found that EPDM offered the best performance. The key function of a binder is to allow volume changes of the crystal lattice of the intercalation compound so that lithium can be intercalated and deintercalates. Three different methods for production of $\mathrm{TiS}_{2}$ were also compared. Brushing was the preferred method for preparing small electrodes for experiments in a glove box, and rolling and pressing were better for larger electrodes. 
Although the insertion of lithium into intercalation compounds is essentially a reversible process, capacity decline with cycling can be observed for polymer electrolyte secondary batteries. Some possible factors causing this include a deterioration of the cathode/electrolyte interface, changes in the cathode structure at the interface, and diffusion-controlled kinetics of the intercalation process. To avoid problems due to the deterioration of the interface, Scrosati et al. (3) tried to improve the composition and structure of the intercalation cathode. They compared a traditional compressed pellet cathode $\left(\mathrm{LiV}_{3} \mathrm{O}_{8}, \mathrm{AB}, \mathrm{PEO} ; 40: 40: 20\right.$ weight $\left.\%\right)$ with a cathode having a laminated structure made with $\mathrm{LiV}_{3} \mathrm{O}_{8}$ (particle size $<1 \mu \mathrm{m}$ ) mixed with $\mathrm{AB}$, $\mathrm{PEO}$, and $\mathrm{LiClO}_{4}$ to make a plastic-like cathode film similar in structure to the polymer electrolyte. Acetylene black $(\mathrm{AB})$ was used to provide electronic transport capability and PEO and $\mathrm{LiClO}_{4}$ were used to provide plasticity and ionic conductivity.

Using $\mathrm{AC}$ impedance spectroscopy, the authors showed that the frequency semicircle associated with the cathode/electrolyte interface expands upon cycling, indicating an increase in the resistance of the interface due to its deterioration. The same experiment conducted on the film cathode showed little change for the frequency semicircle associated with the cathode/electrolyte interface. Due to the plasticity and high electronic-ionic conductivity of the cathode, it maintains fast kinetics and good contact with the electrolyte. Cycling tests showed that the cathode film has very good initial cycling capacity (first 50 cycles), while the pellet cathode showed poor cycling properties. The film cathode does have to be used at a high temperature, around $120^{\circ} \mathrm{C}$, because its conductivity does not reach an acceptable level at temperatures below this.

Another lithium intercalation compound that has gained prominence recently is manganese oxide. This material offers high cell voltage, long shelf life, wide operating temperature and non-toxicity. Button-type and cylindrical primary lithium $/ \mathrm{MnO}_{2} 3-\mathrm{V}$ cells have been produced, usually using $\gamma-\mathrm{MnO}_{2}$, which has an intergrowth structure of ramsdellite- $\mathrm{MnO}_{2}$ and $\mathrm{B}-\mathrm{MnO}_{2}$. In this structure, oxygen ions are hexagonally close-packed, and the batteries using this compound show poor recharge ability.

Another $\mathrm{Mn}-\mathrm{O}$ structure can be prepared by reacting $\gamma-\mathrm{MnO}_{2}$ with $\mathrm{LiOH}$ at a moderate temperature. This forms a Li-Mn-O spinel component $\mathrm{Li}_{x} \mathrm{Mn}_{2-z} \mathrm{O}_{4}(0 \leq x \leq 1.33,0 \leq z \leq 0.33)$, which has a cubic close-packed oxygen array that is better than the HCP structure with respect to 
recharge ability. Cathodes having the spinel structure $\mathrm{Li}_{2} \mathrm{O} \cdot \mathrm{MnO}_{2}$ with high specific surface areas $\left(>50 \mathrm{~m}^{2} / \mathrm{g}\right)$ exhibit promising electrochemical performance. At low current density (100 $\left.\mu \mathrm{A} / \mathrm{cm}^{2}\right), 3 \mathrm{Li}^{+}$ions can be inserted into the $\mathrm{Li}_{2} \mathrm{Mn}_{4} \mathrm{O}_{9}(\mathrm{y}=4)$ structure, allowing the full theoretical capacity $(213 \mathrm{mAh} / \mathrm{g})$ of the electrode to be achieved.

Thackeray et al. [5] evaluated such cathodes by placing them in cells with lithium foil anodes and LiAsF $_{6}$ in PC electrolyte, and cycling the batteries between 2.3 and 3.3 volts at a current density of $0.5 \mathrm{~mA} / \mathrm{cm}^{2}$. Two $\mathrm{Li}_{2} \mathrm{O} \mathrm{yMnO}_{2}$ spinel phases were investigated: $\mathrm{Li}_{2} \mathrm{Mn}_{4} \mathrm{O}_{9}$ (y $=4)$ and $\mathrm{Li}_{4} \mathrm{Mn}_{5} \mathrm{O}_{12}(y=2.5)$, along with $\mathrm{LiMn}_{2} \mathrm{O}_{4}$ cathodes $(y=2)$. The voltage vs. capacity and capacity vs. cycle number for the cathodes indicates that the spinel phases have higher initial capacity and improved cycle ability over $\mathrm{LiMn}_{2} \mathrm{O}_{4}$. The decrease in capacity with cycle number of $\mathrm{LiMn}_{2} \mathrm{O}_{4}$ is partially explained by the onset of the Jahn-Teller distortion when lithium is inserted, which causes a change from cubic to tetragonal crystal symmetry. This distortion is not reversible and reduces the reversibility of the intercalation process. $\mathrm{Li}_{2} \mathrm{Mn}_{4} \mathrm{O}_{9}$ (defect spinel with cubic symmetry) cathodes retain their cubic structure until two $\mathrm{Li}^{+}$ions have been inserted. The Jahn-Teller distortion occurs after this, but not as severely as in $\mathrm{LiMn}_{2} \mathrm{O}_{4} . \quad \mathrm{Li}_{4} \mathrm{Mn}_{5} \mathrm{O}_{12}$ (stoichiometric spinel with cubic symmetry) has even less of a tendency to undergo Jahn-Teller distortion before the lithium is fully intercalated. When the distortion does occur, the effect is less severe and most of the cathode's capacity is retained.

Not only is manganese oxide relatively cheap and non-toxic compared to other lithium intercalation compounds, it is very versatile due to the wide range of morphological structures it has, allowing the cathode to be tailored to a particular application. As noted above, $\gamma-\mathrm{MnO}_{2}$ has been the predominant cathode used in lithium/manganese oxide systems, but other manganese oxide structures also show promise. Thackeray et al. [9] compared the electrochemical properties of some of these different manganese oxides.

$\alpha-\mathrm{MnO}_{2}$ can intercalate one $\mathrm{Li}^{+}$ion over the voltage range 3.8 to $2.0 \mathrm{~V}$ vs. pure lithium. It has an initial discharge capacity of $230 \mathrm{mAh} / \mathrm{g}$ to a $2 \mathrm{~V}$ cutoff voltage, and undergoes a twostage intercalation process, which is indicated by cyclic voltammetry to be reversible. The recharge ability of this compound needs to be further investigated, but there are favorable indications that it will perform well. 
Another promising structure-is layered-type $\mathrm{MnO}_{2}$. When it is heated to remove excess surface water, it can produce initial capacities greater than $200 \mathrm{mAh} / \mathrm{g}$ in lithium cells; however, it exhibits poor cycle life. It is possible that this is due to additional water that is trapped in the crystal structure, and improvements in cycle ability are expected.

. The spinel system $\mathrm{Li}_{2} \mathrm{O} \mathrm{yMnO}_{2}(\mathrm{y} \geq 2.5)$ provides a stable 3-D network for $\mathrm{Li}^{+}$ion transport, and spinel cathodes have good recharge ability and stability due to their cubic structure that undergoes very little expansion over a wide range of lithium intercalation. $\mathrm{Li}_{4} \mathrm{Mn}_{5} \mathrm{O}_{12}$ and $\mathrm{Li}_{2} \mathrm{Mn}_{4} \mathrm{O}_{9}$ cathodes have initial capacities $\geq 120 \mathrm{~mA}-\mathrm{h} / \mathrm{g}$ for the first several cycles. These spinel cathodes also provide greater resistance to Jahn-Teller distortion, which occurs early in the intercalation reaction of $\mathrm{Li}_{1+x} \mathrm{Mn}_{2} \mathrm{O}_{4}$. This distortion causes a change to tetragonal symmetry from cubic symmetry, increases the volume of the crystal unit cell, and diminishes rechargeability. The Jahn-Teller distortion occurs when the average valence of $\mathrm{Mn}$ becomes about 3.5, which tends to occur late in the intercalation process of spinel cathodes.

Manev et al. [11] investigated different manganese oxide structures that have been proposed as cathodes for lithium-ion (rocking chair) batteries, and concluded that the lithium spinel $\mathrm{LiMn}_{2} \mathrm{O}_{4}$ is the only acceptable candidate for this battery. Using a small sample $(10 \mathrm{~g})$ of starting components in a standard muffle furnace with $3 \mathrm{~L}$ of air space, they varied the starting components, synthesis temperature, and duration of synthesis to produce $\mathrm{Li}_{1-x} \mathrm{Mn}_{2} \mathrm{O}_{4}$ with a specific capacity very close to the theoretical capacity. When they tried to use the same procedure with a larger batch amount, they encountered problems that were not present with the smaller batches.

The specific capacity of the cathode produced decreased as the batch size increased. This may be due to nitrogen oxide and water that was trapped in the structure of the chemical manganese dioxide (CMD) and released during synthesis, which caused partial reduction of the materials. When a smaller batch was used, the gas volume to furnace space ratio was smaller, so the effect was not as great. By introducing airflow into the furnace, the reductive effect of these gases was reduced by sweeping them away. However, at higher air speeds the specific capacity is reduced, probably due to the removal of $\mathrm{Li}_{2} \mathrm{O}$, the removal of which cannot be detected by XRD analysis. 
The importance of the starting ratio of the materials on the specific capacity -- and the cycle ability of the cathode - was studied. The maximum specific capacity occurs in the range 98-105\% $\mathrm{Li} / \mathrm{Mn}_{2}$. At a ratio of $105 \%$, improved cycle ability is exhibited, but at atio of $95 \%$, cycle ability is drastically reduced. This $10 \%$ change in lithium content cannot be detected by $\mathrm{XRD}$; therefore, this performance change can only be characterized electrochemically. Since the $\mathrm{L} / \mathrm{Mn}_{2}$ ratio is obviously very important, it is also important that the batch materials are well mixed, which is more difficult to do for larger batch sizes.

As the batch size was increased, it was found that the specific surface area decreased, which would result in a decrease in reversibility and capacity of the cathode. Attempts to remedy this by grinding the product actually lowered the capacity. It is thought that this reduction may be due to mechanical stress produced by grinding, which changed the crystal structure and produced a smaller lattice parameter. This hypothesis is backed by XRD analysis. Another factor that affected the crystal structure was the rate of cooling used during synthesis. The fast cooling produced the highest the specific capacity, probably this is due because a more crystalline state slow the cooling or quenching. By controlling all of these factors, Manev et al. [11] were able to synthesize a cathode with good specific capacity and reversibility.

Although the $\mathrm{LiMn}_{2} \mathrm{O}_{4}$ has been the focus of literature on cathodes for secondary lithium batteries, it has some disadvantages, such as: low specific capacity $(\sim 110 \mathrm{~A}-\mathrm{h} / \mathrm{kg})$ due to low $\mathrm{Li}: \mathrm{MnO}_{2}$ ratio; unstable organic electrolytes that are used to charge the battery; $\mathrm{Li}_{\mathrm{x}} \mathrm{Mn}_{2} \mathrm{O}_{4}$, which slowly dissolves in electrolytes; and because the Jahn-Teller effect occurs when $\mathrm{x} \approx 1$. Some alternative $\mathrm{Mn}$ cathode structures with promising features include defect spinels $\left(\mathrm{Li}_{2} \mathrm{Mn}_{4} \mathrm{O}_{9}\right.$ and $\left.\mathrm{Li}_{4} \mathrm{Mn}_{5} \mathrm{O}_{12}\right)$, LT orthorhombic $\mathrm{LiMnO}_{2}$, rock salt structure $\left(\mathrm{Li}_{2} \mathrm{MnO}_{3}\right)$, tunnel structure $(\alpha-$ $\mathrm{MnO}_{2}$ ), and hydrated and non-hydrated layered $\mathrm{Mn}-\mathrm{O}$ structures. Bach et al. [12] investigated $\mathrm{Mn}-\mathrm{O}$ layered structures for cathodes. These layered structures allow $\mathrm{Li}^{+}$ions to be easily inserted and removed in a kinetically fast process without causing major changes in the crystal structure. Sol-gel birnessites (similar to layered $\mathrm{MnO}_{2}$ ) have high $\mathrm{Mn}^{4+}$ content and a 2-D structure that allow them to achieve capacities close to $200 \mathrm{~A}-\mathrm{h} / \mathrm{kg}$, which is higher than that possible with $\mathrm{Li}_{(1+\mathrm{x})} \mathrm{Mn}_{2} \mathrm{O}_{4}$ spinel cathodes. These lattices contain structural water, which plays a role in the intercalation process, but may cause compatibility problems with lithium. The authors compared a new sol-gel birnessite with traditional $\mathrm{Li}, \mathrm{Na}$, and Al-birnessite-layered structures. 
The chemical composition of the sol-gel and classical compounds were used. Sol-gel birnessite has a higher content of $\hat{\mathrm{Mn}}^{4+}$, which is important, because the onset of the Jahn-Teller effect occurs when the valency of $\mathrm{Mn}$ is about 3.5. The sol-gel birnessite has the highest capacity and the best cycle ability. This superior performance is due to the higher valence state of Mn and faster kinetics of lithium transport for sol-gel birnessite.

The authors also found that the structural water in the compounds plays an important role in intercalation and is stable throughout the intercalation process. The structural water helps to maintain the stability of the layered structure, because it helps maintain the elasticity of the lattice. It has been shown by thermo gravimetric experiments that the water is not disturbed by lithium insertion. After extended cycling $(\approx 30$ days $), X R D$ analysis on the four cathodes showed prominent peaks for the (002) diffraction line, indicating that the lamellar structure was preserved.

Liu et al. [15] investigated the use of the Pechini process to form $\mathrm{LiMn}_{2} \mathrm{O}_{4}$ and the doped compounds $\mathrm{LiNi}_{8} \mathrm{Mn}_{2-\delta} \mathrm{O}_{4}$ and $\mathrm{LiCo}_{8} \mathrm{Mn}_{2-\delta} \mathrm{O}_{4}$ (where $\delta=0.04$ or 0.20 ) in order to arrest the onset of the Jahn-Teller distortion and increase cycling capacity. The Pechini process allows a cathode with a homogeneous structure and flexibility to form the local structure of the cathode. Part of the process involves heating the cathode materials in polyhydroxyl alcohol to form a solid polymeric resin. The authors examined how different heating temperatures and doping concentrations affected the initial capacity, cycling capacity, and internal structure (as measured by $\mathrm{X}$-ray diffraction).

Increasing the temperature for pure $\mathrm{Li}_{2} \mathrm{MnO}_{4}$ during the Pechini process increased the initial capacity, while slightly decreasing the cycle ability. The same are observed for more cycles and for higher current density, but at $1000^{\circ} \mathrm{C}$ the initial capacity and the cycle ability both drop noticeably. X-ray diffraction of the cathodes show a slight tetragonal distortion at $800^{\circ} \mathrm{C}$ and a very severe distortion at $1000^{\circ} \mathrm{C}$, indicating the onset of the Jahn-Teller distortion, which causes the irreversible formation of a tetragonal phase and decreases the cycling capacity. The discharge characteristics of $\mathrm{Li}_{2} \mathrm{MnO}_{4}$ and its doped compounds for 50 cycles at $0.5 \mathrm{~mA} / \mathrm{cm}^{2}$ and 80 cycles at $1.0 \mathrm{~mA} / \mathrm{cm}^{2}$, were studied. The doped compounds showed an increase in cycle ability -- amid a decrease in initial capacity as the dopant concentration was increased -- with the best performance occurring at $\delta=0.04$. The XRD patterns of $\mathrm{Li}_{2} \mathrm{MnO}_{4}, \mathrm{LiCo}_{0.04} \mathrm{Mn}_{1.96} \mathrm{O}_{4}$, and 
$\mathrm{LiNi}_{0.04} \mathrm{Mn}_{1.96} \mathrm{O}_{4}$, indicate that the addition of the dopants decreases the amount of tetragonal distortion that occurs, thus increasing cycle ability.

The authors hypothesized the following reasons for performance improvement with $\mathrm{Ni}$ or Co substitution: 1) $\mathrm{Ni}$ and Co have smaller unit cells than $\mathrm{Mn}$; therefore, they may undergo less structural distortion upon intercalation and deintercalation of $\mathrm{Li}$; 2) Co or $\mathrm{Ni}$ substitution may cause local defects (atomic vacancies, lattice strains) that help to stabilize the structure and keep it from undergoing the Jahn-Teller distortion; 3) $\mathrm{Co}$ and $\mathrm{Ni}$ have covalent states less than or equal to 3, causing the Mn covalent state to be greater than or equal to 3.5 , thus decreasing the number of $\mathrm{Mn}^{3+}$, which are believed to lead to the Jahn-Teller distortion.

Freemantle [16] reports that chemists have succeed in producing a $\mathrm{LiMnO}_{2}$ compound which has the same structure as the layered $\mathrm{LiCoO}_{2}$ compound that is widely used in Li-ion batteries. Manganese is less toxic than cobalt and costs about $1 \%$ as much, but improved cycle ability will have to be achieved before it can replace layered $\mathrm{LiCoO}_{2}$ in these batteries.

In this study we chose to work with a lithium anode, Super-MEEP with lithium triflate (as an electrolyte, because of its good ionic conductivity, chemical stability, and good adhesion to the lithium), and with $\lambda$ - and $\gamma-\mathrm{MnO}_{2}$ based intercalated cathodes, because of their attractive commercial value. We decided to research the failure modes, with the hope that once those failure modes were understood, the cycle life might be improved.

\section{References Chapter 1}

1. S. Subbaro, D. H. Shen, F. Deligiannis, C. -K. Huang, and G. Halpert, Joumal of Power Sources, 29, 579-587 (1990).

2. F. Croce, F. Capuano, A. Selvaggi, B. Scrosati, G. Scibana, Joumal of Power Sources, 32, 381-388 (1990).

3. Selvaggi, F. Croce, B. Scrosati, Journal of Power Sources, 32, 389-396 (1990).

4. M. H. Rossouw, M. M. Thackeray, Materials Research Bulletin, 26, 463-473 (1991).

5. M. M. Thackeray, A. de Kock, M. H. Rossouw, D. Liles, R. Bittihn, D. Hoge, J. Elec. Soc., 139, 363-366 (1992). 
6. S. Surampudi, D. H. Shen, C.-K. Huang, S. R. Narayanan, A. Attia, G. Halpert, Journal of Power Sources, 43-44, 21-26 (1993).

7. O. Chusid, Y. E. Ely, D. Aurbach, M. Babai, Y. Carmeli, Journal of Power Sources, 4344, 47-64 (1993).

8. C. S. Cha, H. X. Wang, Journal of Power Sources, 43-44, 145-155 (1993).

9. M. M. Thackeray, M. H. Rossouw, A. de Kock, A. P. de la Harpe, R. J. Gummow, K. Pearce, C. Liles, Journal of Power Sources, 43-44, 289-300 (1993).

10. D. E. Irish, Z. Deng, M. Odziemkowski, Journal of Power Sources, 54, 28-33 (1995).

11. V. Manev, A. Momchilov, A. Nassalevska, A. Suto, Journal of Power Sources, 54, 323328 (1995).

12. S. Bach, J. P. Pereira-Ramos, N. Baffier, J. Elec. Soc., 143, 3429-3434 (1996).

13. H. Shi, J. Barker, M. Y. Saidi, R. Koksbang, J. Elec. Soc., 143, 3466-3472 (1996).

14. . W. Xing, J. S. Xue, T. Zheng, A. Gibaud, J. R. Dahn, J. Elec. Soc., 143, 3483-3491 (1996).

15. W. Liu, K. Kowal, G. C. Farrington, J. Elec. Soc., 143, 3590-3596 (1996).

16. M. Freemantle, Chemistry and Engineering News, June 10, 1996, p. 5 


\section{Chapter 2. Polymer Syntheis}

\section{MEEP/Alkoxy Mixed Substituent Polymers}

Polyphosphazenes with alkoxy side groups (and thus, no ion-coordinating sites) have very low glass transition temperatures. In an effort to increase polymer-free volume, lower the glass transition temperature and perhaps increase ionic conductivity, a series of co-substituent polyphosphazenes bearing a 50\% loading of methoxyethoxyethoxy substituents and a $50 \%$ loading of non-ion-coordinating alkoxy groups (ranging from propyloxy to decyloxy) were synthesized. For all co-substituent polymers, glass transition temperatures were lower than that of the MEEP homopolymer. However, when complexed with lithium triflate salts, the polymers showed decreasing ionic conductivities with increasing length of the alkoxy co-substituent group.

\section{Small Molecule Additives}

There has been considerable research involving the use of small molecule additives to enhance the conductivity of known polymer electrolytes, such as poly(ethylene oxide). Such small molecules increase the mobility of ions through the host polymer matrix, but often change the engineering characteristics and generate a fire hazard. We have examined the effect of various organic small molecules, such as tetraglyme, and some with high dielectric constants, such as propylene carbonate and $\mathrm{N}$-methyl pyrrolidone, on the conductivity of MEEP/lithium triflate complexes. Furthermore, some non-volatile, non-flammable small molecule cyclotriphosphazenes bearing linear, branched and hyperbranched ethyleneoxy units (such as those shown in Chart 2.1) were synthesized. Their utility as small molecule additives for polymer electrolytes were then studied. The cyclotriphosphazene additives increased the conductivity and lowered the glass transition temperature of MEEP. Preliminary results indicate that organic, high dielectric constant additives have a dramatic effect on raising the conductivity without degrading the physical properties of the electrolyte. These "gel-type" electrolytes using MEEP are a major advance over the additive-free system. 


\section{Controlled Architecture and Molecular Weight of MEEP}

The use of branching in the polyphosphazene backbone may lead to enhanced dimensional stability of the polymer electrolyte. Furthermore, ionic conductivity is known to increase at molecular weights below the chain entanglement molecular weight. A more thorough understanding of ionic conductivity of variable molecular weight MEEP is desired.

\section{New Ion Coordination Sites}

Another aim of this project was to investigate the effect of coordination sites, rather than etheric oxygen atoms on the ionic conductivity of dissolved salts. Polyphosphazenes bearing thioether, sulfoxide, sulfone, dioxolane, dioxane, carbonate and aldehyde units were synthesized. Such polymers may also serve as effective host polymers in gel electrolyte systems.

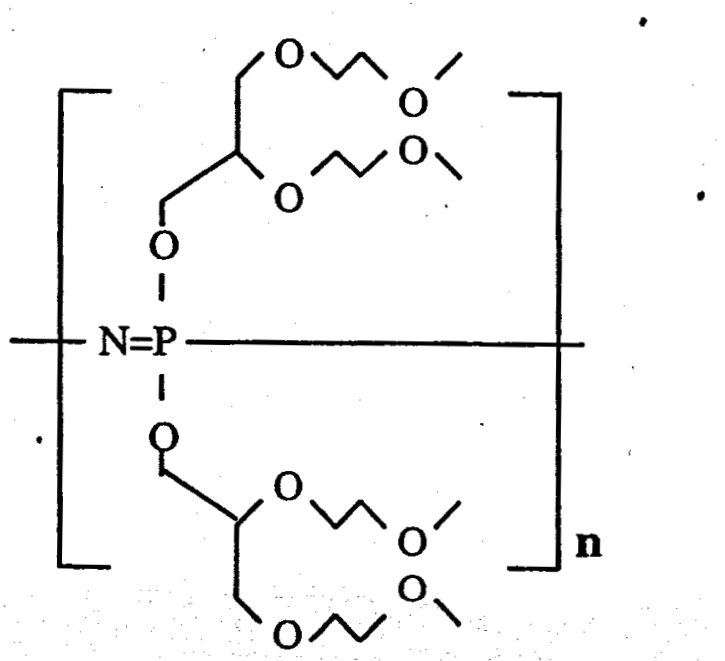

Chart 2.1

Molecular Structure of Poly[bis(2,3-di-(2ethoxyethoxy)propoxy)phosphazene]. 


\section{Chapter 3. Experimental Set Up}

\section{Cathode Composition}

$\mathrm{MnO}_{2}$ was used in the cathode for this project as the electrochemically active material, which participates in electrochemical reactions upon charging and discharging. This compound offers a number of advantages over alternatives such as $\mathrm{TiS}_{2}$ and $\mathrm{V}_{6} \mathrm{O}_{13} \cdot[1,2] \mathrm{MnO}_{2}$ is inexpensive and nontoxic. Lithium/ $/ \mathrm{MnO}_{2}$ cells provide high energy densities as well. A comparison of theoretical energy densities for various cathode compounds is given in Table 3.1. [6]

Table 3.1. Theoretical Energy Densities

Cell Reaction

$\mathrm{Li}+\mathrm{TiS}_{2} \rightarrow \mathrm{LiTiS}_{2}$

$8 \mathrm{Li}+\mathrm{V}_{6} \mathrm{O}_{13} \rightarrow \mathrm{Li}_{8} \mathrm{~V}_{6} \mathrm{O}_{13}$

$3 \mathrm{Li}+\mathrm{Li}_{1+\mathrm{x}} \mathrm{V}_{3} \mathrm{O}_{8} \rightarrow \mathrm{Li}_{4} \mathrm{~V}_{3} \mathrm{O}_{8}$

$\mathrm{Li}+\mathrm{MnO}_{2} \rightarrow \mathrm{LiMnO}_{2}$
$\underline{W-h r / k g}$

480

890

730

1027
W-hr/dm

1200

2110

2500

3185

Lithium manganese dioxide cells produce a high output voltage. Open circuit voltage is slightly above $3 \mathrm{~V}$ and nominal (or operating) voltages are fairly flat over $80 \%$ of the discharge period, ranging from $3.0 \mathrm{~V}$ to $2.8 \mathrm{~V}$. [2] Lithium $/ \mathrm{SPE} / \mathrm{MnO}_{2}$ cells have very good storage characteristics, with a self-discharge rate below $.01 \%$ per year. [6] Finally, they do not exhibit the voltage delay characteristics that are often seen in secondary batteries following storage. [2] For these reasons, $\mathrm{MnO}_{2}$ has become the cathode material of choice in industry and should therefore be of primary interest to the Department of Energy. It is desirable to maximize the amount of the active compound in the cathode in order to produce a battery with the highest possible energy capacity. The depth of discharge under which the battery is operated strongly affects the cycle life. [2] A battery discharged to $50 \%$ of its maximum theoretical capacity may have a cycle life an order of magnitude higher than the same battery discharged to $100 \%$ each cycle. Therefore, maximizing the active material in the cathode allows greater total energy output for a lower depth of discharge and greater cycle life. It may also be advantageous to oversize the battery, sacrificing weight and energy density in favor of increased cycle life. 
However, a cathode composed strictly of $\mathrm{MnO}_{2}$ would provide only limited capacity. The $\mathrm{MnO}_{2}$ structure itself is not a good ionic conductor. Lithium ions travel interstitially through other media and have an extremely low mobility in a $\mathrm{MnO}_{2}$ matrix. Lithium ions, unable to migrate deeply into a solid $\mathrm{MnO}_{2}$ cathode, would react only at the surface of the cathode. After the reduction reaction is completed along the electrolyte/cathode interface, current and voltage would drop toward zero, and the majority of the cathode material would not be utilized. Hence, a means of transporting lithium ions into the cathode interior must be provided to ensure complete $\mathrm{MnO}_{2}$ utilization. A polymer similar to that which was used as the solid polymer electrolyte was employed for this purpose.

In our cathode, $\mathrm{MnO}_{2}$ particles are interspersed throughout a poly-methoxy-ethoxyphosphazine (MEEP) film. In this structure, MEEP provides a flexible polymer backbone and a high concentration of ion coordination sites, which results in high ionic conductivity. Fine $\mathrm{MnO}_{2}$ particles provide maximum surface area for a given volume of material so that the amount of $\mathrm{MnO}_{2}$ able to be reached by -- and react with -- the lithium, is maximized.

MEEP is a comb-like structured polymer. The phosphazene backbone is highly flexible and results in an amorphous macroscopic structure with a low glass transition temperature $\left(T_{g}=-\right.$ $84^{\circ} \mathrm{C}$ ), while its side chains provide four coordination sites per repeat unit. The result is a polymer which exhibits an ionic conductivity three orders of magnitude higher than that of the commonly studied poly(ethylene oxide). [3]

However, another result of this flexible structure is poor dimensional stability, or resistance to mechanical deformation. MEEP undergoes viscous flow under pressure. One resulting advantage is that the MEEP can flow into voids created at the particle interfaces upon discharge and subsequent charging, thus maintaining good contact between the polymer and $\mathrm{MnO}_{2}$. More crystalline solid electrolytes can become mechanically separated from the active material as structural variations occur at the interface, thus reducing or completely preventing the delivery of cations to the active compound surface. 
Moreover, it is also important that the polymer remain mechanically stable in order to maintain the particles within its fixed position. As will be discussed later, if the distance between neighboring particles is allowed to vary, and in particular, to increase overall conductivity could be dramatically reduced. Additionally, electrical properties could undergo radical changes as the particles move, resulting in an unreliable battery at best.

To prevent this, the cathode may be exposed to gamma or ultraviolet radiation to induce cross-linking. Cross-linking has been found to improve mechanical stability without significantly reducing ionic conductivity.[3] The addition of $\mathrm{MnO}_{2}$ and carbon black particles also results in more dimensionally stable material. Preliminary lab work during our study has produced cathodes that appear to be adequately resistant to deformation prior to cross-linking. Further testing under charge cycling and pressure is required however, in order to evaluate the need for cross-linking.

The purpose of the addition of carbon black is to improve electrical conductivity. MEEP by itself is an electrical insulator. A path for electron transport through the polymer to and from the $\mathrm{MnO}_{2}$ particles must be provided so that electrons are available to participate in reduction and oxidation reactions during discharge and charge, respectively. MT carbon black from Vanderbilt can be used initially. Its spherical shape will allow for simplification of the model. Later, other types of carbon black with different particle shape may be substituted in order to optimize cathode performance.

Finally, a lithium salt was included to provide a ready source of lithium ions to begin the reaction process upon commencement of discharge. Lithium trifluoromethanesulfonate (or lithium triflate, $\mathrm{LiCF}_{3} \mathrm{SO}_{3}$ ) was used for this purpose. Conductivity of the polymer initially increased with increasing lithium triflate concentration as the number of charge carriers per unit volume increased. Beyond a maximum, the conductivity decreased due to; (a) a decrease in the number of available coordination sites (free sites are needed to accept ions as they migrate along the polymer chain); (b) ionic cross-linking, which results when coordination sites from different chains become associated with the same cation; and (c) interactions between solvated cations.[3] Unlike the covalent cross-linking resulting from irradiation, ionic cross-linking does appear to cause decreases in polymer chain flexibility, increases in glass transition temperature, and decreases in ionic conductivity.[6] We used a salt concentration just below that corresponding to the maximum for MEEP $(\sim 40 \% \mathrm{wt})$. 


\section{Casting Technique}

Mixing of the cathode materials was achieved by dissolving MEEP, $\mathrm{MnO}_{2}$, carbon black, and lithium triflate in purified tetrahydofuran (THF). Water content of the THF was minimized by the addition of sodium to the THF prior to distillation. This minimized the amount of water that became trapped in the MEEP structure. The solution was mechanically mixed at room temperature in a dry, inert argon atmosphere for 48 hours to ensure complete dissolution of the MEEP and a uniform mixture. The solution was then poured onto nickel in a circular mold with a surface area of approximately $1 \mathrm{~cm}^{2}$. The THF was allowed to evaporate for a period of 120 hours. The resulting film was approximately $0.5 \mathrm{~mm}$ thick.

\section{Intercalate cathodes}

Two types of intercalated cathodes (IC) were made. One contained $\lambda-\mathrm{MnO}_{2}: \mathrm{C}: \mathrm{MEEP}$ and the other containing $\gamma-\mathrm{MnO}_{2}: \mathrm{C}: \mathrm{MEEP}$ at different weight percent ratios.

Carbon black powder was obtained commercially and was composed of fine particles of diameter lower than $10 \mu \mathrm{m}$.

The MEEP (or polymer) was used as a binder.

The $\mathrm{MnO}_{2}$ was purchased from Aldrich and had a diameter size that varied between 1 and $100 \mu \mathrm{m}$. The $\gamma-\mathrm{MnO}_{2}$ (Aldrich) was dense and compact. It was found, using SEMs, that the dense $\gamma-\mathrm{MnO}_{2}$ had an average diameter of $7.15 \mu \mathrm{m}$ plus/minus $0.042 \mu \mathrm{m}$, and that the larger sized grains were apparently a conglomerate of several particles.

The $\lambda-\mathrm{MnO}_{2}$, and the two lithiated molecules $\mathrm{MnO}_{2}\left(\mathrm{LiMn}_{2} \mathrm{O}_{4}\right)$, were synthetised at the laboratory. The $\lambda-\mathrm{MnO}_{2}$ was synthetisized by extracting the lithium from the $\mathrm{LiMn}_{2} \mathrm{O}_{4}$. The resulting $\lambda-\mathrm{MnO}_{2}$ was very porous and hollow and the particles had diameters ranging from 5 to $70 \mu \mathrm{m}$. They appeared to be very porous and have a large surface area.

The SEM results obtained with $\gamma-\mathrm{MnO}_{2}$ shows a non porous texture, with small particles singles $(2 \mu \mathrm{m})$ or in agglomerate group of particles $(100 \mu \mathrm{m})$. The SEM pictures for $\lambda-\mathrm{MnO}_{2}$, synthesized in the lab, show a very porous system with particle diameters ranging from 5 to 70 $\mu \mathrm{m}$. Note the carbon particles, where diameters were much smaller $(0.5$ to $10 \mu \mathrm{m})$. The SEMs for the synthesized $\mathrm{LiMn}_{2} \mathrm{O}_{4}$ were also highly porous and had diameters of particles in the range of 5 to $50 \mu \mathrm{m}$. 
The cathode formed with $\gamma-\mathrm{MnO}_{2}$ shows an IC with a rough surface, with average particles of $30 \mu \mathrm{m}$ diameter. Figures $3.1 \mathrm{a}, \mathrm{b}, \mathrm{c}$, and $\mathrm{d}$ show a 200x magnification of the Backscatter Electron Image (left) and Scanning Electron Image (right). The bottom left shows a Phosporous X-Ray Analog Dot Map, which reflects how evenly the polymer binder (MEEP) is distributed in the sample, and a Manganese X-Ray Analog Dot Map, which indicates how evenly the $\gamma-\mathrm{MnO}_{2}$ is distributed in the sample.

The cathode formed with $\gamma-\mathrm{MnO}_{2}$ shows an IC with a rough surface, with average particles of $30 \mu \mathrm{m}$ diameter. Figures $3.2 \mathrm{a}, \mathrm{b}, \mathrm{c}$, and d show a 150x magnification of the cross section of the Backscatter Electron Image (left) and Scanning Electron Image (right). The bottom left shows a Phosporous X-Ray Analog Dot Map, which reflects how evenly the polymer binder (MEEP) was distributed in the sample. A Manganese X-Ray Analog Dot Map indicates how evenly the $\gamma-\mathrm{MnO}_{2}$ was distributed in the sample.

The cathode formed with $\lambda-\mathrm{MnO}_{2}$ shows an IC with a smooth surface and average particles of $30 \mu \mathrm{m}$ diameter. Figures $3.3 \mathrm{a}, \mathrm{b}, \mathrm{c}$, and d show a $200 \mathrm{x}$ magnification of the Backscatter Electron Image (left) and the bottom left shows a Phosporous X-Ray Analog Dot Map, which reflects how evenly the polymer binder (MEEP) is distributed in the sample. A Manganese X-Ray Analog Dot Map indicates how evenly the $\lambda-\mathrm{MnO}_{2}$ is distributed in the sample. The cathode formed with $\lambda-\mathrm{MnO}_{2}$ shows an IC with a smooth surface and average particles of $30 \mu \mathrm{m}$ diameter. Figures $3.4 \mathrm{a}, \mathrm{b}, \mathrm{c}$, and d show a $150 \mathrm{x}$ magnification of the Backscatter Electron Image (top), and the bottom left shows a Phosporous X-Ray Analog Dot Map, which reflects how evenly the polymer binder (MEEP) was distributed in the sample. Bottom right shows a Manganese X-Ray Analog Dot Map indicates how evenly the $\lambda-\mathrm{MnO}_{2}$ was distributed in the sample. 
The cathode formed with $\mathrm{LiMn}_{2} \mathrm{O}_{4}$ (IC') in Figures 3.5 a, b, c, and d shows a $200 x$ magnification of the Backscatter Electron Image (left) and the bottom left shows a Phosphorous X-Ray Analog Dot Map, which reflects how evenly the polymer binder (MEEP) was distributed in the sample. A Manganese X-Ray Analog Dot Map indicates how evenly the $\mathrm{LiMn}_{2} \mathrm{O}_{4}$ was distributed in the sample. Figures $3.6 \mathrm{a}, \mathrm{b}, \mathrm{c}$, and $\mathrm{d}$ show a 150x magnification of the Backscatter Electron Image (left). The bottom left shows a Phosporous X-Ray Analog Dot Map, which reflects how evenly the polymer binder (MEEP) was distributed in the sample. A Manganese X-Ray Analog Dot Map indicates how evenly the $\mathrm{LiMn}_{2} \mathrm{O}_{4}$ was distributed in the sample.

\section{Instrumentation}

\section{Load Cell}

A load cell is a transducer that converts a load acting on it into an analog electrical signal. This conversion is achieved by the physical deformation of strain gages, which are bonded to the load cell itself and wired in a Wheatstone Bridge configuration. Weight is applied to the load cell through compression of the load button on top of the cell's upper surface, which introduces strain to the gages. The strain produces an electrical resistance change proportional'to the load. Load cells normally require excitation and an output device (i.e., conditioner).

The Model 13 miniature load cell by Sensotec; with a capacity of 250 lbs. of compression force and an accuracy of $\pm 0.25 \%$ of full scale, and with a Model GM signal conditioner from the same company, allows a reasonably accurate measurement of load (pressure) changes during the charge/discharge cycling.

\section{Linear Variable Displacement Transducer (LVDT)}

A linear variable displacement transducer (LVDT) is essentially a miniature transformer having one primary winding, two symmetrically wound secondary coils, and an armature core that is free to move along its linear axis. A connecting rod connects the monitored component to the armature core, such that the displacement of that component moves the core off-center. Physically, the LVDT is a hollow metallic cylinder in which a shaft of smaller diameter (a core) moves freely back and forth along the cylinder's long axis. In common practice, the pushrod (connecting rod) is physically attached to the moveable object whose position is to be determined (the measurand) while the coil assembly is attached to a fixed reference point. 
A voltage is applied across the primary winding and the electrical magnetic force induced in the magnetic circuit produces corresponding voltages in the secondary windings, which are connected differentially, to produce a zero output signal when the armature core is in its central position. When the core is displaced off center in either direction, the efficiency of transformation in the secondary winding on that side is increased, while the secondary coil decreases. This results in a positive (+ve) voltage output signal when the core moves off center in one direction and a negative (-ve) voltage output when the core moves off center in the other direction. The intensity of the output signal is directly proportional to the linear displacement of the core and hence, to the monitored component.

With the Sensotec Model GM signal conditioner, the Model 050 HR LVDT from Lucas Schaevitz can delineate displacements of the system in the range of micrometers $(\mu \mathrm{m})$.

\section{Anaerobic Chamber}

Since the electrode being used in this research work includes metallic lithium, which is quite capable of reacting with both oxygen and nitrogen when exposed to open air, an anaerobic chamber (glove box) is necessary to prevent the oxidation or nitrogenation of the $\mathrm{Li}$ anode. The Plas-Labs Model 855-AC anaerobic chamber has been engineered to eliminate the possibility of oxygen and nitrogen leakage into the chamber. Two vacuum pumps evacuate the chamber atmosphere and circulate the inner atmosphere through drying columns containing chemicals such as $\mathrm{V}_{2} \mathrm{O}_{5}$ or Drierite desiccants (for removal of water vapor), which is introduced from outside the glove box or generated by the chemical reaction of $\mathrm{H}_{2}, \mathrm{Pd}$ and heat in the presence of $\mathrm{O}_{2}$. By using high-purity argon gas and OxiClear Gas Purifier, the argon gas inside the chamber can be maintained to less than $5 \mathrm{ppb}$ oxygen (nominal) and less than $1 \mathrm{ppm}$ of all other impurities, combined. With the cycling experiments, the sample should be continuously exposed to the inside atmosphere for more than a month. Therefore, it is necessary to maintain a high level of gas purity.

\section{Electrochemical Measuring System}


The galvanostatic cycling of the cell and the impedance spectroscopy measurements were conducted with the Gamry electrochemical measuring system, which consists of a CMS 105 DC corrosion system and CMS 300 electrochemical impedance spectroscopy system, as well as a "lock-in" amplifier (Model SR810, by Stanford Research Systems) for high frequency analysis. The system is essentially a potentiostat in the form of a computer board with matching software to let the computer carry out data acquisition and analysis. Customized software allows us to conduct long-period battery cycling tests with frequent and precise data acquisition intervals, and fast switching between electrochemical polarization and impedance measurements --- tasks that hardly could be carried out manually without sacrificing precision during long cycling periods.

A lock-in amplifier was used for impedance measurements, which requires higher frequency ranges due to the nature of samples used in this work. It is used to detect and measure very small AC signals accurately - even in the range of nanovolts -- when the small signal is obscured by noise sources many thousands of times larger. Under the experimental conditions of our measurements, it is very helpful to use the phase-sensitive technique adopted by lock-in amplifiers to single out the component of the signal at a specific reference frequency and phase from the noise signals to guarantee the accuracy and reliability of the impedance spectroscopy data.

Since the majority of the research work in this thesis consists of electrochemical impedance spectroscopy (EIS) measurements, the author would like to use the next chapter to introduce the basics of this technique and the interpretation of the impedance data.

\section{Experimental Approach}

\section{Introduction}


Cell cycling performance studies indicate that failure normally occurs within two hundred cycles, depending on the discharging rate. [5] Destructive analyses show that anode degradation, in the form of massive passivation - or "powdering" -- occurs at the Li/SPE interface, and it is generally believed that the sudden increase in cell impedance and failure of the battery is the result of this phenomenon. Since powdering results from interfacial oxidation processes [5-8], it should lead to an increase in cell volume if the reaction products are more voluminous than the reactants themselves. In this work, we use sensitive dilatometry to follow

the volume change of a $\mathrm{Li} / \mathrm{SPE} / \mathrm{Li}$ laminate as a function of cycle number, while simultaneously using EIS to monitor impedance changes at the Li/SPE interface.

\section{Sample Configuration}

In order to simplify the system and eliminate any unnecessary effects, which can complicate the data, the $\mathrm{Li} / \mathrm{SPE} / \mathrm{Li}$ laminate was adopted. This symmetrical design, consisting of two identical Li/SPE interfaces and a bulk electrolyte, greatly simplifies the components of the system impedance and allows easier and more accurate data interpretation on the purified system. The cell was constructed under an argon atmosphere inside the glove box by mechanically combining two lithium metal foils to both sides of the polymer electrolyte disk.

\section{Dilatometry}

A Linear Variable Differential Transducer (model $050 \mathrm{HR}$, from Schaevitz Engineering, with a sensitivity of $250 \mathrm{mV} / \mathrm{V} / \mathrm{mm}$ ) was used to monitor the volume change of the $\mathrm{Li} / \mathrm{SPE} / \mathrm{Li}$ laminate, while cyclically transferring a fixed charge from one side to the other. The sample was positioned inside a glass syringe (Figure 3.7 ) such that the volume change of the cell was transferred into a thickness variation, which was then monitored by the LVDT. Experiments were performed in an anaerobic chamber from Plas Labs under a controlled atmosphere of highpurity argon gas.

A load cell was also added to the experiment. Pressure is another important factor affecting the performance of the battery, not only in the sense that pressure can lead to better morphology for the plated $\mathrm{Li}$, thus resulting in lower reactivity and less loss of $\mathrm{Li}$ per cycle, but it also helps us to gain a better understanding of the ionic conduction mechanism.

Cycling and Impedance Experiments 
Poly[bis(2,3-di-(2-methoxyethoxy)propoxy)phosphazene] ("SPE") combined with lithium trifluoromethane sulfonate ${ }^{-}\left(\mathrm{LiSO}_{3} \mathrm{CF}_{3}\right)$ in a 4:1 molar ratio, was used as the solid electrolyte. The $\mathrm{Li} / \mathrm{SPE} / \mathrm{Li}$ laminate consisted of two layers of lithium foil with a thickness of $0.1 \mathrm{~mm}$ per layer and a pre-fabricated SPE disk with an average nominal thickness of $0.36 \mathrm{~mm}$ and an area of $1.623 \mathrm{~cm}^{2}$. Because of the rubber-like properties of the SPE, the actual thickness of the electrolyte, when assembled in the cell, could be significantly smaller. The laminate was cycled at a current density of $6 \mathrm{~mA} / \mathrm{cm}^{2}$ at $25^{\circ} \mathrm{C}$. Each cycle lasted $2 \mathrm{hrs}$., with current flowing in each direction for $1 \mathrm{hr}$., corresponding to a "capacity" of $6 \mathrm{~mA} / \mathrm{cm}^{2}$, which is appropriate for $\mathrm{Li} / \mathrm{SPE}$ batteries. EIS measurements were carried out on the Li/SPE/Li laminate every 5 cycles, with the cycling current being interrupted during the measurements. The interruption lasted about 15 minutes for each frequency scan. The voltage across the laminate was also monitored continuously. Voltage data were collected every 5 minutes (24 data points for each cycle) over the entire cycling period.

\section{References Chapter 3}

1. Thackaray, M.M. et.al. "The Versatility of $\mathrm{MnO} 2$ for Lithium Battery Applications," Journal of Power Sources, 43-44, 1993, pp. 289-300.

2. Lenk, John D. Simplified Design of Micropower and Battery Circuits. Butterworth-Heinemann, 1996, p. 15.

3. Allcock, H. R. et.al. "Polyphosphazenes Bearing Branched and Linear Oligoethyleneoxy Side Groups as Solid Solvents for Ionic Conduction," Macromolecules, 29, 23, 1996, p. 7544-7552.

4. Allcock, H. R. et.al "Radiation Cross-linking of Poly[bis(2-(2methoxyethoxy)ethoxy) phosphazene]: Effect on Solid State Ionic Conductivity," Chemistry of Materials, 1, 1, 1989, p. 14-16.

5. Gao, L. and Macdonald, D.D. "Characterization of Irreversible Processes at the Li/Poly[bis(2,3-di-(2-methoxyethoxy) propoxy) phosphazene] Interface on Charge Cycling," Journal of the Electrochemical Society, Vol 144, N0. 4, p1174$1179,1997$.

6. Gray, Fiona. Solid Polymer Electrolytes: Fundamentals and Technological Applications. VCH Publishers, Inc., 1991, p.13. 
7. Scrosati, B. et.al. "The Lithium Polymer Electrolyte Battery: V. The Roles of the Composition and Morphology of the Positive Electrode," Journal of Power Sources, 32, 1990, p. 389-396.

8. Linden, David, ed. Handbook of Batteries and Fuel Cells. Mcgraw-Hill, Inc., 1984. 
Figure 3.1 Surface Amorphous $\square-\mathrm{MnO}_{2}$ cathode 200x Magnification 4 images: Top row, Left: Backscatter Image; Top row, Right: Scanning Electron Image; Bottom row, Left: Phosphorous X-Ray Analog Dot Map; Bottom row, Right: Manganese X-Ray Analog Dot Map
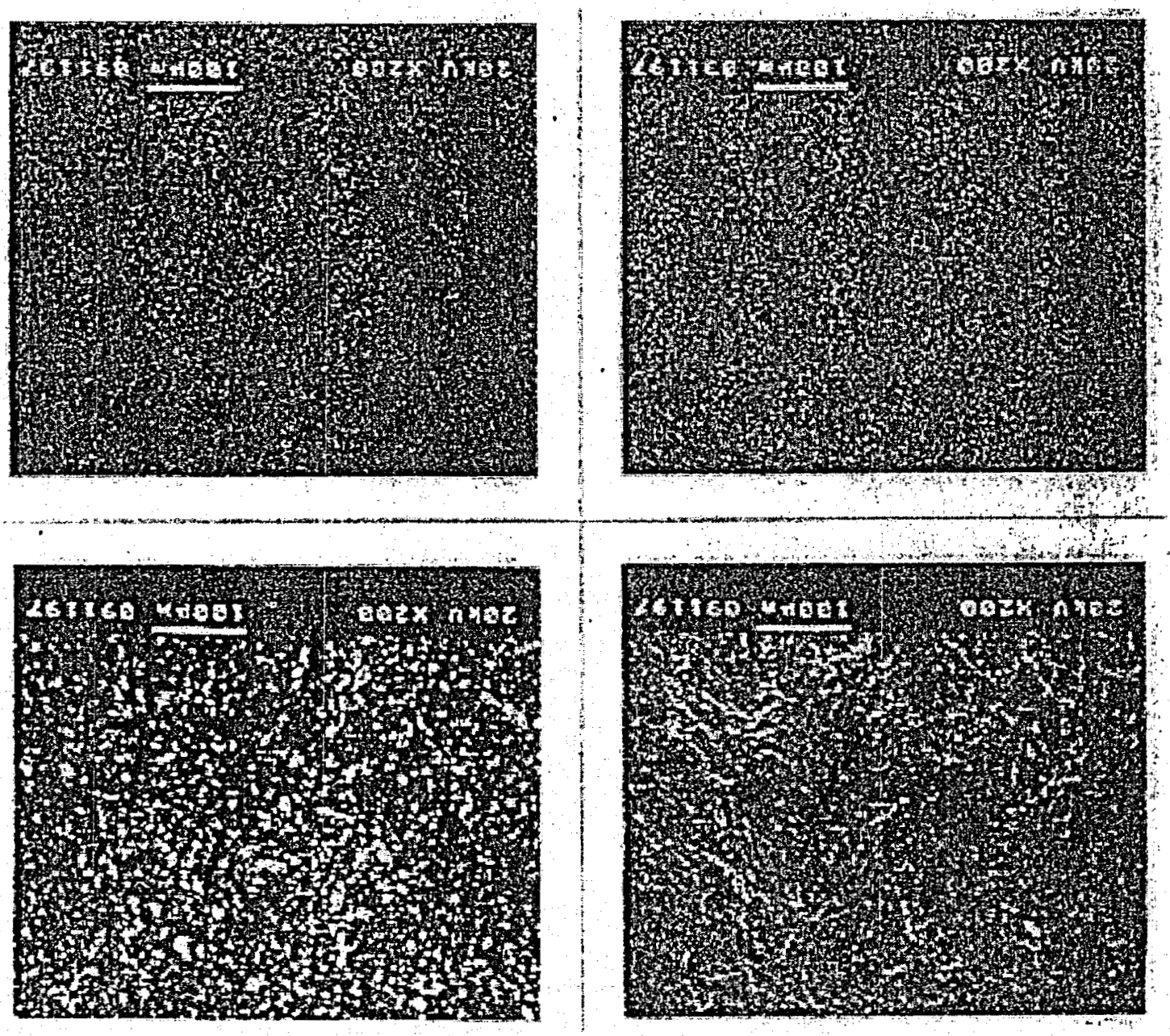
Figure 3.2 Cross-Section of Amorphous $\gamma-\mathrm{MnO}_{2}$ cathode, $150 x$ magnification 3 images:; Top row: Backscatter Electron Image; Bottom row, Left: Phosphorous X-Ray Analog Dot Map; Bottom row, Right: Manganese X-Ray Analog Dot Map

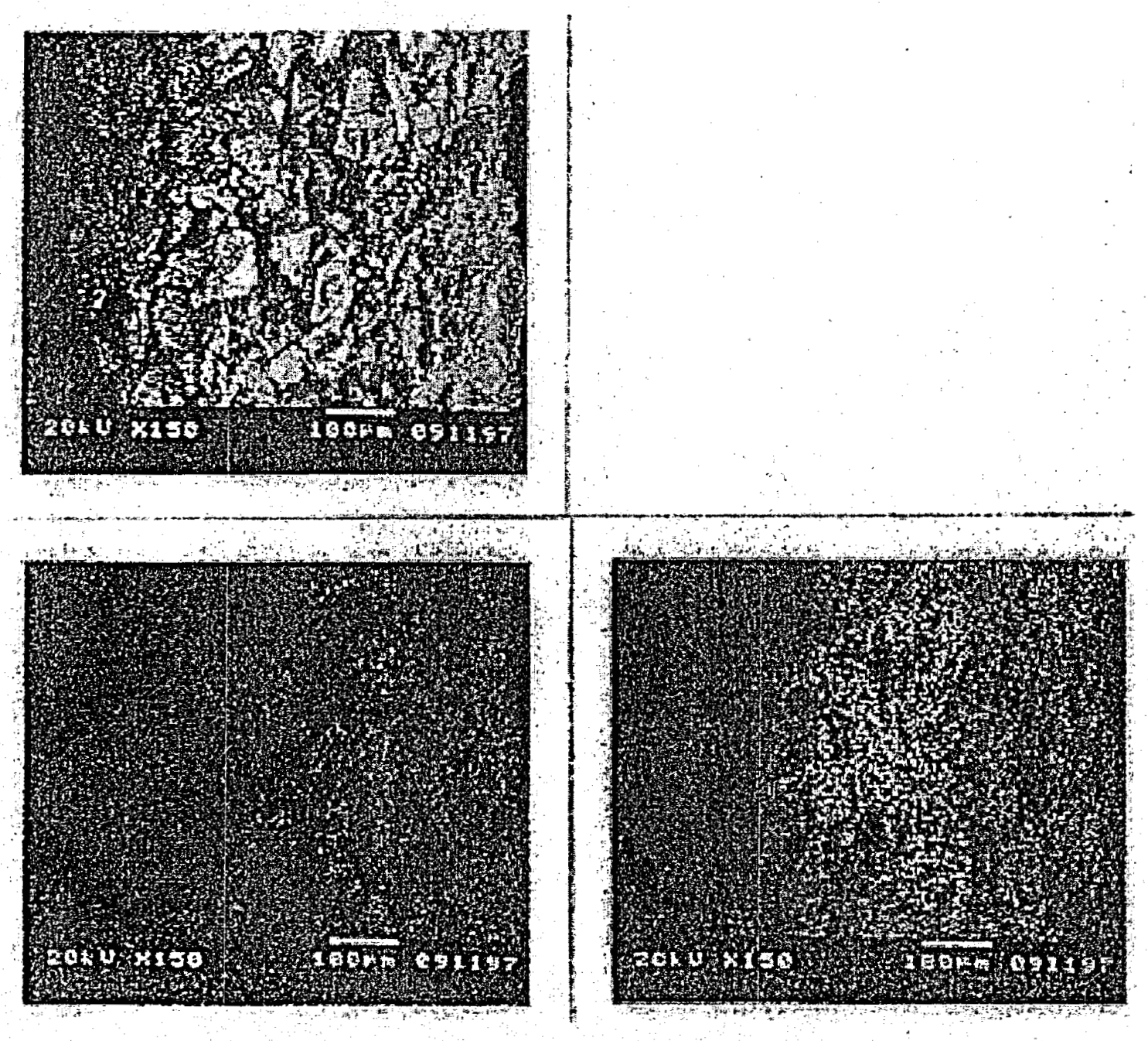


Figure 3.3 Surface of a Lambda- $\mathrm{MnO}_{2}$ cathode, 200x magnification 3 images; Top row: Backscatter Electron Image; Bottom row, Left: Phosphorous X-Ray Analog Dot Map; Bottom row, Right: Manganese X-Ray Analog Dot Map

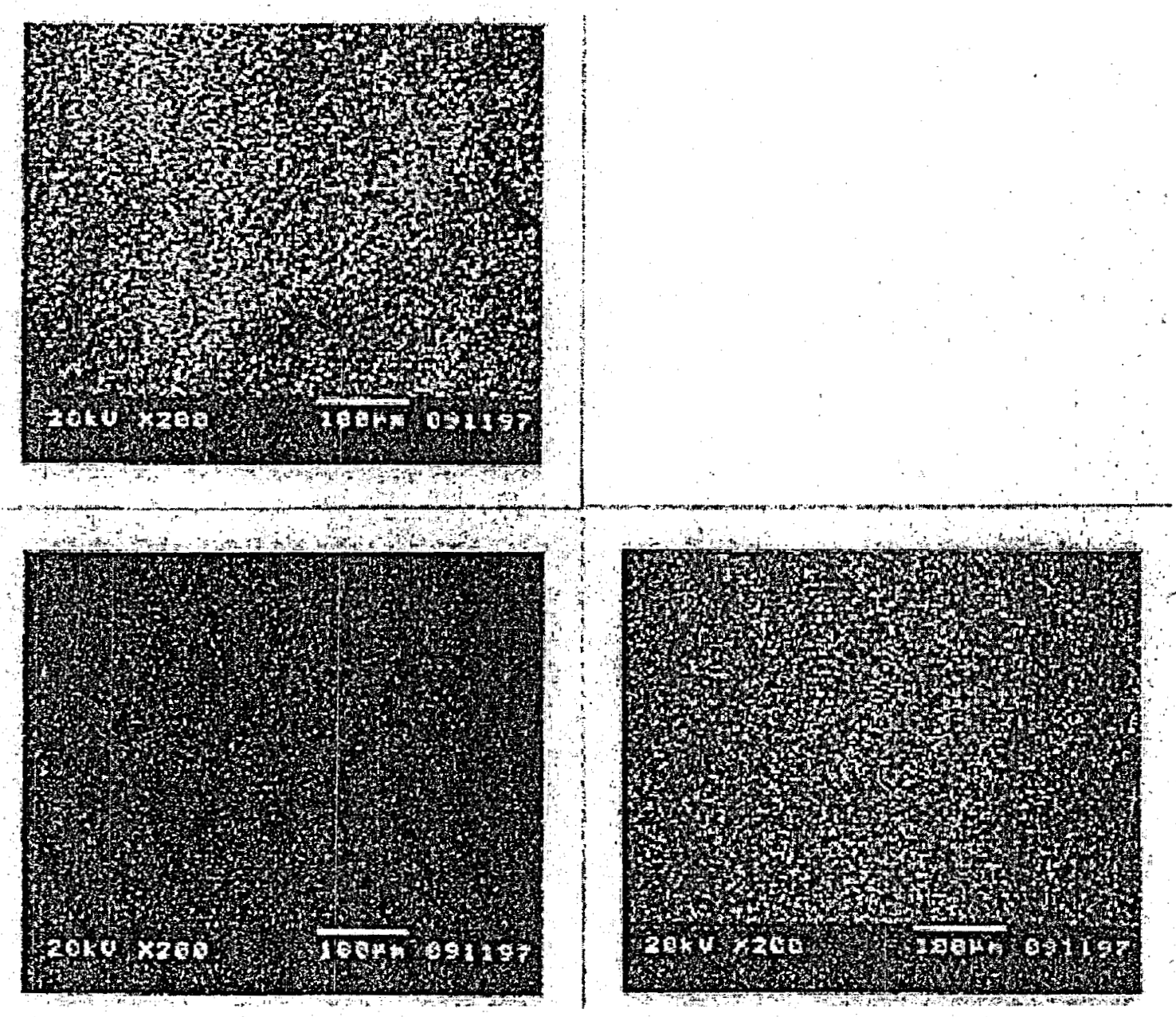


Figure 3.4 Cross Section of Lambda $\mathrm{MnO}_{2}$ cathode $150 \times$ Magnification 3 images; Top row: Backscatter Electron Image; Bottom row, Left: Phosphorous X-Ray Analog Dot Map;p Bottom row, Right: Manganese X-Ray Analog Dot Map
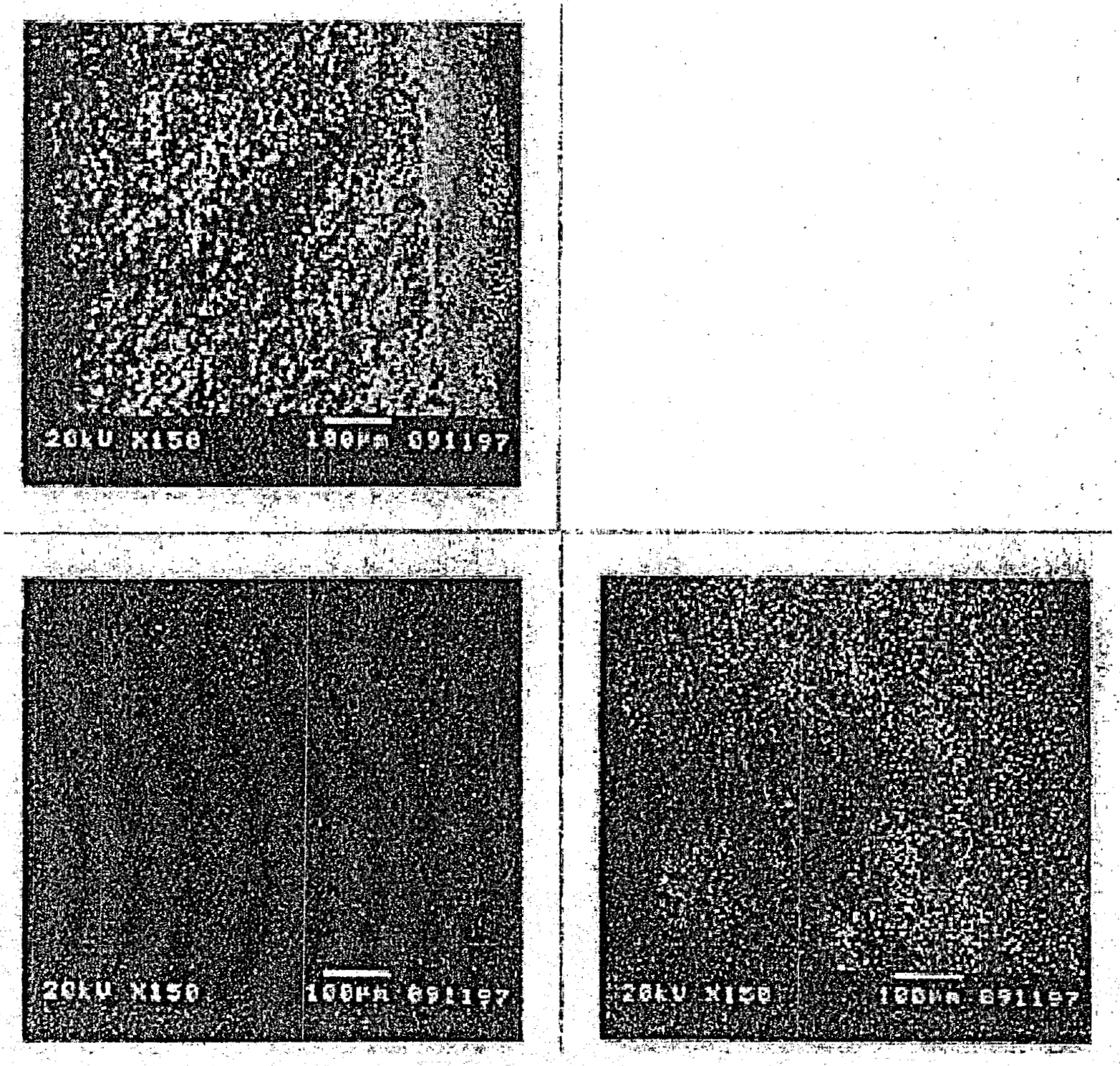
Figure 3.5 Surface of $\mathrm{LiMn}_{2} \mathrm{O}_{4}$ cathode, 200x magnification 3 images; Top row: Backscatter Electron Image; Bottom row, Left: Phosphorous X-Ray Analog Dot Map; Bottom row, Right: Manganese X-Ray Analog Dot Map
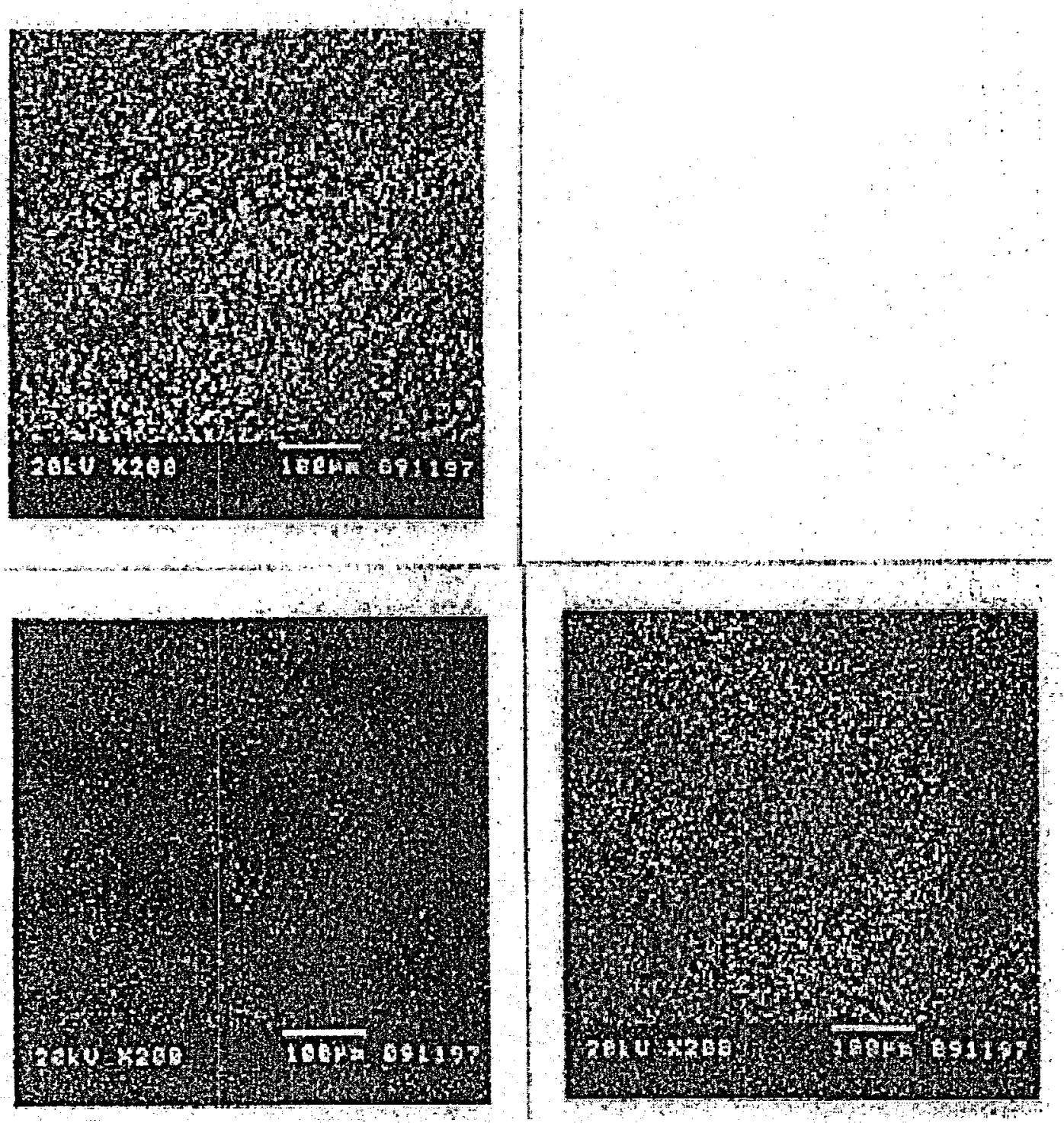
Figure 3.6 Cross-Section of $\mathrm{LiMn}_{2} \mathrm{O}_{4}$ cathode $150 \mathrm{x}$ magnification 3 images; Top row:

Backscatter Electron Image; Bottom row, Left: Phosphorous X-Ray Analog Dot Map;

Bottom row, Right: Manganese X-Ray Analog Dot Map

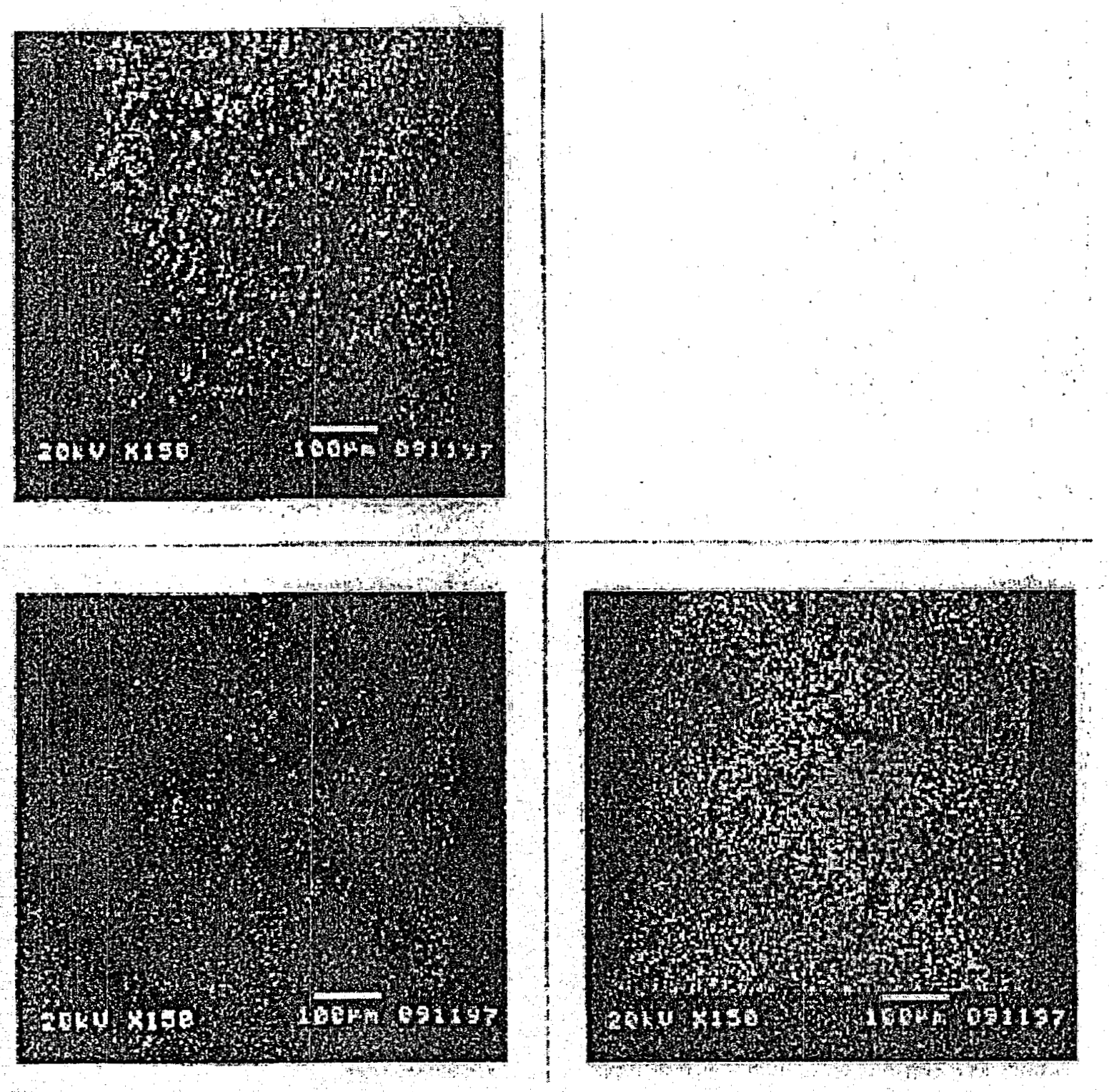




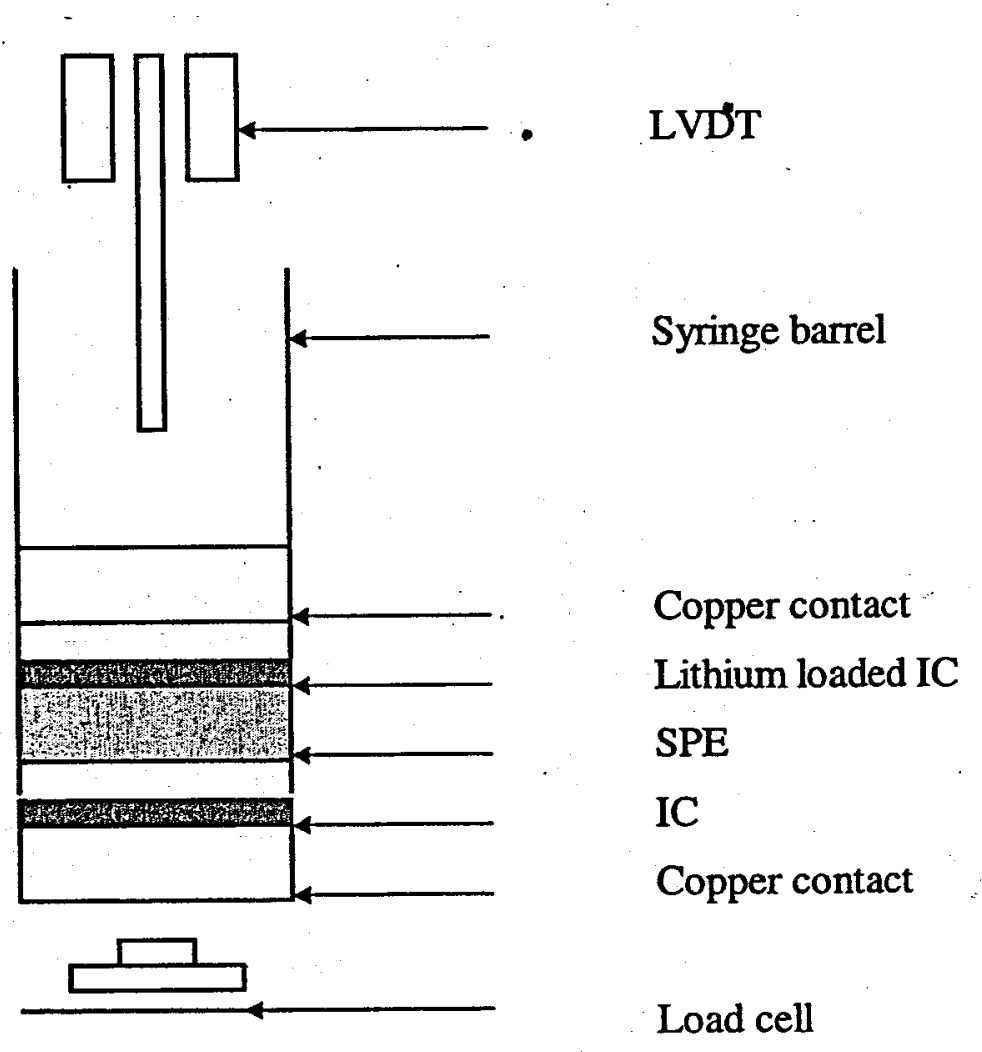

Figure 3.7: Schematic of a test cell for measuring volume changes and impedance data for $\mathrm{LiMnO}{ }_{2}-\mathrm{IC} / \mathrm{SPE} / \mathrm{MnO}_{2}-\mathrm{IC}$ laminates. 


\section{Chapter 4. Experimental Results}

\section{Electrolyte Complexation}

MEEP (2) was complexed with lithium triflate for use as the binder material in the intercalation cathodes. A mixture of $2.2 \mathrm{~g} \mathrm{MEEP}+0.3 \mathrm{~g} \mathrm{LiSO}_{3} \mathrm{CF}_{3}$ was dissolved in anhydrous tetrahydrofuran (THF) under an inert argon atmosphere and stirred for $24 \mathrm{hrs}$. The solvent was evaporated, the residue was dried under vacuum at $40{ }^{\circ} \mathrm{C}$, and the polymer-salt complex was recovered.

SMEP (1), for use in the electrolyte layer of the cell, was complexed with lithium triflate as well. A mixture of $1.9 \mathrm{~g} \mathrm{SMEP}+0.1 \mathrm{~g} \mathrm{LiSO}_{3} \mathrm{CF}_{3}$ was dissolved in anhydrous methanol and stirred for $24 \mathrm{hrs}$. before the solvent was evaporated. The recovered polymer-salt complex was dried at $40^{\circ} \mathrm{C}$ under vacuum $(<200 \mu \mathrm{m} \mathrm{Hg}$ ) and shaped into $1.43 \mathrm{~cm}$ diameter discs by pressing $0.1 \mathrm{~g}$ samples in a die at $2500 \mathrm{psi}$.

\section{Cathode Construction}

The intercalation cathode is a composite consisting of the cathode active material $\left(\mathrm{MnO}_{2}\right.$, in this case), a current distributor (carbon black, in most cases), and a binding polymer material pressed onto a current collector ( $\mathrm{Ni}$ or $\mathrm{Al}$ mesh or foil). Conventional construction methods utilize non-active binding polymers, such as Teflon or poly(vinylidene difluoride). Cathodes using these binding polymers suffer low ionic conductivity of the cations, thus lowering the power density of the batteries utilizing such cathodes. For cathodes to be used with polymer electrolyte-based batteries, it is common to use an ionically conducting polymer as the binding material. In this study, MEEP (2) was used as the binder, which facilitated the transfer of $\mathrm{Li}^{+}$ species between active cathode particles within the electrode.

Two methods for preparing cathodes are commonly employed. The polyphosphazenes utilized as polymer electrolytes are soluble in conventional organic solvents, unlike the commonly used inactive materials, such as Teflon. Therefore, the cathode may be cast from a solution of the polymer with the active cathode material and carbon black particles suspended in the mixture. The cast samples were then dried under a vacuum to remove the remaining solvent. However, they were also fabricated by compression. In the case of conventional cathodes, this method allows for the sintering of the non-soluble, Teflon binder material to produce a mechanically stable structure. For non-crystalline amorphous polymers, such as the 
polyphosphazenes used in this study, it was unclear whether compression would produce composite materials with sufficiently good mechanical properties.

For this present work, in order to investigate the performance of the cathode in relation to sample processing methods, cathodes were fabricated both by solvent casting and pressing. Mixtures of different weight percents (i.e., $29 \%$ by wt. $\mathrm{MEEP} / \mathrm{LiSO}_{3} \mathrm{CF}_{3}, 6 \%$ acetylene carbon black, and $65 \%$ of the active cathode material $\left(\mathrm{LiMn}_{2} \mathrm{O}_{4}, \gamma-\mathrm{MnO}_{2}\right.$ or $\left.\lambda-\mathrm{MnO}_{2}\right)$ ) were dissolved/suspended in dry THF in an argon-filled dry box. A concentration of approximately $0.8 \mathrm{~g}$ polymer-salt complex per $10 \mathrm{~mL}$ THF as solvent was used. The solution was poured onto a $1.43 \mathrm{~cm}$ diameter $\mathrm{Pt}$ electrode in a $0.5 \mathrm{~cm}$-deep well. The solvent was allowed to evaporate over 24 hours.

Materials for the pressed samples were of the same composition as for the solvent cast cathodes. The solvent was removed under vacuum and the polymer-salt-carbon- $\mathrm{MnO}_{2}$ mixture was recovered as a black paste. Approximately $0.25 \mathrm{~g}$ of the mixture was placed into a $1.43 \mathrm{~cm}$ diameter die and pressed at approximately 5000 psi into a disc.

\section{Characterization of Li/SPE/C and IC/SPE/C' Laminate}

In order to investigate the electrolyte/cathode interface, IC/SPE/IC' laminates were fabricated where IC and IC' represent the lithium-intercalated and virgin cathodes, respectively. Thus, one cathode (IC) was initially composed of $\mathrm{LiMn}_{2} \mathrm{O}_{4}$, while the other electrode (IC') contained $\mathrm{MnO}_{2}$ particles without $\mathrm{Li}$ atoms intercalated into the crystal structure. Two crystal forms of manganese dioxide were used, $\gamma-\mathrm{MnO}_{2}$ and $\lambda-\mathrm{MnO}_{2}$ (the SPE used was a $\mathrm{LiSO}_{3} \mathrm{CF}_{3}$ complex of SMEP, 1). The laminates were then continuously cycled at constant current, alternating polarity periodically. After a certain number of cycles, the laminate was characterized by EIS.

The IC/SPE/C' laminate consisted of two layers of intercalation cathodes with a thickness of 0.2-0.5 mm per layer, and a pre-fabricated SPE (SMEP/LiSO ${ }_{3} \mathrm{CF}_{3}$ ) disk with an average thickness of $0.3 \mathrm{~mm}$ and an area of $1.623 \mathrm{~cm}^{2}$. The laminate was cycled galvanostatically at a current density of $6 \mathrm{~mA} / \mathrm{cm}^{2}$ at $25^{\circ} \mathrm{C}$. Each cycle lasted $2 \mathrm{hrs}$, with current flowing in either direction for $1 \mathrm{hr}$. Thus, about $3.6 \times 10^{-4}$ moles of electrons, and correspondingly, the same amount of $\mathrm{Li}^{+}$, were cycled through the electrolyte. The average IC layer weighed around $0.25 \mathrm{~g}$, with $65 \%$ by weight of $\mathrm{LiMn}_{2} \mathrm{O}_{4}$, or about $8.9 \times 10^{-4}$ moles of $\mathrm{Li}^{+}$. 
Therefore, more than $1 / 3$ of the $\mathrm{Li}^{+}$present in the $\mathrm{LiMn}_{2} \mathrm{O}_{4}$-containing cathode was transferred between the electrodes in each cycle. EIS measurements were carried out on the IC/SPE/IC' laminate every 5 cycles (10 hrs.), with the cycling current being interrupted during the measurements, which took about 15 minutes. The pressure on the laminate and the thickness of the laminate were also monitored continuously. Voltage data were collected every 5 minutes (24 data points for each cycle) over the entire cycling period.

\section{Dilatometry}

Based on the cycling experiments described in the previous section, cycling tests of $\mathrm{Li} / \mathrm{SPE} / \mathrm{Li}$ laminar samples were conducted under the same experimental conditions, repetitively. Sample dimensional change and system pressure were closely monitored with the process of the cycling experiments. With the computer-monitored electrochemical test system, voltage across the cell and the current associated with it have also been measured and their changes with the cycle time were plotted in this section.

The volume change of the laminate is expressed in terms of an increase in thickness, due to the restricted cross-sectional area of the syringe. It was found that the thickness of the laminate increased sharply with cycle number over the first 200 cycles, then more slowly over the next 300 cycles, and ultimately reached a constant value for $\mathrm{N}>750$ cycles (Figure 4.1 ). The change in thickness corresponds to a volume change of almost 33\% (maximum) based upon the nominal thickness of the SPE. Similar behavior was observed while the cell was under different pressures.

\section{Destructive Analysis}

At the end of each cycling test, the sample was removed from the testing unit and dissected inside the glove box under argon gas. No obvious oxidation at the Li/SPE interface could be identified with the naked eye. Light oxidation was found at the lithium/electrode surface, which was in contact with the metal blocks. This is believed due to the contamination of the metal surface with oxygen or moisture molecules before it was assembled inside the syringe.

\section{Impedance}

Impedance of Li/Super-MEEP/Li Systems

EIS measurements were performed using Gamry CMS 105 and CMS 300 test systems with a lock-in amplifier from Stanford Research Systems. Sinusoidal potential perturbations (10 
$\mathrm{mV}$ peak-to-peak), at frequencies within the range of $1 \mathrm{~Hz}$ to $100 \mathrm{kHz}$, were applied across the laminate after interruption of the galvanostatic charging current and after the impedance was measured by the CMS 300 system. Predominantly resistive impedance was observed, with the phase angle being close to zero for a frequency lower than $10 \mathrm{kHz}$. The measured cell impedance data were scattered around an average value of $10 \Omega$ over the entire cycle periods (Figure 4.2). No sudden impedance increase has been found throughout the entire cycling regimen that would indicate failure due to powdering of the lithium metal. The voltage data were scattered around $\pm 0.1 \mathrm{~V}$, depending upon the direction of the current. Interestingly, the voltage drop across the laminate did not change as the thickness of the laminate increased on charge cycling, indicating no change of internal impedance.

\section{Impedance of ICi/Super-MEEP/IC' Systems}

IC/Super-MEEP/C' systems have two similar intercalated cathodes sandwiching a polymer electrolyte made of Super-MEEP with 40\% wt. Lithium Triflate. One of the IC (IC') was "charged" with Lithium ion; i.e., had been lithiated and was ready to discharge.

Figure 4.3 shows the changes of pressure with cycles. It can be observed that the sample volume did not change with cycles, indicating that there were no changes in volume in the intercalated cathode, contrary to experiments when Li/Super-MEEP/C was used (above). In this latter case, the lithium ion experienced a change of volume when it changed from the metal to the intercalate state (from the anode to the cathode).

Every 5 cycles of one charge and one discharge ( 1 or 2 hrs. each way, as indicated in Table 4.1), the cycling was stopped and the impedance was measured. The sample then continued to be cycled and every 5 cycles the impedance was measured again. : This procedure was repeated until the sample failed, or after about 500 cycles $(500$ cycles $=1000$ hours of 1 hour charge and $1 \mathrm{hr}$. discharge, or 2000 hours of $2 \mathrm{hr}$. charge and $2 \mathrm{hr}$. discharge). Impedance curves started at time equal to zero.

It is of great importance that the validity of the EIS data be verified. The EIS measurement is based on the assumptions of a steady state and a linear system and can be affected by quite a few factors, such as the test environments, the magnitude of the sinusoidal voltage, and the arrangement of the testing cell. It is possible that, instead of measuring the real impedance data, the data are merely artifacts due to improper measurements. Kramers-Kronig transformation has been performed in the past to validate the impedance data[1,2]. Provided that 
the system is causal, linear and stable, and provided that the impedance of the system is finite valued and continuous at all frequencies, Kramers-Kronig transforms are purely a mathematical result and do not reflect any other physical property or condition of the system.

The KK transformed were applied to all impedance sets. Twenty-three different sets were tested. The difference between tests were the type of $\mathrm{MnO}_{2}$ used, weight percentile of the mixture MEEP: $\mathrm{C}: \mathrm{MnO}_{2}$, used to make the IC, the method used to make the IC, and the system used (Li/SMEEP/IC or IC/SMEEP/IC'), as indicated in Table 4.1.

Because no degradation was ever found at the Li/SMEEP interface, we concentrated our efforts on studying the IC systems only. Accordingly, the Li/SMEEP/IC data is not discussed in this report. Most of the samples that had an IC, which were fabricated using a cast intercalated cathode, failed mechanically and the results are not discussed in this report. The only systems that were studied were samples $8,23,6,12,17,9,22,5,7,17$, and 19 . Those samples correspond to IC/SMEEP/IC' systems where the IC was fabricated by pressing all the ingredients (MEEP, $\mathrm{C}$, and $\mathrm{MnO}_{2}$ ) and for which $\lambda$ - or $\gamma-\mathrm{MnO}_{2}$ were used and at different IC and IC' compositions and thickness, as indicated in Table 4.1. The samples tested are listed in black in 12-point font at the bottom part of Table 4.1. Table 4.2 summarize the polarization resistance of the systems studied.

With the exception of Sample 22, which shows mechanical failure at the end of the test (listed in table 4.1 in italic letters), all tests show small changes of impedance with cycle time.

KK transforms were performed on the real and imaginary components of the impedance measured at the beginning and end of the cycling tests (not shown, because the very large number of graphs involved). We observed that the impedance measured in all samples had a constant resistive error, which displaced the real component vs. frequency signature to higher resistance values. It was also observed that the low and high frequency data did not transform correctly, in that the KK transforms did not reproduced the measured data. An apparent capacity tail in the $4^{\text {th }}$ quadrant was observed at high frequencies. The impedance at those frequencies for which the $\mathrm{KK}$ did not transform satisfactorily $\left(10^{3}\right.$ to $\left.10^{6} \mathrm{~Hz}\right)$ possibly contain inductance due to the longer-than-normal cables used during the experiments. Those cables were necessary because the cell were contained in a glove box. 
Accordingly, only the middle- range of frequencies of the impedance data were interpreted. Ignoring that negative "tail" in the $4^{\text {th }}$ quadrant at high frequencies, the Nyquist diagram show a semicircle that slowly increases in diameter with the number of cycles, corresponding to a slow increase in the resistance of the cathode. Eventually, upon continued cycling, the resistance would suddenly and dramatically increase on further cycling, corresponding to "failure". In some cases, a second, smaller loop would appear in the $1^{\text {st }}$ quadrant. This loop was observed to develop with increasing cycle number, perhaps indicating the development of an additional R//C element in the system (e.g., at the IC/current collector interface).

In Table 4.2 the polarization resistance (difference between the intercepts of the impedance locus on the real axis at limiting high and low frequencies) is listed in order of increasing value. For the different sets listed, as indicated in Table 4.2, the results suggest that cathodes fabricated using $\gamma-\mathrm{MnO}_{2}$ are superior to those containing $\lambda-\mathrm{MnO}_{2}$ (lower polarization resistance, $R_{p}$, and a lower rate of increase of $R_{p}$ with cycle number). Also, the data summarized in Table 4.2 indicate that a smaller amount of MEEP or SMEEP results in a lower $R_{p}$ value. No doubt that this reflects the higher volume fraction of conductive carbon in the composite structure.

\section{Reference Chapter 4}

1. M. Urquidi-Macdonald, S. Real and D. Macdonald, J. Electrochem. Soc., 133, p. 2018-2024, 1986.

2. M. Urquidi-Macdonald, S. Real and D. Macdonald, J. Electrochem. Soc., 35, p. 1559-1566, 1990. 


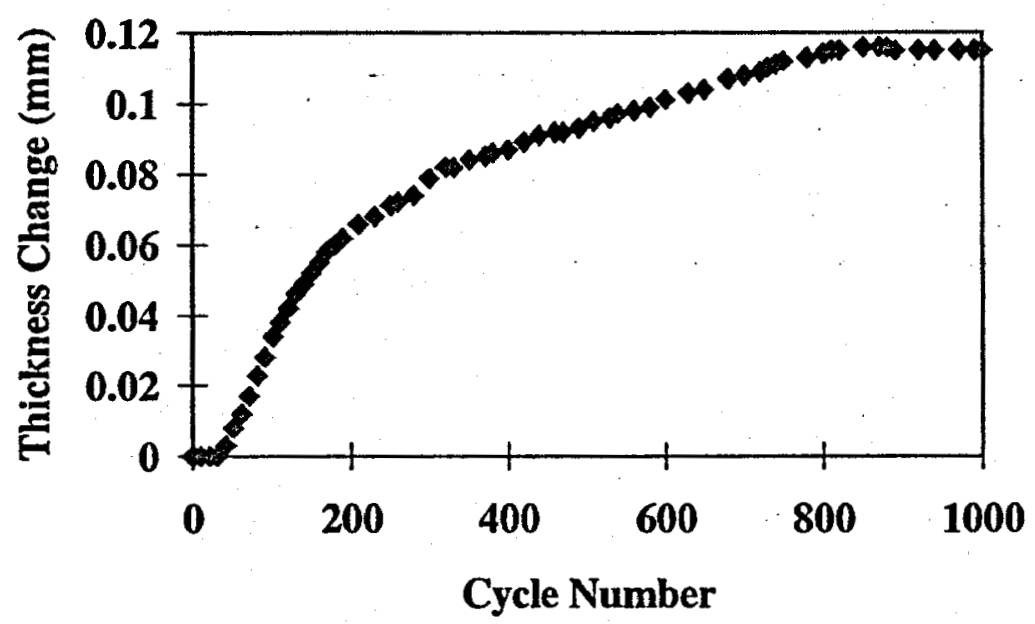

Figure 4.1. Change of $\mathrm{L} / \mathrm{SPE} / \mathrm{Li}$ laminate thickness as a function of cycle number. The total change in thickness represents about $30 \%$ of the original thickness.

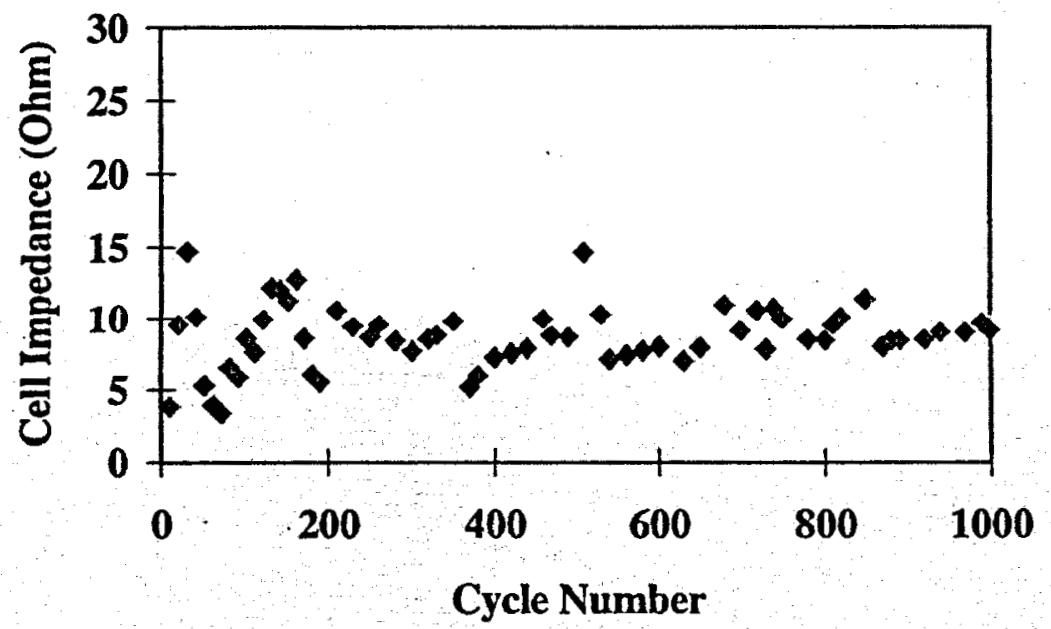

Figure 4.2. Measured impedance of the $\mathrm{Li} / \mathrm{SPE} / \mathrm{Li}$ laminate as a function of cycle number. 


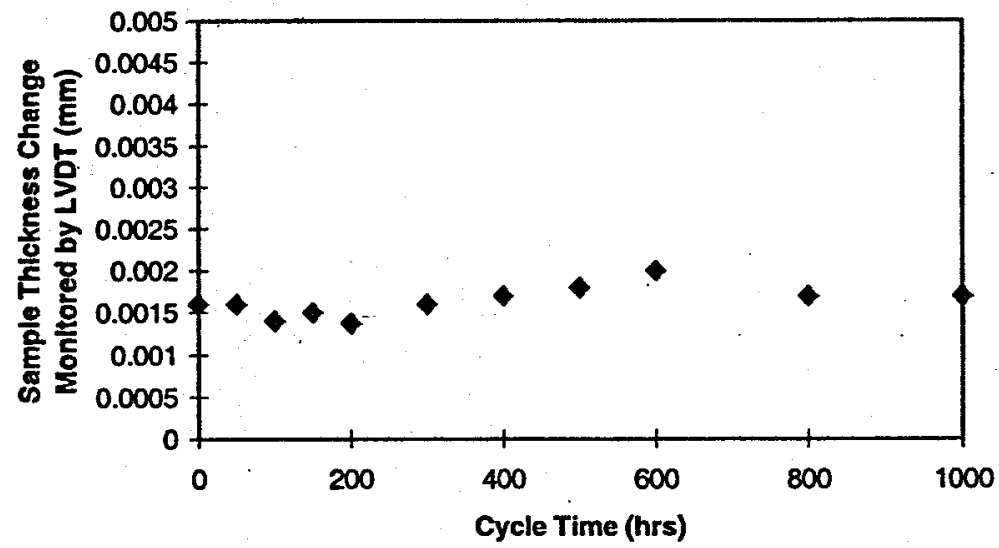

Figure 4.3. Change of IC/SPE/C' laminate thickness as a function of cycle number. Note that this system did not fail; that is, there was no sudden increase in laminate impedance with cycle number.

Table 4.1. List of systems tested. The impedance was measured every 5 cycles of 2 or 4 hrs. (as indicated) and the number of times that the impedance was measured and then $\mathrm{KK}$ transformed, is also listed. The number of cycles that the sample was tested over can be calculated as: (Number of impedances measured-1)*5.

\begin{tabular}{|c|c|c|c|c|c|c|c|c|}
\hline $\begin{array}{l}\text { File } \\
\text { No. }\end{array}$ & $\begin{array}{l}\mathrm{MnO}_{2} \\
\text { Type }\end{array}$ & $\begin{array}{l}\text { MEEP: C: } \\
\mathrm{MnO}_{2}\end{array}$ & $\begin{array}{l}\text { Comme } \\
\text { nts }\end{array}$ & $\begin{array}{l}\mathrm{R}_{\mathrm{p}}(\mathrm{Ohm}) \\
\text { Change } \\
\text { between } \\
\text { ist and } \\
\text { last } \mathrm{AC} \\
\text { impedanc } \\
\text { e Run }\end{array}$ & $\begin{array}{l}\text { Thickness, } \\
\mathrm{mm}\end{array}$ & $\begin{array}{l}\text { No. } \\
\text { Impe } \\
\text { danc } \\
\text { e } \\
\text { Runs }\end{array}$ & $\begin{array}{l}\text { C } \\
\text { Rate }\end{array}$ & $\begin{array}{l}\text { System and } \\
\text { method to } \\
\text { make IC }\end{array}$ \\
\hline 1 & $\lambda$ & $29: 6: 65$ & FAILED & & & & $\begin{array}{l}2 \mathrm{hr} / \\
6 \mathrm{~mA}\end{array}$ & $\begin{array}{l}\text { Cast } \\
\text { IC/SPE/IC' }\end{array}$ \\
\hline 3 & $\gamma$ & $29: 6: 65$ & FAILED & & & & $\begin{array}{l}2 \mathrm{hr} / \\
6 \mathrm{~mA}\end{array}$ & $\begin{array}{l}\text { Cast } \\
\text { IC/SPE } / C^{\prime}\end{array}$ \\
\hline 4 & $\gamma$ & $29: 6: 65$ & FAILED & & & & $\begin{array}{l}2 \mathrm{hr} / \\
6 \mathrm{~mA}\end{array}$ & $\begin{array}{l}\text { Cast } \\
\text { IC/SPE } / C^{\prime}\end{array}$ \\
\hline
\end{tabular}




\begin{tabular}{|c|c|c|c|c|c|c|c|c|}
\hline 21 & $\lambda$ & $15: 20: 65$ & $\begin{array}{c}\text { FAILED } \\
\cdots \quad=\end{array}$ & & & & $\begin{array}{l}2 h r / \\
6 m A\end{array}$ & $\begin{array}{l}\text { Pressing } \\
\text { IC/SPE /IC' }\end{array}$ \\
\hline 2 & $\bar{\lambda}$ & $29: 6: 65$ & $\begin{array}{l}\text { Medium } \\
\mathrm{MnO}_{2} \\
\text { Low } \kappa_{e}\end{array}$ & .. & & 51 & $\begin{array}{l}2 \mathrm{hr} / \\
6 \mathrm{~mA}\end{array}$ & $\begin{array}{l}\text { CAST } \\
\text { IC/SPE/IC' }\end{array}$ \\
\hline 10 & $\bar{\lambda}$ & $29: 6: 65$ & $\begin{array}{l}\text { Medium } \\
\mathrm{MnO}_{2} \text {, } \\
\text { Low } \kappa_{e}\end{array}$ & & & 33 & $\begin{array}{l}2 \mathrm{hr} / \\
6 \mathrm{~mA}\end{array}$ & $\begin{array}{l}\text { CAST } \\
\text { Li/ SPE /IC }\end{array}$ \\
\hline 11 & $\bar{\gamma}$ & $29: 6: 65$ & $\begin{array}{l}\text { Medium } \\
\mathrm{MnO}_{2}, \\
\text { Low } K_{e}\end{array}$ & & & 33 & $\begin{array}{l}2 \mathrm{hr} / \\
6 \mathrm{~mA}\end{array}$ & $\begin{array}{l}\text { CAST } \\
\text { Li/ SPE /IC }\end{array}$ \\
\hline 13 & $\lambda$ & $30: 20: 50$ & $\begin{array}{l}\text { Low } \\
\mathrm{MnO}_{2}, \\
\text { High Ke }\end{array}$ & & & 64 & $\begin{array}{l}2 \mathrm{hr} / \\
6 \mathrm{~mA}\end{array}$ & $\begin{array}{l}\text { CAST } \\
\text { Li/ SPE /IC }\end{array}$ \\
\hline 14 & $\gamma$ & $30: 20: 50$ & $\begin{array}{l}\text { Low } \\
\mathrm{MnO}_{2}, \\
\mathrm{High} \mathrm{K}_{\mathrm{e}}\end{array}$ & & & 64 & $\begin{array}{l}2 \mathrm{hr} / \\
6 \mathrm{~mA}\end{array}$ & $\begin{array}{l}\text { CAST } \\
\text { Li/ SPE /IC } \\
14\end{array}$ \\
\hline 16 & $\lambda$ & $15: 5: 80$ & $\begin{array}{l}\mathrm{High} \\
\mathrm{MnO}_{2} \text {, } \\
\mathrm{Low} \mathrm{Ke}_{\mathrm{e}}\end{array}$ & & & 60 & $\begin{array}{l}2 \mathrm{hr} / \\
6 \mathrm{~mA}\end{array}$ & $\begin{array}{l}\text { Press } \\
\text { Li/ SPE /IC }\end{array}$ \\
\hline 18 & $\gamma$ & $15: 5: 80$ & $\begin{array}{l}\text { High } \\
\mathrm{MnO}_{2} \text {, } \\
\text { Low } \mathrm{K}_{e}\end{array}$ & & & 61 & $\begin{array}{l}2 \mathrm{hr} / \\
6 \mathrm{~mA}\end{array}$ & $\begin{array}{l}\text { Press } \\
\text { Li/ SPE /IC }\end{array}$ \\
\hline 20 & $\gamma$ & $15: 20: 65$ & $\begin{array}{l}\text { Medium } \\
\mathrm{MnO} 2, \\
\text { High } \kappa_{e}\end{array}$ & & & 59 & $\begin{array}{l}2 \mathrm{hr} / \\
6 \mathrm{~mA}\end{array}$ & $\begin{array}{l}\text { Press } \\
\text { Li/ SPE /IC }\end{array}$ \\
\hline 8 & $\lambda$ & $29: 6: 65$ & $\begin{array}{l}\text { High } \\
\text { MnO2, } \\
\text { Low Ke }\end{array}$ & $5-15$ & $0.64 / 0.22 / 0.64$ & 38 & $\begin{array}{l}4 \mathrm{hr} / \\
10 \mathrm{~mA}\end{array}$ & $\begin{array}{l}\text { Press } \\
\text { IC/ SPE /IC' } \\
\end{array}$ \\
\hline 17 & $\lambda$ & \begin{tabular}{|l|l}
$15: 5: 80$ \\
\end{tabular} & $\begin{array}{l}\text { Medium } \\
\mathrm{MnO}_{2},\end{array}$ & $15-18$ & $0.64 / 0.12 / 0.64$ & 68 & $\begin{array}{l}4 \mathrm{hr} / \\
10 \mathrm{~mA}\end{array}$ & \begin{tabular}{|l|} 
Press \\
IC/ SPE $/ C^{\prime}$ \\
\end{tabular} \\
\hline
\end{tabular}




\begin{tabular}{|c|c|c|c|c|c|c|c|c|}
\hline & & & Low $k_{e}$ & & & & & \\
\hline 9 & $\gamma$ & $29: 6: 65$ & $\begin{array}{l}\text { High } \\
\mathrm{MnO}_{2}, \\
\mathrm{Low} \mathrm{K}_{\mathrm{e}}\end{array}$ & $5-5.2$ & $0.60 / 0.26 / 0.66$ & 71 & $\begin{array}{l}2 \mathrm{hr} / \\
6 \mathrm{~mA}\end{array}$ & $\begin{array}{l}\text { Press } \\
\text { IC/ SPE /IC' }\end{array}$ \\
\hline 22 & $\gamma$ & $15: 20: 65$ & $\begin{array}{l}\text { Medium } \\
\mathrm{MnO}_{2}, \\
\mathrm{High} \mathrm{K}_{e}\end{array}$ & $\begin{array}{l}58- \\
7.2 \times 10^{6} \\
\end{array}$ & $0.58 / 0.22 / 0.60$ & 61 & $\begin{array}{l}4 \mathrm{hr} / \\
10 \mathrm{~mA}\end{array}$ & $\begin{array}{l}\text { Press } \\
\text { ICSPE } / C^{\prime}\end{array}$ \\
\hline 5 & $\bar{\gamma}$ & $29: 6: 65$ & $\begin{array}{l}\text { Low } \\
\text { High } \\
\mathrm{MnO}_{2} \text {, } \\
\text { Low } \mathrm{K}_{\mathrm{e}}\end{array}$ & $38-42$ & $0.80 / 0.76 / 0.70$ & 97 & $\begin{array}{l}2 \mathrm{hr} / \\
6 \mathrm{~mA}\end{array}$ & $\begin{array}{l}\text { Press } \\
\text { IC/ SPE /C' }\end{array}$ \\
\hline 7 & $\gamma$ & $29: 6: 65$ & $\begin{array}{l}\text { Low } \\
\text { High } \\
\mathrm{MnO}_{2} \text {, } \\
\text { Low } \mathrm{K}_{\mathrm{e}}\end{array}$ & $4-5.5$ & $0.80 / 0.76 / 0.70$ & 110 & $\begin{array}{l}2 \mathrm{hr} / \\
6 \mathrm{~mA}\end{array}$ & $\begin{array}{l}\text { Press } \\
\text { IC/ SPE } / C\end{array}$ \\
\hline 15 & $\gamma$ & $30: 20: 50$ & \begin{tabular}{|l|} 
Low \\
$\mathrm{MnO}_{2}$, \\
High $\kappa_{e}$ \\
\end{tabular} & $26-35$ & $0.60 / 0.14 / 0.40$ & 38 & $\begin{array}{l}4 \mathrm{hr} / \\
10 \mathrm{~mA}\end{array}$ & \begin{tabular}{|l|} 
Press \\
IC/ SPE /C
\end{tabular} \\
\hline 19 & $\gamma$ & $15: 5: 80$ & $\begin{array}{l}\mathrm{High} \\
\mathrm{MnO}_{2}, \\
\mathrm{Low} \mathrm{K}_{\mathrm{e}}\end{array}$ & $14-19$ & $0.58 / 0.10 / .64$ & 96 & $\begin{array}{l}4 \mathrm{hr} / \\
10 \mathrm{~mA}\end{array}$ & \begin{tabular}{|l|} 
Press \\
IC/ SPE /IC
\end{tabular} \\
\hline
\end{tabular}


Table 4.2. Summary of Results Listed in Table 4.1 and ordered by composition ratios and by layers of the system thickness (IC/SMEEP/IC').

\begin{tabular}{|c|c|c|c|}
\hline $\begin{array}{l}\text { Type of } \\
\mathrm{MnO}_{2}\end{array}$ & MEEP:C: $\mathrm{MnO}_{2}$ & $\mathbf{R}_{\mathrm{p}}$, Change (Ohm) & IC/SPE/IC' \\
\hline$\gamma$ & $15: 5: 80$ & $\begin{array}{l}14 \rightarrow 19 \text { Ohms } \\
35 \% \text { increased in } 96 \\
\text { cycles }\end{array}$ & $0.58 / 0.10 / .64$ \\
\hline$\lambda$ & $15: 5: 80$ & $\begin{array}{l}15 \rightarrow 18 \text { Ohms } \\
20 \% \text { increased in } 68 \\
\text { cycles }\end{array}$ & $0.64 / 0.12 / 0.64$ \\
\hline$\lambda$ & $29: 6: 65$ & $\begin{array}{l}5 \rightarrow 15 \text { Ohms } \\
200 \% \text { increased in } 38 \\
\text { cycles }\end{array}$ & $0.64 / 0.22 / 0.64$ \\
\hline$\gamma$ & $29: 6: 65$ & $\begin{array}{l}5 \rightarrow 5.2 \text { Ohms } \\
4 \% \text { increased in } 71 \\
\text { cycles }\end{array}$ & $0.60 / 0.26 / 0.66$ \\
\hline$\gamma$ & $29: 6: 65$ & $\begin{array}{l}4 \rightarrow 5.5 \text { Ohms } \\
38 \% \text { increased in } 110 \\
\text { cycles }\end{array}$ & $0.80 / 0.76 / 0.70$ \\
\hline & & & \\
\hline$\gamma$ & $30: 20: 50$ & $\begin{array}{l}26 \rightarrow 35 \text { Ohms } \\
35 \% \text { increased in } 38 \\
\text { cycles }\end{array}$ & $0.60 / 0.14 / 0.40$ \\
\hline$\gamma$ & $30: 5: 65$ & $\begin{array}{l}38 \rightarrow 42 \text { Ohms } \\
10 \% \text { increased in } 97 \\
\text { cycles }\end{array}$ & $0.80 / 0.76 / 0.70$ \\
\hline
\end{tabular}




\section{Chapter 5. Cathode/Polymer Interface Modeling and Results: Interpretation}

\section{Possible Causes of Degradation}

Many studies have suggested that changes in the morphology of passivating films at the lithium/electrolyte interface are responsible for the short cycle life of lithium/solid polymer electrolyte (SPE) batteries. Although a film does develop, and is postulated to result from reactions between lithium and residual water and impurities in the electrolyte, Gao and Macdonald [1] have not found any significant changes in the impedance at the junction of a lithium anode in mechanical contact with a solid polymer electrolyte. Gray [2] agrees that these passivating films do not hinder the ionic or electronic exchange between metal and the electrolyte. We propose, instead, that changes within the composite intercalation cathodes used in these batteries may lead to failure. This possibility has also been previously suggested and investigated by Scrosati et al. [3]

Failure is largely defined by the intended application of the battery. For electronic applications, which require that a constant voltage be supplied within tight tolerance, a reduction in output voltage below a minimum threshold may defined as "failure". Electric vehicle traction batteries that operate in a deep discharge regimen may tolerate greater differences between the high and low end voltages. In these applications, however, the total energy output available between charge cycles -- and subsequently the range the vehicle may achieve -- determines the suitability of a given battery. Failure in this case is defined by a reduction in total energy capacity below a minimum threshold. [4]

To date, little work has been done to quantitatively identify the physical properties of the cathode that govern its performance and which may be responsible for degradation or failure. Identifying all of the physical parameters of such a complex system is an extremely difficult task. Additionally, local variations in cathode composition, which arise during fabrication, are difficult to control and may significantly affect experimental reproducibility and cathode performance. Nonetheless, it is the goal of this study to understand and characterize the role of the cathode/polymer interface; the development of theoretical models comprising, to the maximum extent possible, real physical parameters, which are generally poorly known. Such parameters include the electrical conductivity of the materials involved, size and distribution of particles in 
the polymer matrix (carbon powder, lithium salt, and $\mathrm{MnO}_{2}$ particles), pressure, and temperature, among others.

By fitting the theoretical model to experimental DC conductivity and charge/discharge data, we seek to determine which parameters have the greatest impact upon cathode performance. Once a model is developed that accurately describes the behavior of a fresh cathode, it will be refitted progressively to data obtained following extensive simulated charge/discharge cycling. In this way, we hope to identify the parameters that change significantly over the cathode life and which eventually lead to battery failure. Once identified, ways to control these parameters and optimize cathode and battery performance can be determined.

As the reader by this point is aware, the intercalation cathode and the processes that occur within it are extremely complex. There are many possible causes of degradation and shortened cycle life. Several have been proposed in other studies, and we have alluded to some in the previous paragraphs. In this section, we will summarize some of the more likely sources of degradation, the presence and effects of which we investigated in our experiments.

As we have already suggested, a loss of either electron or lithium cation conductivity reduces the concentrations of these species at the polymer $\mathrm{MnO}_{2}$ interface, thereby preventing the necessary reduction reaction -- intercalation of lithium in the $\mathrm{MnO}_{2}$ structure - from occuring. Several possibilities exist that might explain a loss of electrical conductivity. As we have described earlier, electron conductivity is a strong function of the tunneling gap between neighboring, conducting carbon particles. If the sample expands, the average gap length will increase, causing a drastic reduction in electrical conductivity, particularly if the system is close to the percolation limit. Expansion may result from several sources.

Armand et al investigated a similar cathode, which utilized $\mathrm{V}_{6} \mathrm{O}_{13}$ as the active material. They discovered that upon lithium insertion, the $\mathrm{V}_{6} \mathrm{O}_{13}$ structure exhibited cracking, even upon the first discharge cycle of the battery. The cracks widened upon the second discharge and the electrode measurably swelled. Assuming that cracking does not affect the ability of the $\mathrm{V}_{6} \mathrm{O}_{13}$ to intercalate lithium during subsequent cycling, its expansion may still cause the carbon particles to be drawn apart, thus increasing gap length and, therefore, the resistivity. Or stated another way, sample expansion will reduce the volumetric concentration of carbon, causing a sudden 
decrease in conductivity. A similar phenomenon may occur in $\mathrm{MnO}_{2}$-based cathodes. Formation of a passivating layer on $\mathrm{MnO}_{2}$ similar to those seen at the lithium-polymer interface may cause an increase in $\mathrm{MnO}_{2}$ diameter. This would result in a macroscopic increase in cathode volume.

Aurbach et al [5] investigated the ability of carbon electrodes to intercalate lithium ions using organic, liquid electrolytes. They found that upon the first charging cycle, the same lithium undergoes irreversible reactions with species in the electrolyte. The products of these reactions form a film on the carbon surface analogous to that formed on a pure lithium electrode. If such a film is formed on the carbon particles in the cathode by reaction with impurities in the polymer, the tunneling gap may increase enough to reduce electronic conductivity. Additionally, this passivating film may be electrically insulating and impede the motion of electrons through the cathode.

Although the mechanism is not well understood, it is known that ionic conductivity decreases with increasing pressure. The free-volume model of ionic motion in amorphous polymers suggests that as pressure is increased, the motion of the polymer chains may be restricted. It is the chain motion upon which polymer ionic conductivity depends. The pressure control used in many of the studies we reviewed is not described. It may be that this was a variable that was allowed to fluctuate, leading to a drastic reduction in polymer ionic conductivity. As will be described in the final section, each sample in our work was tested at a constant pressure.

A literature review was conducted to assemble relevant information from previous studies in this field and in related fields. The review had two purposes: to collect theoretical and semi-empirical expressions, which may be incorporated into our model; and to evaluate existing modes of cathode failure. Relevant theories used to construct the model include: 1) Percolation and tunneling, which describe electronic conductivity, ionic conductivity theory; and charge transfer kinetics; and 2) Diffusion of lithium ions on the $\mathrm{MnO}_{2}$ (is this case) particle clusters. These theories and their applicability to our study are discussed in this report, as are some of the modes of failure that are currently under consideration. 


\section{Percolation Model}

\section{Electronic Conductivity}

Percolation theory can be used to describe the motion of electrons across a system comprised of conducting particles interspersed throughout an insulating or dielectric medium. $[6,7,8,9,23-36]$. It has been shown that the electronic conductivity of such a system remains very low as the volumetric concentration of the conductor increases from zero. As the conductor concentration is increased, conducting chains of progressively longer length are randomly formed. However, it is not until a critical concentration is reached that a complete chain, which forms an unbroken path from one side of the system to the other, is established. At this critical volume concentration, called the percolation threshold, electrons are able to travel through a strictly conducting medium across the system, while the conductivity suddenly increases by several orders of magnitude [7]. In the composite cathode case, the resistivity would be plotted against carbon black concentration and would be found to decrease drastically at the percolation threshold.

In the vicinity of the critical concentration, the conductivity follows the relationship:

$$
\sigma=\sigma_{0}\left(X-X_{c}\right)^{t}
$$

where $\sigma_{0}$ is the conductivity of the conducting filler (in our case, carbon black); $\mathrm{X}$ is the volume concentration of the filler; $X_{c}$ is the concentration at the percolation threshold; and $t$ is critical exponent, which is dependent upon the geometry of the system. Note that this relation holds only in the region near the percolation threshold. The value of the critical exponent can be experimentally determined by varying the filler concentration about the percolation threshold, measuring the corresponding conductivity, and plotting $\log (\sigma)$ vs. $\log \left(\mathrm{X}-\mathrm{X}_{\mathrm{c}}\right)$. The slope of the resulting line gives the value of the exponent for the given system. While threshold concentration and the critical exponent can also be predicted theoretically using percolation models, they have little physical meaning. We desire to build a model that describes the physical properties of the system including the parameters in Equation (5-1).

Meissner et al [9] and Narkis et al [8] have used this experimental technique to quantify the critical concentration and exponent for several different types of carbon black in dielectric media. They have shown that the values of the parameters vary considerably between the 
different conducting fillers. This indicates that the percolation parameters depend not only upon the distribution of the particles in the dielectric medium (i.e., their spacing and packing factor), but also upon the geometry of the particles themselves. Sherman et al [6] combines electronic tunneling theory and percolation theory to explain the physical origins of the differing behavior of the various carbon black types.

It is proposed that at the percolation threshold, carbon black particles do not form a continuous matrix through which electrons may be simply conducted, as in a wire. Instead, electrons actually tunnel through the insulating medium between near conducting particles, hopping from particle to particle. The ability of a tunneling electron to reach the next particle is strongly dependent upon the distance between neighboring conducting particles. At the percolation threshold, the tunnel gap between particles throughout the system passes below a critical maximum. The probability of electron tunneling rises rapidly in all parts of the system, and conductivity increases dramatically.

Based upon this theory, Sherman derived an expression for the resistivity of a binary system:

$$
\rho=\frac{1.67 \times 10^{-3}\left(l_{c}+l_{g}\right) l_{g}}{\left(m^{*} / m\right)^{1 / 2} \Phi^{1 / 2} a_{c t}}\left[1-\left(\frac{v_{c}}{f}\right) \frac{z}{2}\right] \exp \left[8 \times 10^{7}\left(\frac{m^{*}}{m}\right) \Phi^{1 / 2} l_{g}\right]
$$

where:

$l_{c} \quad$ is the length of a conducting particle

$l_{g} \quad$ is the gap between neighboring particles

$m \quad$ is the effective mass of an electron

$m \quad$ is the rest mass of an electron

$\Phi \quad$ is the potential barrier to tunneling between neighboring particles

$a_{c t}$ is the effective cross-sectional area of neighboring particles at the point of tunneling

$v_{c}$ is the volume concentration of the conducting filler at the percolation threshold 
$f \quad$ is the packing fraction of the conducting filler

$z \quad$ is the coordination number, which defines the number of nearest neighbors (particles) into which an electron may tunnel.

The effective tunneling area accounts for the geometric variations between different types of carbon black. The use of this expression assumes that normal tunneling occurs without quantum fluctuation. We will also begin by assuming equal distance between neighboring particles and uniform dimensional properties for all particles. As we refine our model, these constants will be replaced by distribution functions. Additionally, the assumption is made that tunneling between carbon black particles and $\mathrm{MnO}_{2}$ can be described by the same equation. Because the electrons are expected to participate in reduction reactions once they have reached the $\mathrm{MnO}_{2}$, we assume that no conduction will take place from one $\mathrm{MnO}_{2}$ particle to another, or from $\mathrm{MnO}_{2}$ to carbon. The inverse of this expression describes the electronic conductivity of the system, which will be incorporated into our model.

As the cathode ages, it may undergo macroscopic dimensional changes. As the sample expands, neighboring conducing particles are drawn further apart. This is manifested as an effective change in the gap length between particles. As Equation (5-2) indicates, the exponential dependence upon gap length would result in a marked increase in electrical resistivity, or decrease in conductivity, of the cathode. If electrons are unable to effectively tunnel through the cathode, they will not reach the $\mathrm{MnO}_{2}$ and the reduction reaction will be unable to proceed.

\section{Electrical Impedance}

Expressions for the electrical conductivity and the dielectric constant are combined to derive a theoretical expression for the impedance of the cathode. The following expressions are used to formulate the impedance function:

$$
\begin{gathered}
Z_{\text {electronic }}=Z_{R}+j Z_{I} \\
Z_{R}=\frac{\sigma \frac{L}{A}}{\sigma^{2}+\omega^{2} \varepsilon^{2}}
\end{gathered}
$$




$$
Z_{I}=\frac{\omega \varepsilon \frac{L}{A}}{\sigma^{2}+\omega^{2} \varepsilon^{2}}
$$

where:

$\mathrm{L} \quad$ is the cathode thickness
A is the cathode cross-sectional area
$\omega \quad$ is the frequency of the applied voltage

\section{Ionic Conductivity}

The average conductivity and permittivity of the cathode is calculated by using expressions proposed by several different authors. However, all of them need to know the equivalent conductivity of each species and the permittivity of the medium in the composite cathode. It is of great importance to realize that the ionic conductivity will depend on the actual concentrations of the ions in the system, which may be different from the stoichiometric salt concentration, because of incomplete dissociation of the salt.

\section{Species Transport Model}

We also explored a transport model for explaining the failure of composite cathodes on cyclic charging/discharging. In doing so, we employed the Nernst-Planck equation to calculate the concentration profiles of the lithium and the triflate ions, and the partially charged $\mathrm{MnO}_{2}$ sites, within the intercalation cathode. An electrical neutrality condition was imposed, which precludes the allowance for space charge. In this model, "failure" is envisioned to be due to the loss of mobile $\mathrm{Li}^{+}$within the composite structure, possibly due to their complexing with impurities within the electrolyte binder (e.g., $\mathrm{OH}$ ).

The Nernst-Planck equation for steady state conditions, coupled with the electrical neutrality condition for charged particles within the cathode, can be written in the form of a single, second-order, highly non-linear equation. The form of this equation is as follows (when the potential gradient is modified by the ionic species concentrations):

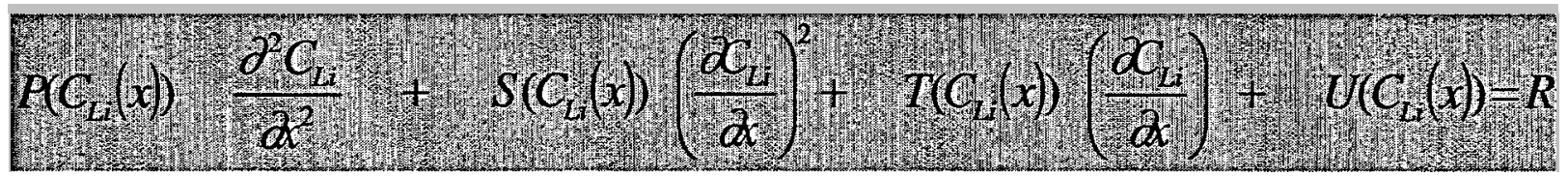


The boundary conditions for this equation are $\mathrm{C}_{\mathrm{Li}}(\mathrm{x}=0)=0$, and $\mathrm{C}_{\mathrm{Li}}(\mathrm{x}=\mathrm{L})=\mathrm{C}_{\mathrm{Li}}{ }^{\text {bulk }}$; where $\mathrm{x}=0$ indicates the cathode/current-collector interface, $\mathrm{x}=\mathrm{L}$ indicates the cathode/polymer interface; and $\mathrm{C}_{\mathrm{Lj}}$ refers to the lithium concentration. The functions $\mathrm{P}, \mathrm{S}, \mathrm{T}$, and $\mathrm{U}$, are nonlinear functions of the concentration profiles of lithium ion inside the cathode $\left(\mathrm{C}_{\mathrm{Li}}(\mathrm{x})\right)$. Finding the solution of such an equation represents a major mathematical challenge. Once the profiles of concentrations of lithium are calculated, the concentration profiles of the other species transferring charge in the cathode can then be calculated. However, in order to solve the coupled equations, it was necessary to adopt several simplifying assumptions that essentially reduce the problem to the ideal case.

The physical model assumes that lithium and triflate ions are transported by diffusion through the intercalation cathode and that $\mathrm{Li}^{+}$enters (intercalates) into the $\mathrm{MnO}_{2}$ particles, which have a limited capacity to accommodate the ions (a "critical" concentration). The $\mathrm{MnO}_{2}$ particles also contain traps that irreversibly bind $\mathrm{Li}^{+}$, such that the bound lithium is not free to move on subsequent discharge. Thus, upon charging, $\mathrm{Li}^{+}$moves from the SPE into the IC and then into the active, $\mathrm{MnO}_{2}$ particles. Some of the $\mathrm{Li}^{+}$are then trapped and are removed from the inventory of free $\mathrm{Li}^{+}$inside of the active particles. Upon discharge, only the free $\mathrm{Li}^{+}$moves out of the $\mathrm{MnO}_{2}$ particles, and hence on subsequent charging fewer $\mathrm{Li}^{+}$can be accommodated in the particle lattice. Accordingly the capacity of the active material decreases with cycle number. It is postulated that accumulation of trapped $\mathrm{Li}^{+}$in the $\mathrm{MnO}_{2}$ lattice causes the particles to expand thereby resulting in an expansion of the IC. At some point, the volume fraction of the electronically conducting carbon phase drops below the percolation limit and the resistivity increases catastrophically, resulting in failure.

The nature of the traps within the $\mathrm{MnO}_{2}$ are not specified at this point, but they may be water molecules existing within the lattice (presumably located between the crystallographic planes). Thus, reaction of $\mathrm{Li}^{+}$with $\mathrm{H}_{2} \mathrm{O}$ would yield immobile $\mathrm{LiOH}$ and $\mathrm{H}^{+}$in the lattice, with the former occupying sites that otherwise would be available for mobile $\mathrm{Li}^{+}$. A constant current $\pm 6 \mathrm{~mA} / \mathrm{cm}^{2}$ and in some cases (as indicated in Table 4.1), of $\pm 10 \mathrm{~mA} / \mathrm{cm}^{2}$ was assumed to be applied to the IC/SMEEP/IC system.

It is a fact that the voltage profile decays with cycles when the battery starts to fail and the initial voltage can no longer be reached. This is modeled by assuming that the Li ions react at the $\mathrm{MnO}_{2}$ sites. The number of $\mathrm{Li}$ atoms that the $\mathrm{MnO}_{2}$ particles can "accommodate" depends 
on the $\mathrm{MnO}_{2}$ characteristics (we call this the "critical concentration" on the outside surface of the $\mathrm{MnO}_{2}$ particle). On the discharge cycle, the amount of $\mathrm{Li}^{+}$that can leave the $\mathrm{MnO} 2$ particle during discharge will depend on whether or not the lithium atoms were irreversibly "trapped" inside the $\mathrm{MnO}_{2}$ during previous charge cycles (e.g., by water molecules). This issue is explored further below.

A current density across the IC, $\mathrm{J}_{\mathrm{s}}$, is assumed to be constant [10 to 22] and is considered to be independent of the position of the $\mathrm{MnO}_{2}$ in the intercalation cathode:

The concentration profile of the $\mathrm{Li}^{+}$outside of the $\mathrm{MnO}_{2}$ is calculated by solving the transport equation across the IC at the end of the $1 / 2$ cycle $=1$ hour (end of the charge cycle, as used in our experimental work). Results obtained by solving for the concentration of lithium ions indicate that, under certain conditions, $\left[\mathrm{Li}^{+}\right]$is "quasi constant" across the IC thickness. The problem may be formulated as follows: $C=\left[\mathrm{Li}^{+}\right]$, and

$$
\varepsilon \frac{\partial C}{\partial t}=\varepsilon D_{e f f} \frac{\partial^{2} C}{\partial x^{2}}-a J_{n}\left(1-t_{t}\right)
$$

where $\mathrm{J}_{\mathrm{n}}$ represents the flux of lithium ions and $\varepsilon$ the specific interfacial area in units $\mathrm{of} \mathrm{cm}^{2} / \mathrm{cm}^{3}$

$$
D_{\text {eff }}=D \varepsilon^{1 / 2}
$$

with initial and boundary conditions being stated as

$$
\begin{aligned}
& \mathrm{C}=\mathrm{C}_{0} \text { at } \mathrm{t}=0 \\
& i=\frac{F \varepsilon^{3 / 2} D \partial C}{\left(1-t_{t}\right) \partial x} \text { at } x=0 \\
& \frac{\partial C}{\partial x}=0 \quad \text { at } \quad x=L
\end{aligned}
$$

By changing the variables to re-write the above equations in dimensionless form we have

$$
\begin{aligned}
& X=\frac{x}{a} \\
& \tau=\frac{\varepsilon^{1 / 2} D t}{L^{2}}
\end{aligned}
$$




$$
\begin{gathered}
Q=\frac{a J_{n}\left(1-t_{t}\right) L^{2}}{D \varepsilon^{3 / 2} C_{o}} \\
J=\frac{i\left(1-t_{t}\right) L}{F \varepsilon^{3 / 2} D C_{o}}
\end{gathered}
$$

and hence

$$
\frac{\partial C}{\partial \tau}=\frac{\partial^{2} C}{\partial X^{2}}-Q
$$

with the boundary conditions being given by

$$
\begin{aligned}
& C=1 \quad \text { at } \tau=o \\
& -\frac{\partial C}{\partial X}=J \quad \text { at } \quad X=0 \\
& \frac{\partial C}{\partial X}=0 \quad \text { at } \quad X=1 \quad \text { (uniform current distribution) } \\
& J_{n} a F L=i \quad \text { (charge conservation) } \\
& \Rightarrow Q=J .
\end{aligned}
$$

The partial differential equation can be solved as a series

$$
C=1+J\left\{\frac{3(1-X)^{2}-1}{6}-\frac{2}{\pi} \sum_{n=1}^{\infty} \frac{e^{-\pi^{2} n^{2} \tau}}{n^{2}} \cos (n \pi X)\right\}
$$

which for steady state can be written as

$$
C_{s s}=1+J \frac{3(1-x)^{2}-1}{6}
$$

Exploring the solution we obtain

$$
C_{\min }=\left.C\right|_{x=1}=1-J\left\{\frac{1}{6}+\frac{2}{\pi^{2}} \sum_{n=1}^{\infty} \frac{(-1)^{n}}{n^{i}} e^{-\pi^{2} n^{2} \tau}\right\}
$$

Limiting forms exist if 


$$
C_{s s}, \min \leq 0 \Rightarrow \mathrm{J} \geq 6
$$

(i): Short times yield

$$
C_{\min }=1-J t \quad \text { with } \tau \leq 0.007
$$

(ii) Long times give

$$
C_{\min }=1-J\left\{\frac{1}{6}-\frac{2}{\pi^{2}} e^{-\pi^{2} \tau}\right\} \quad ; \quad \tau \geq 0.07
$$

Accordingly, for

$$
J \leq 6 \text { no limitations }
$$

$$
\begin{aligned}
& 6 \leq J \leq \frac{1}{0.07} \approx 14.28 \quad ; \quad \tau=\frac{J}{6}-1 \\
& J \geq \frac{1}{0.07} \quad ; \quad \tau=-\frac{1}{\pi^{2}} \ln \left(\frac{\pi^{2}}{12}-\frac{\pi^{2}}{2 J}\right)
\end{aligned}
$$

Figures 5.1 to 5.3 show the calculated concentration of $\mathrm{Li}$ ions across the normalized IC for dimensionless thickness between 0 and 1 . Notice that for a $1 / 2$ cycle of $1 \mathrm{hr}$. we get $\tau=0.05$ and that for the calculated $\tau=0.01$ the concentration of $\mathrm{Li}$ ions is quasi constant across the IC thickness.

Once we establish that, for long cycles ( $2 \mathrm{hrs}$. and $4 \mathrm{hrs}$.), the lithium ion concentration across the IC thickness is approximately constant, we proceed to model the diffusion of the $\mathrm{Li}^{+}$ inside of the $\mathrm{MnO}_{2}$ particles, in order to estimate the radius, $\mathrm{r}_{\mathrm{b}}$, of a $\mathrm{MnO}_{2}$ particle for which the maximum concentration $\mathrm{C}_{\text {critical }}=\mathrm{C}$, i.e. the $\mathrm{Li}^{+}$concentration that the particle of $\mathrm{MnO}_{2}$ can accommodate in the absence of trapping. The mathematical problem is stated as follows:

$$
\begin{aligned}
& C_{s}=[L i] \text { inside of } \mathrm{MnO}_{2} \\
& \frac{\partial C_{s}}{\partial t}=D_{s}\left[\frac{\partial^{2} C_{s}}{\partial r^{2}}+\frac{2}{r} \frac{\partial C_{s}}{\partial r}\right] \\
& C_{s}=0 \quad \text { at } \quad t=0 \\
& \frac{\partial C_{s}}{\partial r}=0 \quad \text { at } \quad r=0
\end{aligned}
$$




$$
\begin{aligned}
& -D \frac{\partial C_{s}}{\partial r}=J_{s} \quad r=r_{b} \\
& J_{s}=\frac{i}{a F L}
\end{aligned}
$$

The equation is transformed into dimensionless form using the following variables:

$$
\begin{aligned}
& R=\frac{r}{r_{b}} \\
& \tau_{s}=\frac{D_{s} t}{r_{b}^{2}} \\
& C_{s}=\frac{C_{s}}{J_{s}} \frac{D_{s}}{r_{b}}
\end{aligned}
$$

The equation can be then written as follows:

$$
\begin{array}{ll}
\frac{\partial C_{s}}{\partial \tau_{s}}=\frac{\partial^{2} C_{s}}{\partial R^{2}}+\frac{\tau_{s}}{R} \frac{\partial C_{s}}{\partial R} \\
C_{s}=0 \quad \text { at } \quad \tau_{s}=0 \\
\frac{\partial C_{s}}{\partial R}=0 \quad \text { at } & \mathrm{R}=0
\end{array}
$$

and

$$
-\frac{\partial C_{s}}{\partial R}=1 \quad \text { at } \quad R=1
$$

with the solution being given as

$$
C_{s}=3 \tau_{s}+\frac{5 R^{2}-3}{10}-2 \sum_{n=1}^{\infty} \frac{\sin \left(R \alpha_{n}\right)}{\partial_{n}^{2} \sin \left(\alpha_{n}\right)} e^{-\alpha_{n}^{2} \tau_{s}}
$$

where $\alpha_{n}$ is the positive roots of equation $\tan \left(\alpha_{n}\right) \sim \alpha_{n}$

$$
\text { At } \mathrm{R}=1 \text { a maximum in } \mathrm{C}_{\mathrm{s}} \text { is obtained as }
$$

$$
C_{s, \max }=C_{s_{R=1}}=3 \tau+0.2-2 \sum_{n=1}^{\infty} \frac{e^{-\alpha_{n}^{2} \tau_{s}}}{\alpha_{n}^{2}}
$$


For small values of time

$$
C_{s, \max }=2 \sqrt{\frac{\tau}{\pi}} \quad ; \quad \tau_{s}=C_{s, \text { critical }}^{2} \frac{\pi}{4}
$$

and for long time

$$
C_{s, \max }=3 \tau_{s}+0.2 ; \quad \tau_{s}=\frac{C_{s, \text { critical }}-0.2}{3}
$$

The critical value at the outside surface of the $\mathrm{MnO}_{2}$ particle $\left(R=1=\frac{r=r_{b}}{r_{b}}\right)$ for time $\tau=0.05$, is $\mathrm{C}_{\text {critical }}=\mathrm{C}_{\mathrm{cr} 1}=\mathbf{0 . 3 5}$. The critical value calculated corresponds to the maximum $\mathrm{Li}$ ion concentration at $\mathrm{R}=1$ that the $\mathrm{MnO}_{2}$ particle can accommodate. Figure 5.4 shows the dimensionless time versus the critical concentration (normalized and dimensionless).

Depending on the type of $\mathrm{MnO}_{2}$ particle, there will be a $\mathrm{C}_{\text {crit }}$ or critical concentration of $\mathrm{Li}$ ions that can be intercalated into the active material within the IC. This mechanism explains, to a certain extent, why the capacity of an IC depends upon the form of the active material.

If this were the only mechanism operating, the IC, would never deteriorate with increasing cycle number. To account for the deterioration of the cathode capacity upon cycling, we assume that inside the $\mathrm{MnO}_{2}$ particles there exists "traps" which will react with the lithium ions in an irreversible manner, consuming or trapping the lithium and losing the amount of lithium available.

To account for this observable phenomenon of loss of capacity with cycle, we propose describing the trapping as follows.

$$
\frac{\partial C}{\partial t}=D\left[\frac{\partial^{2} C}{\partial r^{2}}+\frac{2}{r} \frac{\partial C}{\partial r}\right]-\sum_{K=1}^{K} \frac{\partial C_{r, k}}{\partial t}-\sum_{l=1}^{L} \frac{\partial C_{i, l}}{\partial t}
$$

where

$$
\frac{\partial C_{r, k}}{\partial t}=N_{r, k}\left\{k_{r, k} C\left(1-\Theta_{r, k}\right)-P_{k} \Theta_{r k}\right\}
$$


$\Theta_{r, k}=\frac{C_{r k}}{N_{r, k}}$

and

$\frac{\partial C_{i, e}}{\partial t}=N_{i, \ell} k_{i, e} C\left(1-\Theta_{i, e}\right)$

with

$$
\Theta_{i, l}=\frac{C_{i, l}}{N_{i, l}}
$$

where $\mathrm{K}$ is the dimensionless rate constant for the reaction between $\mathrm{Li}^{+}$and the traps. In the present model, we have assumed only a single trapping reaction.

By assuming a single, irreversible reaction, and spherical geometry, the diffusion equation becomes

$$
\frac{\partial C}{\partial t}=D\left[\frac{\partial^{2} C}{\partial r^{2}}+\frac{2}{r} \frac{\partial C}{\partial r}\right]-\frac{\partial C_{t}}{\partial t}
$$

where

$$
\begin{aligned}
& \frac{\partial C_{t}}{\partial t}=N_{r} K C(1-\Theta) \\
& \Theta=\frac{C_{t}}{N_{r}}
\end{aligned}
$$

$\mathrm{C}_{\mathrm{t}}$ and $\mathrm{C}$ are in units of number $/ \mathrm{cm}^{3}$

$$
\begin{array}{lc}
\left.J_{s}=-D \frac{\partial C}{\partial r}\right]_{r=r_{b}}=J_{n} \cdot N_{a}=\frac{i N_{a}}{a F L} \\
\frac{\partial C}{\partial r}=J_{r} \quad \text { at } \quad r=r_{b} \\
\frac{\partial C}{\partial r}=0 \quad \text { at } \quad r=0
\end{array}
$$

by changing variables to make the equation and variables dimensionless we have 


$$
\begin{aligned}
& R=\frac{r}{r_{b}} \quad \text { Dimensionless distance inside the } \mathrm{MnO}_{2} \text { particle } \\
& \tau=\frac{t D}{r_{b}^{2}} \quad \text { Dimensionless time } \\
& \hat{C}=\frac{C D}{J_{s} r_{b}} \quad \text { Dimensionless lithium concentration } \\
& \hat{C}_{t}=\frac{c_{t} D}{l_{s} r_{b}} \quad \text { Dimensionless concentration of trap } \\
& K=\frac{k J_{s} r_{b}^{3}}{D^{2}} \quad \text { Dimensionless rate constant between Li ions and traps } \\
& N=\frac{N_{r} D}{J_{s} r_{b}} \quad \text { Dimensionless number of traps } \\
& \frac{\partial \hat{C}}{\partial \tau}=\frac{\partial^{2} \hat{C}}{\partial R^{2}}+\frac{2}{R} \frac{\partial \hat{C}}{\partial R}-\frac{\partial \hat{C}_{t}}{\partial \tau} \\
& \frac{\partial \hat{C}_{t}}{\partial \tau}=N K \hat{C}(1-\Theta) \\
& \frac{\partial \hat{C}}{\partial R}=1 \quad \text { at } \quad R=1 \\
& \frac{\partial \hat{C}}{\partial R}=0 \quad \text { at } \quad R=0
\end{aligned}
$$

where $C_{t}$ is the concentration of traps.

Figures 5.5 to 5.7 show the dimensionless (normalized to the critical concentration corresponding to the normalized time chosen) lithium concentration inside the $\mathrm{MnO}_{2}$ particles and available for future cycles, as a function of the cycle number for several concentrations of traps and for a dimensionless rate constant --between the lithium ions and the trap-- as indicated.

Figure 5.5 shows the results obtained when a dimensionless rate constant of 1:corresponding to a high rate constant value -is used, where $\mathrm{N}$ is the dimensionless number of 
traps per $\mathrm{MnO}_{2}$ particle. The critical (outer surface) lithium concentration was normalized to 0.317, which corresponds to a dimensionless time for one cycle of 2 hrs (see Figure 5.4). The critical concentration of ions outside the active material decreases if the traps are occupied inside the $\mathrm{MnO}_{2}$. Also the figure shows that the concentration of available ions for future cycles decreases with number of cycles.

Figure 5.6 show similar results obtained when the dimensionless rate constant between the lithium ion and the traps is set to 0.1 instead of 1 . The effect of the traps is less dramatic.

Figure 5.7 shows the available lithium concentration changes with cycles. The data is normalized to a critical concentration of 0.09 (see Figure 5.4) corresponding to a dimensionless time of 0.005 . To choose a smaller time will reflect to choose a shorter cycle period, equivalent to $2 / 10 \mathrm{hrs}$. When the cycle period is shorter the IC takes a longer time to deteriorate (compare figures 5.5 and 5.7). However, is worth to remember that the critical concentration is much smaller, 0.09 compared to 0.317 , which will translate in a lower capacity of the cathode.

The model described in this section is obviously crude and incomplete. The most glaring deficiency is not take into account the structure and inhomogeneity of the composite structure and in not addressing the impedance characteristics. Future work should focus on eliminating the homogeneous medium assumption, and on extending the treatment to the frequency domain, but this can be done only at the expense of an enormous increase in complexity.

\section{References Chapter 5}

1. Gao, L. and Macdonald, D.D. "Characterization of Irreversible Processes at the Li/Poly[bis(2,3-di-(2-methoxyethoxy) propoxy) phosphazene] Interface on Charge Cycling," Journal of the Electrochemical Society, Vol 144, N0. 4, p1174$1179,1997$.

2. Gray, Fiona. Solid Polymer Electrolytes: Fundamentals and Technological Applications. VCH Publishers, Inc., 1991, p.13.

3. Scrosati, B. et.al. "The Lithium Polymer Electrolyte Battery: V. The Roles of the Composition and Morphology of the Positive Electrode," Journal of Power Sources, 32, 1990, p. 389-396. 
4. Linden, David, ed. Handbook of Batteries and Fuel Cells. McGraw-Hill, Inc., 1984.

5. Aurbach, D. et.al. "Electrochemical and Spectroscopic Studies of Carbon Electrodes in Lithium Battery Electrolyte Systems," Journal of Power Sources, 43-44, 47-64, 1993.

6. Sherman, R.D. et.al. "Electron Transport Processes in Conductor-Filled Polymers," Polymer Science and Engineering, 23, 1, January, 1983, pp. 36-46.

7. Tang, Hao, et.al. "Studies on the Electrical Conductivity of Carbon Black Filled Polymers," Journal of Applied Polymer Science, 59, 1996, pp. 383-387.

8. Narkis, M. and Yacubowicz, J. "Dielectric Behavior of Carbon Black Filled Polymer Composites," Polymer Science and Engineering, 26, 22, December, 1996, pp. 1568-1573.

9. Meissner, Bohumil et.al. "Percolation Concept: Polymer-filler Gel formation, Electrical Conductivity and Dynamic Electrical Properties of Carbon-Black-Filled Rubbers," Polymer Joumal, 28, 2, p. 121-126, 1996.

10. I, J.S. Lundsgaard and R. Koksbang, C.A.C. Sequeira (editor), Chemistry and Energy - Elsevier, p. 153, 1991.

11. D. Fauteux, J. Electrochem. Soc., 135, p. 2232, 1988.

12. D. Fauteux, Solid State Ionics, 17, p. 133-138, 1985.

13. S. Morzilli, F. Bonino, and B. Scrosati, Electrochimica Acta, 32, 961-964, 1987.

14. T. Momma, S. Kakuda, H. Yarimizu and T. Osaka, J. Electrochem. Soc., 142, No 6, p. 1766-1769, 1995.

15. D. Fauteux, Solid State Ionics, 17, p. 133-138, 1985.

16. S. Sloop and M. Lerner, J. electrochem. Soc., 143, p. 1292-1297, 1996.

17. V. Manev, A. Momchilov, A. Nassalevska and A. Kozawa. Rechargeable lithium battery with spinel-related $\lambda-\mathrm{MnO}_{2}$ I. Synthesis of $\lambda-\mathrm{MnO}_{2}$ for battery applications. Journal of Power Sources. 43-44. 1993. 551-559. 
18. J. Newman and T. W. Chapman. Restricted diffusion in binary solutions. AlChE Journal. 19, 2. 1973. 343-348.

19. M. Doyle and J. Newman. The use of mathematical modeling in the design of lithium/polymer battery systems. Electrochimica Acta. 40, 13. 1995. 2191-2196.

20. J. Newman. Optimization of porosity and thickness of a battery electrode by means of a reaction-zone model. Journal of the Electrochemical Society. 142, 1. 1995. 97-101.

21. M. Doyle, T. Fuller and J. Newman. Modeling of galvanostatic charge and discharge of the lithium/polymer/insertion cell. Joumal of the Electrochemical Society. 140, 6. 1993. 1526-1533.

22. C. R. Pals and J. Newman. Thermal modeling of the lithium/polymer battery. I. Discharge behavior of a single cell. Journal of the Electrochemical Society. 142, 10. 1995. 3274-3287.

23. S. Whitaker. Radiant energy transport in porous media. Ind. Eng. Chem. Fundam. 19. 1980. 210-218.

24. W. Liu, K. Kowal and G. C. Farrington. Electrochemical characteristics of spinel phase $\mathrm{LiMn}_{2} \mathrm{O}_{4}$-based cathode materials prepared by the pechini process. Journal of the Electrochemical Society. 143, 11. 1996. 3590-3596.

25. S. Bach, J. P. Pereira-Ramos and N. Baffier. Rechargeable 3 V Li cells using hydrated lamellar manganese oxide. Journal of the Electrochemical Society. 143, 11. 1996. 3429-3434.

26. M. M. Thackeray, A de Kock, M. H. Rossouw and D. Liles. Spinel electrodes from the Li-Mn-O system for rechargeable lithium battery applications. Journal of the Electrochemical Society. 139, 2. 1992. 363-366.

27. V. Manev, A. Momchilov, A. Nassalevska and A. Sato. Rechargeable lithium battery with spinel-related $\lambda-\mathrm{MnO}_{2}$ III. Scaling-up problems associated with $\mathrm{LiMn}_{2} \mathrm{O}_{4}$ synthesis. Journal of Power Sources. 54. 1995. 323-328.

28. W. L. Bowden, N. Iltchev, E. Wang and F. Goebel. Electrical performance of spirally wound ion $\mathrm{LiMn}_{2} \mathrm{O}_{4}$ spinel cells. IEEE. 1998. 223-224. 
29. G. Pistoia, A. Antonini and D. Zane. Synthesis of $\mathrm{LiMnO}_{2}$ and its characterization as a cathode for rechargeable Li cells. Solid State Ionics. 78. 1995. 115-122.

30. B. Ammundsen, D. J. Jones, J. Roziere and G. Burns. Effect of chemical extraction of lithium on the local structure of spinel lithium manganese oxides determined by x-ray absorption spectroscopy. Chem. Mater. 8, 12. 1996. 27992808.

31. T. Tsumura, A. Shimizu and M. Inagaki. Lithium extraction/insertion from $\mathrm{LiMn}_{2} \mathrm{O}_{4}$-effect of crystallinity. Solid State Ionics. 90. 1996. 197-200.

32. Momchilov, V. Manev, A. Nassalevska and A. Kozawa. Rechargeable lithium battery with spinel-related $\mathrm{MnO}_{2}$ II. Optimization of the $\mathrm{LiMn}_{2} \mathrm{O}_{4}$ synthesis conditions. Journal of Power Sources. 41. 1993. 305-314.

33. T. Tsumura, A. Shimizu and M. Inagaki. Synthesis of $\mathrm{LiMn}_{2} \mathrm{O}_{4}$ spinel via tartrates. J. Mater. Chem. 3, 9. 1993. 995-996.

34. G. Pistoia. Some restatements of the nature and behavior of $\mathrm{MnO}_{2}$ for $\mathrm{Li}$ batteries. Joumal of the Electrochemical Society. 129, 9. 1982. 1861-1865.

35. N. A. Godshall. Dissertation. Electrochemical and thermodynamic investigation of ternary lithium-transition metal-oxygen cathode materials. Submitted to the Department of Materials Science and Engineering and the Committee on Graduate Studies of Stanford Univerity, 1980.

36. Thesis Lei Gao. The Pennsylvania State University College of Earth and Mireal Sciences (1998). 


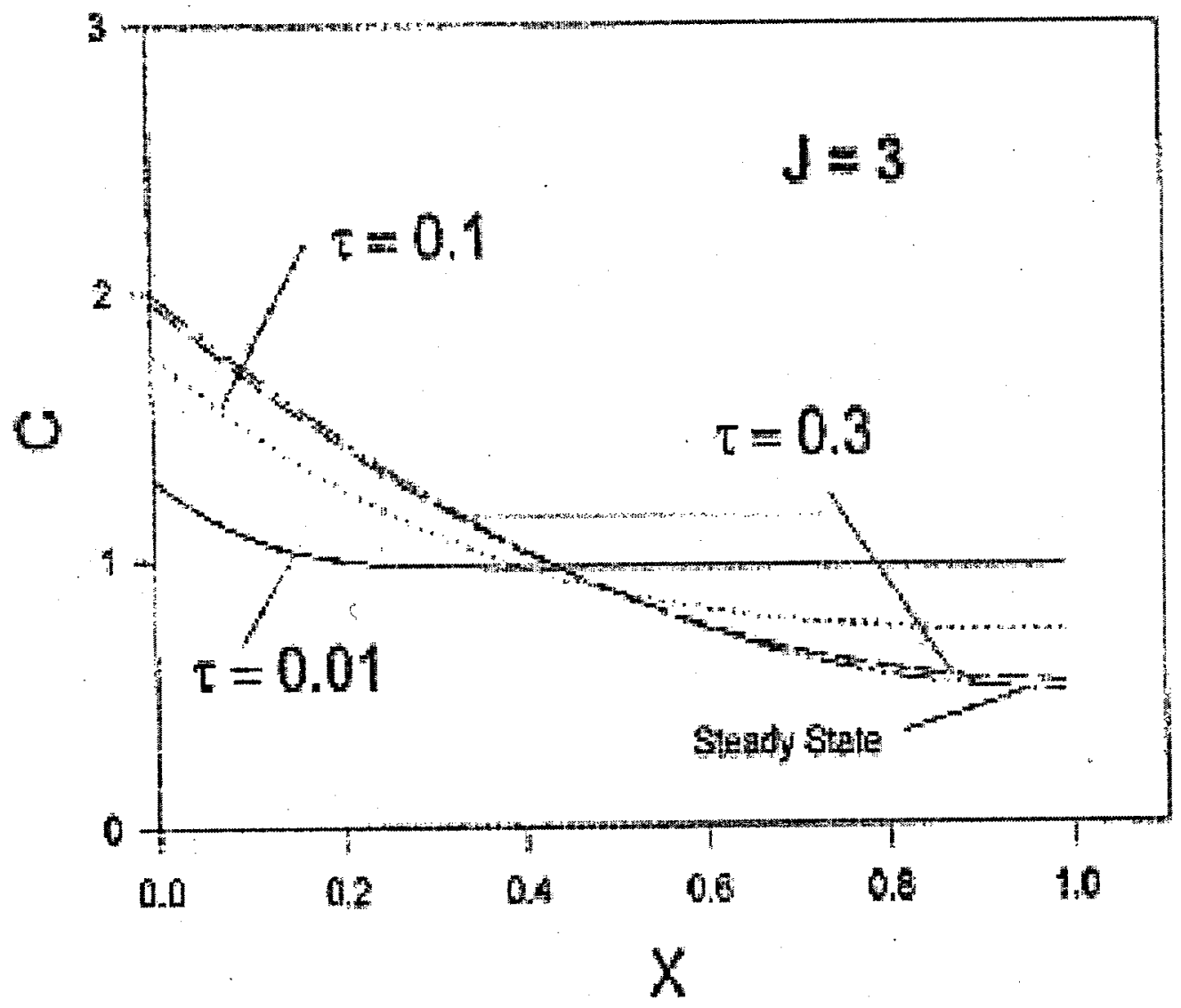

Figure 5.1. Dimensionless $\mathrm{Li}^{+}$concentration inside the intercalation cathode as a function of dimensionless position ( $X=0$ corresponds to the IC/SPE interface and $X=1$ to the IC/current collector interface). $\mathrm{J}=3$ corresponds to a low current density and $\tau=0.05$ corresponds to a charge cycle of 1.0 hours. 


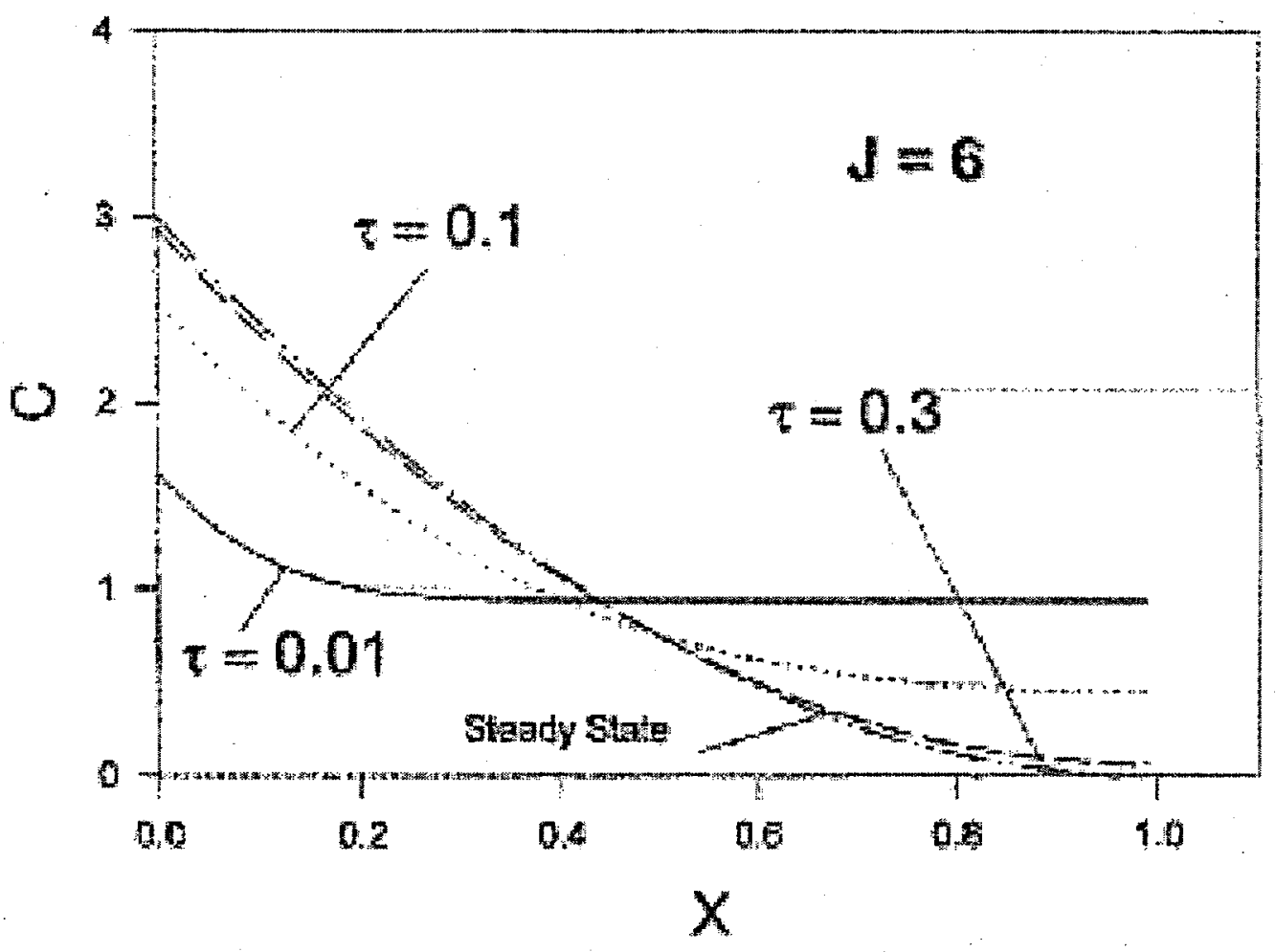

Figure 5.2. Dimensionless $\mathrm{Li}^{+}$concentration inside the intercalation cathode as a function of dimensionless position ( $X=0$ corresponds to the IC/SPE interface and $X=1$ to the IC/current collector interface). $J=6$ corresponds to a medium high current density $(<6$ $\mathrm{mA} / \mathrm{cm}^{2}$ ) and $\tau=0.05$ corresponds to a charge cycle of 1.0 hours 


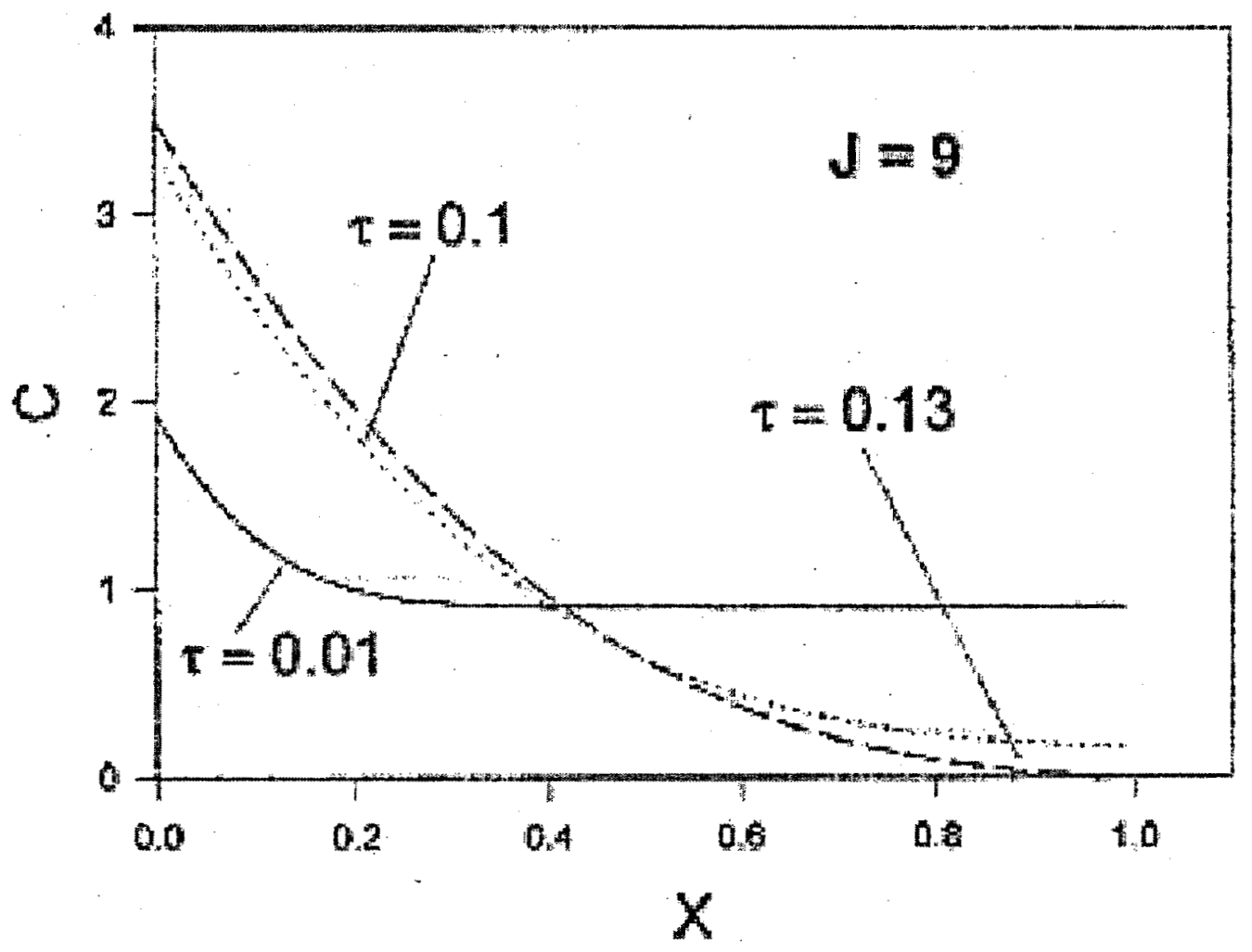

Figure 5.3. Dimensionless $\mathrm{Li}^{+}$concentration inside the intercalation cathode as a function of dimensionless position ( $X=0$ corresponds to the IC/SPE interface and $X=1$ to the IC/current collector interface). $J=9$ corresponds to a a very high current density $\left(>10 \mathrm{~mA} / \mathrm{cm}^{2}\right)$ and $\tau=0.05$ corresponds to a charge cycle of 1.0 hours 


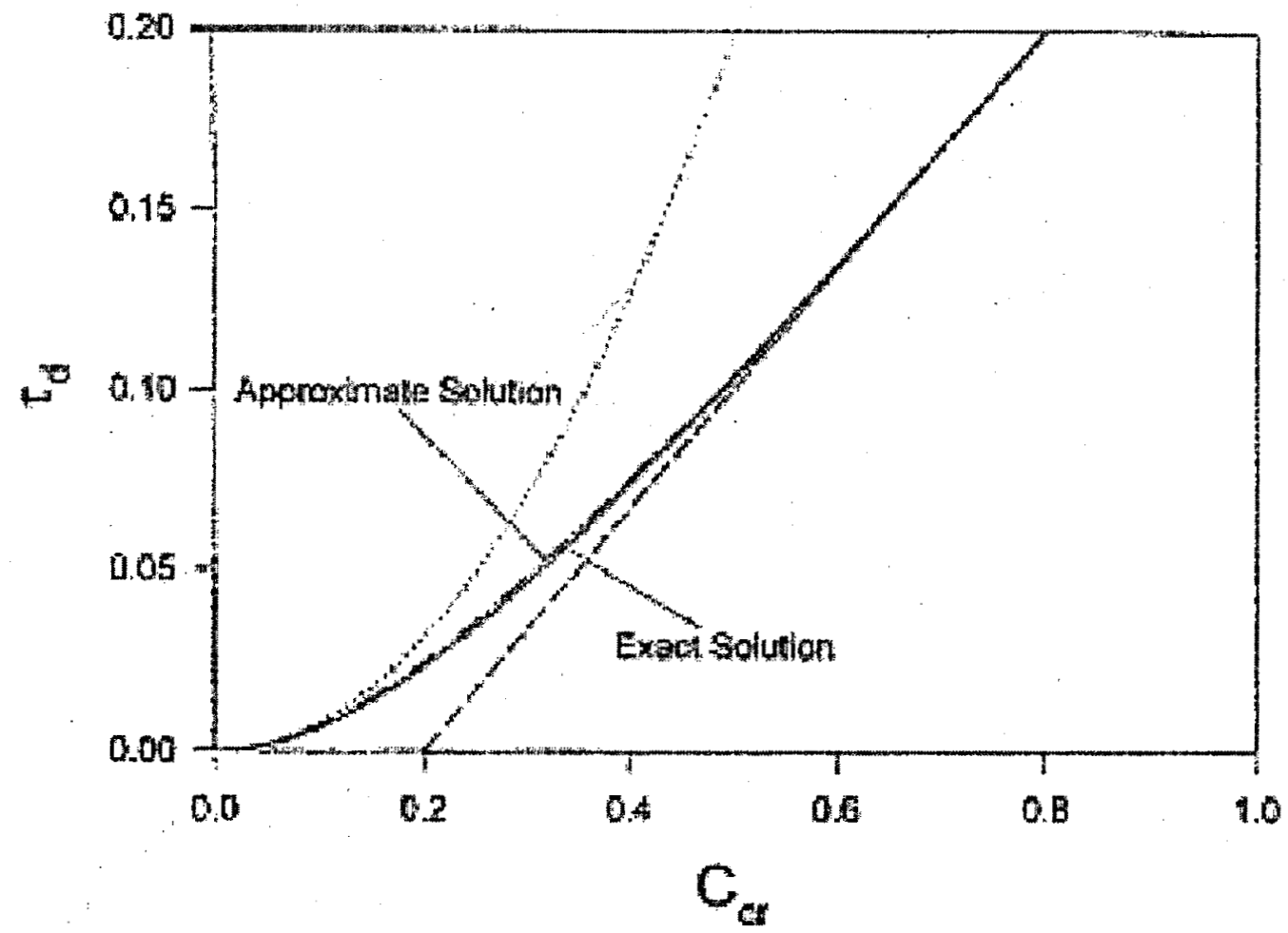

Figure 5.4. Dimensionless time versus critical concentration of lithium ion $\left(C_{c r}\right)$ outside the $\mathrm{MnO}_{2}$ active material. Notice that for a $\tau=0.05$ correspond a $\mathrm{C}_{\mathrm{cr}}=0.317$, and for a $\tau=0.005$ correspond a $\mathrm{C}_{\mathrm{cr}}=0.09$. 
Figure 5.5: Dimensionless normalized concentration of lithium ion inside the active material (1- or $\mathrm{g}-\mathrm{MnO}_{2}$ ) versus cycle number. Parameters: dimesionless critical concentration of lithium ion at the active material surface of 0.317 , dimesionless cycle time of 0.05 (corresponding to half cycle of $1 \mathrm{hr}$ ), and dimesionless rate constant of 1 . The critical lithium ion concentration outside the active material decreases with the number of traps.

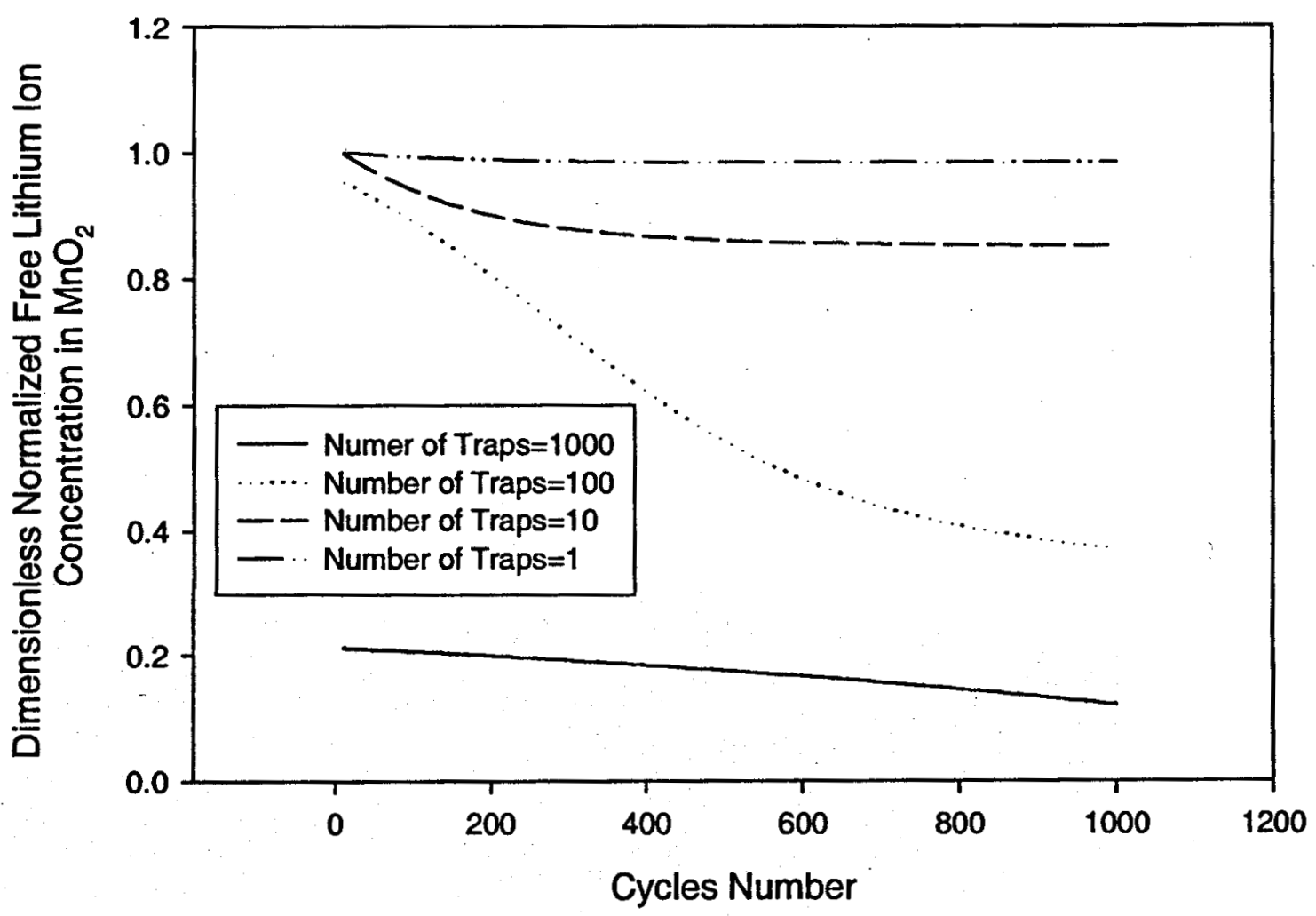


Figure 5.6: Dimensionless normalized concentration of lithium ion inside the active material ( 1 - or $\mathrm{g}-\mathrm{MnO}_{2}$ ) versus number of cycles. Parameters: dimesionless critical concentration of lithium ion at the surface of the active material of 0.317 , dimesionless cycle time of 0.05 (corresponding to half a cycle of $1 \mathrm{hr}$ ), and dimesionless rate constant of 0.1 . The critical lithium ion outside the active material decreases with the number of traps.

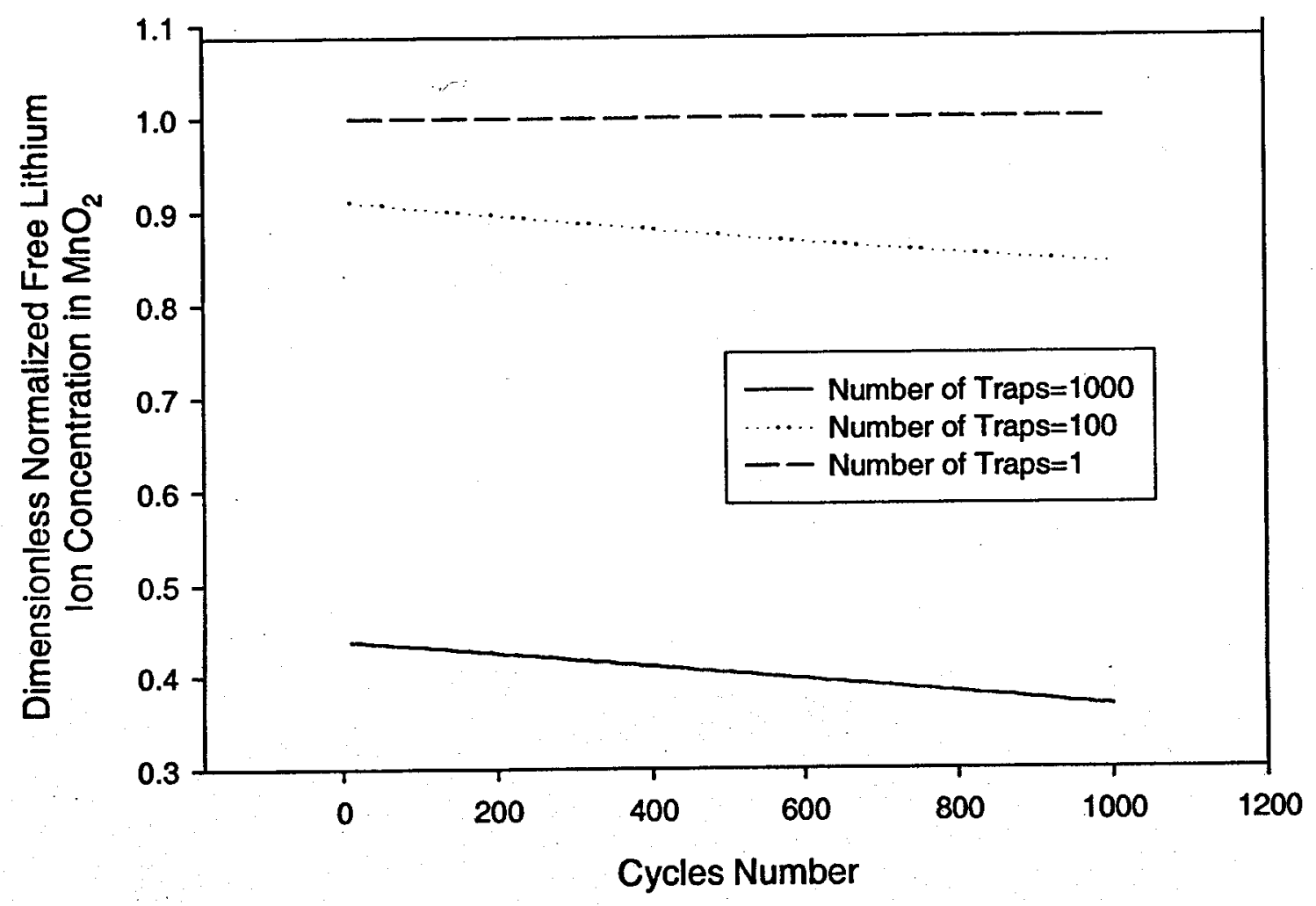


Figure 5.7: Dimensionless normalized concentration of lithium ion inside the active material ( 1 - or $\mathrm{g}-\mathrm{MnO}_{2}$ ) versus number of cycles. Parameters:

dimesionless critical concentration of lithium ion at the surface of the active material of 0.09 (see Figure 5.4), dimesionless cycle time of 0.005 , and a dimensionless rate constant of 1 . The critical lithium ion concentration outside the active material decreases with the number of traps.

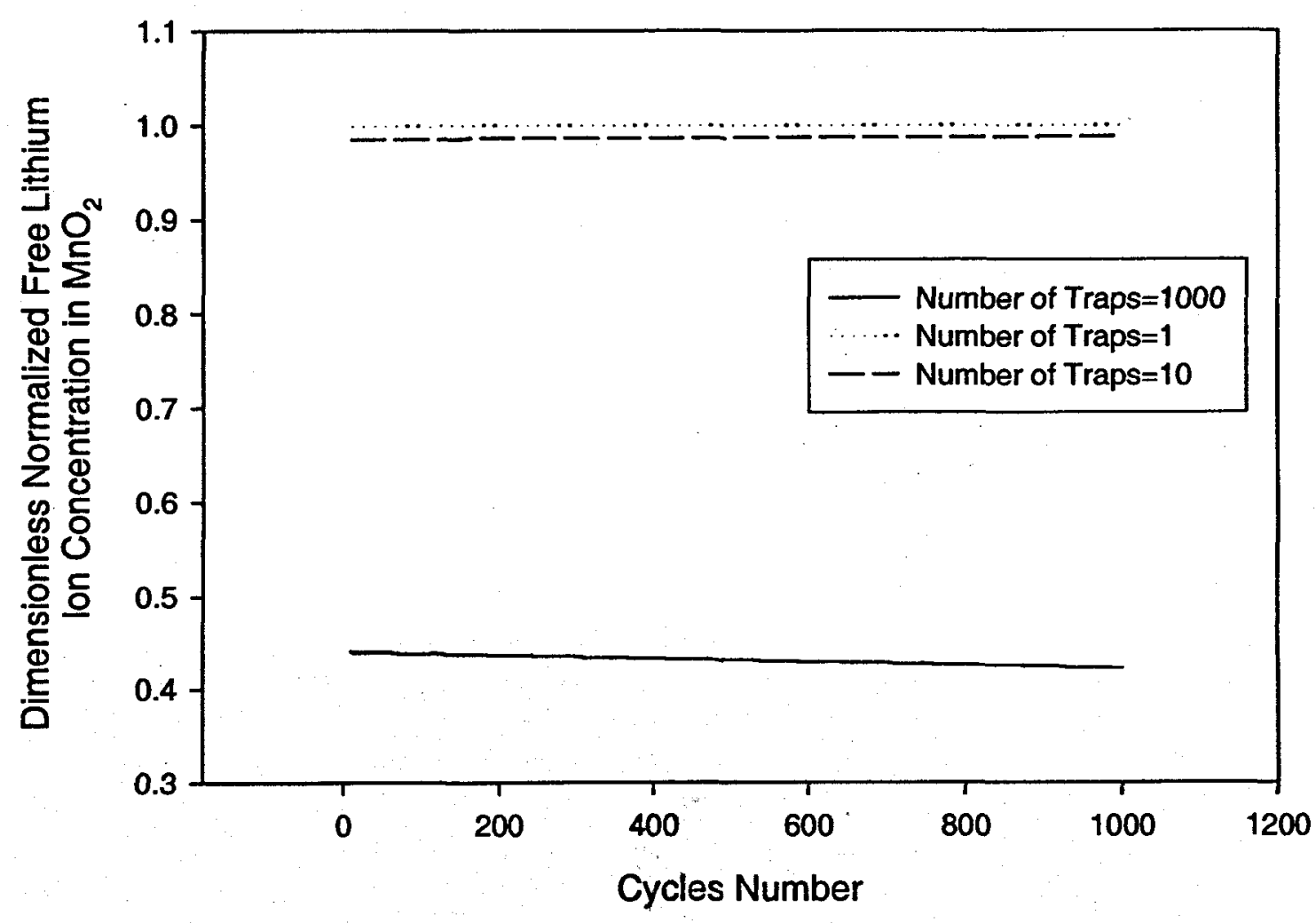




\section{Chapter 6. Artificial Neural Network Model-Predicting Failure of Secondary Batteries}

The ability to predict the failure of secondary batteries is important. However, when determinism is not used to make the predictions because the complexity of the problem, difficult questions arise. Data analysts must always determine how much information is available in a given data base and how much information can be squeezed from the data base. A philosophical question is frequently posed: How long into the future can we predict based on past information? For the prediction of battery cycling life this question can be formulated as: How long must a battery (or cell) be tested to predict when it will fail?

The answer to this type of question depends on how many variables define the problem, how much we know of the problem, how effective we are at squeezing information from the data base, and how much knowledge and reliable data we have available to build a predictive model. The quality of the model will be measured by its ability to predict the future behavior of the system.

The prediction of cycling life of batteries has been until now an impossible task. We are convinced that this is in part because the problem is very difficult, and in part, because the information available in data bases has not been manipulated enough to produce a reliable predictive model.

Models based on similar techniques are expected to have similar predictive capabilities. The methodology used in this project is now being used on an extensive data base (thousand of hours) for NiCd batteries (NASA Goddard Space Flight Center data), and on a complete data base (many variables are being controlled and measured) for $\mathrm{Li}$ /polymer batteries generated at the Battery Laboratory at Penn State.

It is our intention in this chapter to present and discuss a methodology aimed at squeezing information from a data base. The model learned from a small database containing two hours of cycling life of Lithium-ion secondary batteries. The model used short-term information (60 and 10 minutes) to predict longer term information ( 2 hours) for which measured data exist; that actual data was used to assess the predictive performance of the model. The model was then used to explore the system's longer term response (10 hours) for which measured data was not 
available. Extrapolation of knowledge (expectations based on experience) was used to assess the system performance.

Two types of current/time patterns were imposed on a battery (10 cells) and voltage/time response patterns were measured. The patterns were imposed at three different temperatures. This research effort identified those variables collected during life testing of the battery system that contributed the most to predicting the performance of the battery in the future. The prediction model used a pattern recognition artificial neural network (ANN). Data was presented to the net as inputs (current pattern) and outputs (voltage pattern) during the net training. The way the data is represented is very important and defines the net's learning speed. In general, we can state that to squeeze information from data, it is very important to represent the data in various ways. For example, we learn music by reading it but also by expressing it throughout a musical instrument (transformation). Data transformation and data representation are key issues in the learning process and in squeezing information from data. In this paper we discuss the advantages and disadvantages of three different data representations.

Some of the secondary batteries on the market (e.g., Lithium-based) are promising because they offer a high power density, and great mechanical flexibility. However, not all of the batteries built under the same specifications and with the same methodology will reach the expected long life. Until now, the reasons why these promising Lithium-polymer technologies do not reach that desired long life ( $>1000$ cycles) are not well understood nor do we know why the life of certain batteries belonging to more long life family systems (Li-ion) are shortened while other batteries of the same family last a long time.

It would be of great interest especially for low-weight applications to be able to predict the performance life of a battery by running a short series of tests on it. One such application is space flight. It is important to minimize the weight of the launch vehicle. For these applications, tests are run on many cells (one or several cells may form a battery system), and statistics are used to calculate how many cells will be included in a flight, using information on the number of cells needed to supply the required power, the probability that cells will fail, and a safety factor of extra cells. These extra cells are excess weight for the launch. If a method could be developed to determine whether cells will fail by running a short series of tests on individual batteries, the weight and volume of the battery pack could be reduced. 
The objective of this project is to use artificial neural networks, specifically feed-forward backpropagation (FBP) networks, to explore the possibility of predicting cycling life failure; based only on short-term data. The research work is based on certain predictive capabilities shown by artificial neural networks[1].

The predictive capabilities of FBP nets are presented and discussed. Three data representations of the inputs and outputs used to train the network are discussed: an amplitudetime representation (data representation one), a frequency representation using the Discrete Fourier Transform (data representation two), and a wavelet coefficient representation using wavelets to compress the current and voltage signals (data representation three). In this study we also present an analysis that aims to categorize the variables measured during battery testing in order to determine their relative importance in predicting the cell cycling life.

\section{Neural networks: An overview}

Artificial neural networks are a mathematical tool with excellent capabilities for pattern matching, recognition, and classification. ANNs are inspired by the biological behavior of neurons. The fundamental building blocks of biological neural (nervous) systems are cells called neurons. The neurons are represented by a summation and a transfer function. An artificial neural network may also consist of layers of interconnected neurons. A network is composed of one output layer, one input layer, and one to three hidden layers. Signals travel from the input layer, through the hidden layers, to the output layer. Only two hidden layers are usually needed to learn non-linear signals. Each hidden layer in a network adds one degree of non-linearity.

There are two main types of nets: supervised and no-supervised. Supervised nets learn by examples, and during the training process the weights or connections in between neurons change with time (the transfer functions remain practically constant) so that the net as a whole adapts to reach an answer close to the desired output (presented as a single value, vector, or matrix of information) given an input vector. Once the net learns "a job" the weights remain" constant. During the learning process, the net establishes relationships (highly non-linear) between the inputs and the outputs; once the net is trained, that categorization of the inputs by weight-importance or "contribution to the learning process" can be used to explore the importance of the input variables in reproducing the desired output. 
For this research a supervised type of learning was chosen; the input and output data were run through the net during training. The learning was accelerated with additional information in the form of input series calculated from the input data (functional links). In this work we explored several types of supervised net designs; the results of only one of them are reported.

Feed-forward backpropagation (FBP) networks are composed of multiple layers of processing elements (PEs) that are represented by transfer functions such as sigmoids. The network consists of an input layer, and output layer and any number of hidden layers that give the network the ability to solve non-linear problems. No more than two hidden layers are usually necessary to learn a difficult task. The input layer sends all of the input values through weighted connections to the first hidden layer, where these inputs are summed and the processing elements use the transfer function to produce an output. This output is sent through weighted connections to the next hidden layer, where the PEs similarly produce an output, which is finally sent to the output layer. The network undergoes supervised training, which means that the desired output has to be known for each given input, and the network adjusts its weights to produce an output close to the desired output. The FBP network uses an error gradient descent learning rule to properly adjust its weights. The error between the network output and the desired output is expressed in terms of the network weights, so the gradient of the error with respect to the weights can be found. The weights change by descending this error surface along the gradient.

For this project, a commercially available neural network building package was used to design and create the FBP networks used. The hyperbolic tangent $(\tan H)$ was used as the transfer function. The Extended Delta-Bar-Delta learning rule was used. This adds a momentum term to the error gradient descent learning rule to avoid the net response getting trapped in local minima of the error surface. The networks had two hidden layers: the first had twice as many elements as the input layer, and the second had the same number of elements as the input layer. The number of elements in the input and output layers was determined by the size of the input and output vectors in the data representation being used.

\section{Lithium-ion battery tests}

Battery test data were received from tests run on lithium-ion secondary batteries by SAFT America, Inc. under contract to NASA Goddard Space Flight Center. These tests were conducted to evaluate Lithium-ion secondary batteries as a power source for the pistol grip tool 
(PGT). This is a tool for tightening and loosening fasteners when repairing satellites in orbit, such as the Hubble Space Telescope. The PGT requires a minimum voltage of $28 \mathrm{~V}$ to operate, so a drop below this voltage would be considered a failure. A series of tests were run on a tencell lithium-ion battery using two different current discharge profiles and three different temperatures. The two current discharge profiles were a typical current discharge Profile (Figure 6.1 - Profile 1), and a worst-case discharge profile (Figure 6.2 - Profile 2). The typical current discharge profile has current spikes ranging from 2 to 8 amps in groups of four to simulate the high torque needed to initially loosen a fastener, and longer current discharges at 1 and 1.5 amps to simulate the removal or tightening of a fastener. The worst-case current discharge profile has current spikes ranging from 4 to 10 amps and an extended current discharge plateau at 2.5 amps to simulate the deployment of a solar array. These discharge profiles were applied to the battery in the order profile 1 , then profile 2 , at temperatures of 20,0 , and $40^{\circ} \mathrm{C}$, and the running time, current, output voltage, and internal temperature of the battery were measured. Between each test, the battery was recharged to full power. These tests, including the recharge cycles, were labeled alphabetically. The data received was from test $\mathrm{B}$ (profile $1,20^{\circ} \mathrm{C}$ ), test $\mathrm{D}$ (profile 2,20 ${ }^{\circ} \mathrm{C}$ ), test $\mathrm{H}$ (profile $2,0^{\circ} \mathrm{C}$ ), and test $\mathrm{J}$ (profile $1,40^{\circ} \mathrm{C}$ ).

\section{Data representation one}

The format in which the data is presented to an FBP network is important in determining whether the network learns effectively. In this case, the data contained a record of the current, running time, temperature, and resulting voltage output of the battery at discrete moments in time. Merely presenting a datum point of the current, running time, and temperature of the battery to the network would not be sufficient for the network to learn the relationship between these few inputs and the output voltage. Among variables that impact cell behavior other than the instantaneous current and temperature are the previous currents and the previous "over threshold" current value that the cells experience. Those variables affect the cell performance at any given moment. In order to train the net effectively, information about these variables also had to be presented to the network.

Four sets of data from tests $(\mathrm{A}, \mathrm{D}, \mathrm{H}$, and $\mathrm{J}$ ) performed on secondary lithium-ion batteries were used to train a backpropagation network. For each battery test, the current, time step, running time, amp-hours, temperature, and resulting voltage output for a ten-cell battery stack were recorded. 
Data representation one contains the following inputs: current $(I)$, time step $(\Delta t)$, time from start of the test $(\mathrm{t}), \Delta \mathrm{I},|\Delta \mathrm{I}|$, amp-hours, amp-hours (resets at $0 \mathrm{amp}), \Sigma(\Delta \mathrm{I}), \Sigma|\Delta \mathrm{I}|$, temperature $(T), \log (\mathrm{T})$, a counter of the current peaks in the ranges 4-6 A, 6-8 A, and 8-10 A, and a current history vector recording the time spent in the current ranges 0-to-1, 1-to-4, 4-to-8, and 8-to-10 amps. Functional links of the form $x^{n}$ and $x^{1 / n}$ (where $x$ represents any of the variables described above and $n=2,3,4$ ) were also included. These functional links add information to the network and help it to obtain more efficiently the relationship between inputs and outputs [2].

The composite training file contained 54 inputs and 1 output. Each input vector corresponded to a single current value applied to the battery and a single voltage response measured (1416 data points were measured in a two-hour test). Sections of these files (also called tests $B, D, H$, and $)$ were used to train a backpropagation network with a first hidden layer of 108 processing elements, a second hidden layer of 54 processing elements, and a bias of -1 added to each layer.

\section{Results of data representation one}

A network was trained using with several representations of current and temperature as described above, and voltage was the output. We arbitrarily chosen to train the net using the first 60 minutes of tests $B$ and $D$, and 10 minutes of tests $H$ and J. Tests $B$ and $D$ consist of tests run with discharge profiles 1 and 2 , respectively, both at $20^{\circ} \mathrm{C}$. Tests $\mathrm{H}$ and $\mathrm{J}$ consist of tests run with discharge profiles 2 and 1 , at 0 and $40^{\circ} \mathrm{C}$, respectively. The network had to be trained with both profiles (tests $B$ and $D$ ) so that the network could learn the relationship between the different current discharge profiles and the output voltage; and the temperature dependence from tests $\mathrm{B}, \mathrm{H}$, and $\mathrm{J}$. The net was trained with 60 minutes of patterns $\mathrm{B}$ and $\mathrm{D}$ and 10 minutes of patterns $\mathrm{J}$ and $\mathrm{H}$. Longer patterns time were necessary for the net to learn the dependency in profiles 1 and 2, because the 2.5 A current plateau was imposed on the battery (Figure 6.2) in the first hour.

This trained network was tested using the full test $\mathbf{H}$ (two hours) as shown in Figure 6.3. The results for the network tested on full test $J$ (two hours) are shown in Figure 6.4. The net predictions were compared to the measured voltage response. In both cases, the network output voltage conformed very closely to the actual output voltage. 
The net had to be trained with portions of tests $\mathrm{H}$ and $\mathrm{J}$ in order to learn the temperature (other than $20^{\circ} \mathrm{C}$ ) dependence of the voltage output. We also tried training the net using the whole 120 minutes of only test $\mathrm{B}$ (Profile 1 and $20^{\circ} \mathrm{C}$ ); we then test the net by using the 120 minutes of test $\mathrm{H}$ (profile 2, at $0{ }^{\circ} \mathrm{C}$ ). The results are shown in Figure 6.5. The net that was trained with this representation using only one temperature $\left(20^{\circ} \mathrm{C}\right)$ and one applied current profile (profile 1) did not learn to differentiate well between different input profiles nor different temperatures. When the net was tested with a different profile and temperature, it had problems identifying the proper response. The net did not perform well in describing the response of the cells when a constant 2.5 A current was applied over a longer period of time. The net did not predict the correct response (deep voltage spikes) to the deep current spikes corresponding to the cells' response at low temperature, but instead the net prediction response was more modest (corresponding to what the net learned at $20^{\circ} \mathrm{C}$ ).

To perform well using this representation, the net must be trained using "best" and "worst" profiles and "best" and "worst" environmental conditions. The net has no problem interpolating a given response, but it under estimates the extrapolated cell behavior. The results appear to indicate that under this representation, to extrapolate the cell behavior properly, it is necessary to have some measured information about the expected response of the cell to parameters that impact the cell cycling life (such as temperature and type of input current pattern applied to the cells). If the inputs used to train the net change from an example to the other and do not remain constants, the net will learn the trends and to extrapolate behaviors properly.

A network was also trained with all the data available from all four tests, then tested with extended time input patterns to get an idea of the long-term voltage performance of the cell. The hypothetical current input pattern used for training the net was constructed by placing input of tests $\mathrm{B}, \mathrm{D}, \mathrm{H}$, and $\mathrm{J}$ in series and making a cumulative, continuous input, which represented a simulated 10-hour battery test without recharging. The net was tested in an hypothetical pattern similar to test B (pattern 1, "typical case"- the testing pattern was BBBB), but using a temperature sequence of $20^{\circ} \mathrm{C}$ for 5 hours, followed by 2 hours at $0{ }^{\circ} \mathrm{C}$, and finally followed by 3 hours at $40^{\circ} \mathrm{C}$. The net voltage response was expected to have a lower voltage rate at high temperature than at low temperatures (experimentally observed, but not shown here [3]). The depth of the spikes of the voltage signature were expected to be smaller at high temperatures than at low temperatures. Figure 6.6 shows the input pattern applied to the trained net and the output 
voltage pattern predicted by the net. The net indeed produced lower output voltage spikes at the end of the simulated test corresponding to a temperature of $40^{\circ} \mathrm{C}$ than the section (between 5 to 7 hours) corresponding to $0{ }^{\circ} \mathrm{C}$. The slope of the voltage-time response (or voltage rate) is more negative for low temperatures $\left(0^{\circ} \mathrm{C}\right)$ than for higher temperatures $\left(40^{\circ} \mathrm{C}\right)$, as expected.

One of the disadvantages of data representation one is the time required to pre-process the data before training the net. To avoid this problem, we propose to use as input to the net a compressed representation of the whole signature (two hours). The problem that we may face in this new approach is that few hours of data may use a large number of data points. The following two data representations consider the use of the two hour whole signature as input and the whole voltage signature as output. An identically sized signature must be used to train the net and to test it; the net produces an output voltage response of the same size as the one used during the net training process.

\section{Data representation two}

Data representation two was developed by considering the discrete Fourier transform of the current and voltage patterns. In this representation, the entire signature of the current and voltage patterns of a test were transformed to a series of Fourier coefficients, which contain a smaller number of Fourier coefficients than the number of data points used to represent the signature. The Fourier coefficients of the current and voltage (as inputs and outputs, respectively) are presented to the network during training.

To reduce the training time of the network we sought to use only a few coefficients. Accordingly, the first 16 Fourier coefficients representing the signature (current or voltage) were used, resulting in 32 inputs and 32 outputs (the coefficients have real and imaginary parts). One problem with using only 16 coefficients was that the first 16 coefficients only roughly approximated the shape of the current and voltage patterns. For this reason, the network would not be able to duplicate the detailed measures of current or voltage. Because we may be interested in changing the time length of the input signatures, the time of the test (or time-length of the signature) was used along the temperature as inputs, bringing the total number of inputs to 34. 
The advantage of this representation over the previous one (representation one) is that pre-processing the input data was fast and easy. A disadvantage was that for the current and voltage profiles to be represented exactly, we had to use as many Fourier coefficients as sampled test datum points. For these tests, which were sampled at about 5-second intervals over two to three hours, that would mean 2000-3000 input (and output) elements. Another disadvantage was that in addition to recording the size of the input signature (current), the network should be trained and tested with Fourier coefficients from samples of the same length. This way, a Fourier coefficient input or output element will represent the same frequency for every vector that is presented to the network. If this is not the case, an input neuron (or process element, PE) will receive Fourier coefficients representing different frequencies, and the network may not learn the proper relationship between input and output frequencies.

The equation used to obtain the first 16 Fourier coefficients was

$$
a(k)=\frac{1}{N} \sum_{n=0}^{N-1} u(n) e^{\frac{-j 2 \pi k n}{N}}
$$

where $\mathbf{N}$ is the number of sampled points in the pattern, $u(n)$ is the value of the current or voltage at a sampled point, and $0 \leq \mathrm{k} \leq 15$. The equation used to reconstruct a pattern from the coefficients a(k) was

$$
u(n)=\sum_{k=0}^{15} a(k) e^{\frac{j 2 \pi k n}{N}}
$$

where the reconstructed current or voltage pattern consists of the real part of $u(n)$. A Matlab program was written to find the coefficients, and another MatLab program was written to reconstruct the pattern from the coefficients.

\section{Results of data representation two}

On the analysis that follows, one has to remember that a smaller number of Fourier coefficients will not nearly capture the detailed information on large data bases.

To ensure that the Fourier coefficient inputs represented the same frequency in each input vector, the first two hours (the length of the shortest test) of each test were used to find the Fourier coefficients. Then, a network was trained with tests $B$ (profile $1,20^{\circ} \mathrm{C}$ ). The trained net (Figure 6.7) was tested using the current pattern of test $\mathrm{D}$ (profile $2,20^{\circ} \mathrm{C}$ ). The net voltage 
predictions were the "typical case" current profile and tested on a "never seen" input pattern from the "worst case" current profile test. We believe that because the 16 Fourier coefficient representation was a very poor representation of the real imposed current pattern, the Fourier representation lost a great deal of detail. Although the net predictions were very close to the Fourier representation of the measured voltage, the prediction does not have the level of detail required to determine whether the net "sensed" the impact of the cell when the worst case current pattern was imposed on the battery instead of the typical case.

We also trained the net by using the four available files $(\mathrm{B}, \mathrm{D}, \mathrm{H}$, and $\mathrm{J}$ ) over a period of two hours each. The current and voltage pattern corresponding to each of the files was represented by 16 Fourier coefficients. Once the net was trained, and could reproduce the Fourier representation of the measured voltage pattern signature very closely, we looked for the weight that had the highest values, indicating the greatest contribution to the learning. By averaging the effect of changes in each input (the Fourier coefficients), the most important inputs --the inputs that contributed the most to the learning--were found. Figure 6.8 shows the relative importance for the inputs used to train this network. Inputs 1 through 16 correspond to the real current Fourier coefficients, 17 through 32 to the imaginary Fourier coefficients, 33 to sample time length (in our example, two hours), and 34 to temperature (in our example 0,20 , or $40^{\circ} \mathrm{C}$ ). Temperature is by far the most important input. This result is consist what we anticipated, because the only difference in the inputs between tests $B$ and $J$ and tests $D$ and $H$ is the temperature, so it is the sole cause of the difference in voltage output. Since the tests were conducted in series with recharge cycles between them, the resulting capacity loss due to discharge/recharge cycles would also have an impact on the voltage output. However, this effect is expected to be small over two hours and is difficult to estimate from the data since the tests were conducted at different temperatures, so no information about this capacity loss was included in the input data. The next most important inputs were the later Fourier coefficients, which have highest frequencies. This is also logical because the coefficients with higher frequency produced interesting changes in the current patterns and had the most effect on the voltage output.

The network trained under data representation two was efficient in approximating the general shape of the Fourier voltage representation, however, the fine details were lost when the data is transformed using only 16 Fourier coefficients. 


\section{Data representation three}

Data representation three was developed using the wavelet method of data compression. Wavelets represent an efficient way to compress data without losing too much information. Wavelets were used to compress 1416 data points representing the imposed current patterns and measured voltage patterns. The 1416 data points represented two hours of real time testing on the battery system under different conditions (two applied current signatures, and three temperatures), as indicated in tests $\mathrm{B}, \mathrm{D}, \mathrm{H}$, and $\mathrm{J}$. These 1416 data points were compressed to 106 data points for each test by using a double compression scheme of a sparse representation (1/3) of the total signal. The wavelet used was a discrete biorthogonal exhibiting the property of linear phase, which is needed for signal and image reconstruction [4]. The first compression yielded a high frequency signal and a low frequency signal. The low frequency signal contained more information. Accordingly, the low frequency signal was compressed by forming a sparse vector ( 1 of 3 data points were retained); the resulting signal was compressed again resulting in 106 coefficients that were used to represent the original current or voltage signal from the 4 Tests.

The signal reconstructed by using the wavelet captured most of the main features of the original signature or signal (current/time or voltage/time) and also the same scale by only using 106 data points instead of 1416, as can be seen for test $D$ in Figure 6.9. This is an important step to perform before designing a neural network. The number of neurons in a layer of a neural network depends on the number of inputs and outputs; accordingly, it is more efficient to work with an input vector that does not have many elements (network designs containing more than 200 hundred neurons per layer become time-inefficient to operate on a PC). A compressed representation of the two hour time-length vector reduces considerably the size of the neural network and accordingly the training time.

When compared to a Fourier transform, the same number of coefficients used in a wavelet representation gives superior results. The Fourier representation of the pattern (current or voltage) obtained does not come close to capturing the information that a wavelet representation captures.

\section{Results for data representation three}

A network was trained with time 106 wavelet coefficients obtained by compressing the current and voltage signal or pattern (2-hours time-length) of test B. Then the network was 
tested with the 106 wavelet coefficients of current pattern from tests $D, H$, and J. Since these tests all occurred for different lengths of time, they were all trimmed to their first two hours, so that respective wavelet coefficients for each test would refer to the same sections of the test.

Figures 6.10, 6.11, and 6.12 show the results for the network tested with tests $J, D$, and $H$, respectively. The initial and final data points of the file produced severe oscillations on the wavelet representation because the information was truncated at those two ends; the results of the net for those end points should be ignored.

Ignoring those end points, Figure 6.10 compares the network prediction (gray) of the compressed wavelet representation and the compressed wavelet representation of the measured voltage (black). The training of the net was performed at $20^{\circ} \mathrm{C}$ under a current profile "typical case" and tested on a current profile "typical case" but at $40{ }^{\circ} \mathrm{C}$. The network predictions followed the voltage response of the cells to the input current profile very well. This input current profile was characterized by small spikes when the measures were performed at high temperature. The training contained the wavelet representation of the current and voltage signatures measured at $20^{\circ} \mathrm{C}$ under "typical case" current profile. Therefore the only way to explain the capability of the net to predict the modest response of the cells when the same profile of current was applied but at high temperature (as expected) is that the net learned the correct function that describes the temperature effect on the voltage response.

Figure 6.11 compares the network prediction (gray) of the compressed wavelet representation and the compressed wavelet representation of the measured voltage (black). The training of the net was performed at $20^{\circ} \mathrm{C}$ under a current profile "typical case" and tested on a current profile "worst case" also at $20^{\circ} \mathrm{C}$. The network predictions closely followed the voltage negative slopes (e.g., 0.7 to 0.9 hours, see also Figure 6.2) corresponding to the response of the cells to the 2.5 amp plateau current profile; the net overestimate those plateaus, but it detected and differentiated them from the regular spikes very easily. We noticed the response of the net to the current spikes when the system test was measured at $20^{\circ} \mathrm{C}$ instead of $40{ }^{\circ} \mathrm{C}$; the spikes were more pronounced and closely followed the expected measured voltage response of the cell. The training contained the wavelet representation of the current and voltage signatures measured at $20{ }^{\circ} \mathrm{C}$ under a "typical case" current profile. Therefore, we explained the capability of the net to predict the negative slope-plateau voltage responses occurring at times when the current 
plateaus were imposed (2.5 Amp imposed between 0.7 and 0.9 hours time sample) by assuring that the net learned the correct function describing the voltage response of the cell.

Figure 6.12 compares the network prediction (gray) of the compressed wavelet representation and the compressed wavelet representation of the measured voltage (black) when the net was trained at $20^{\circ} \mathrm{C}$ under a current profile "typical case" and tested on a current profile "worst case" at $0{ }^{\circ} \mathrm{C}$ (lower temperatures causes cells to respond to current spikes by producing larger voltage spikes than that obtained at high temperatures). The network closely predicted the large spikes at $0{ }^{\circ} \mathrm{C}$, the spikes were more pronounced and closely follows the measured voltage response of the cell. Again, these results reaffirm our conclusion advanced above, we believe that the net learned the correct temperature response of the cell.

\section{Acknowledgments}

The authors are grateful for the support obtained from DOE/BES (Contract No. DEFG02-93ER14387/A003). Dr. Urquidi-Macdonald is especially grateful to the NASA-ASEE summer fellowship program. Special thanks are extended to Dr. Chris Smith, SAFT AMERICA, Inc. for providing the data employed in this work (obtained under NASA contract).

\section{References Chapter 6}

1. M. Urquidi-Macdonald and P. Egan. Author of a Chapter in Corrosion Reviews, special issue on Applications of Computers in Corrosion, Vol XV, Nos. 1-2, Freud Publishing House, 1997.

2. Yoh-Han Pao. Adaptive pattern recognition and Neural Networks. Addison Wesley, 1989.

3. L. Romero, Discharge Profile Test Report for the Pistol Grip Tool Engineering Battery, SAFT America, Cockeysville, MD. Internal Report prepared for Fairchild Space, Washington Technical Support Center.

4. Gilbert Strand and Truong Nguyen. Wavelets and Filters. Wellesley Cambridge Press, 1996. 


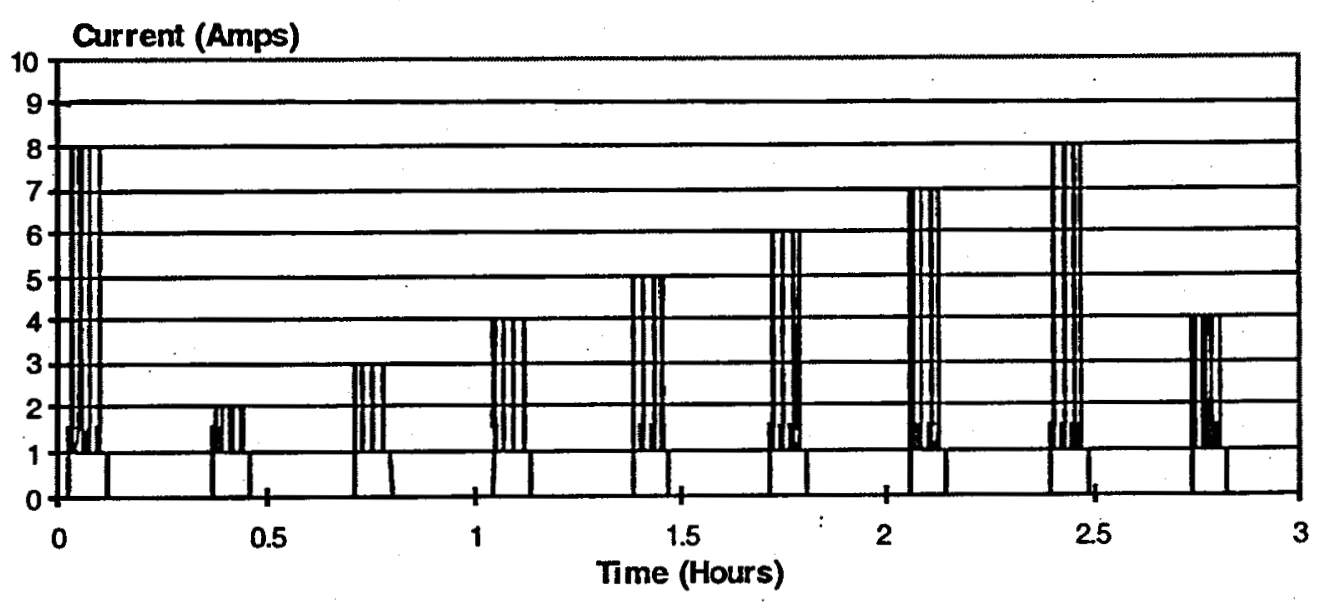

Figure 6. 1. Discharge profile 1: Typical current discharge profile. Test B at $20^{\circ} \mathrm{C}$, and test $\mathrm{J}$ at $40^{\circ} \mathrm{C}$.

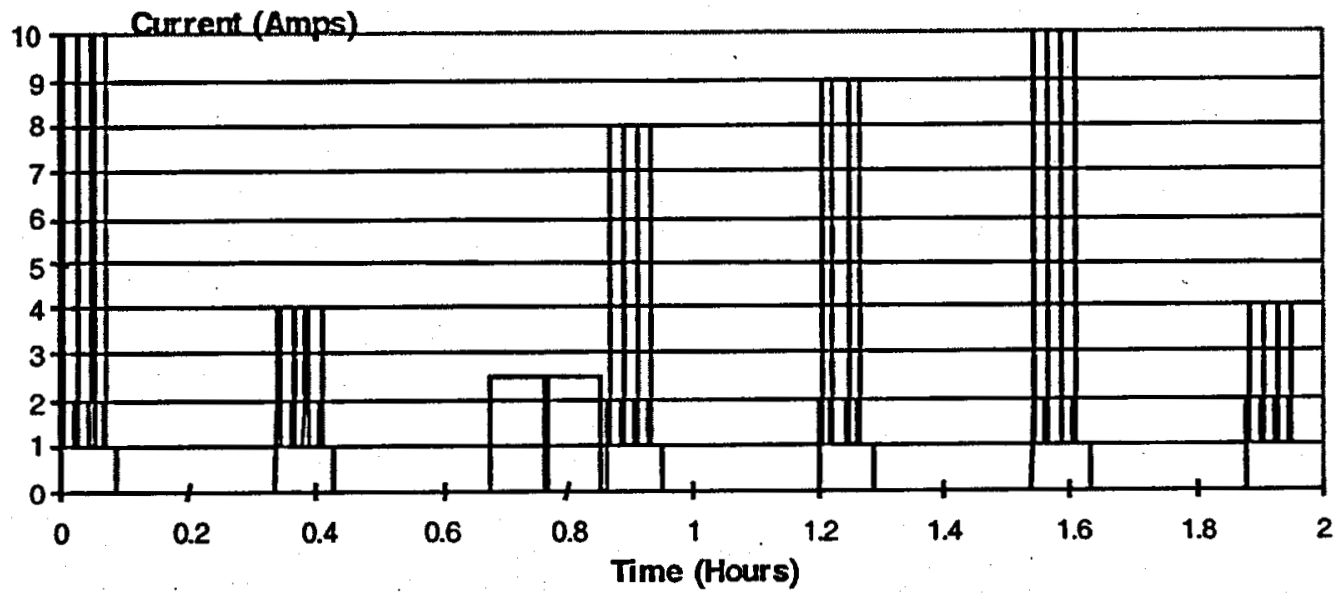

Figure 6.2. Discharge profile 2: Worst-case current discharge profile. Test $D$ at $20^{\circ} \mathrm{C}$, and test $\mathrm{H}$ at $0^{\circ} \mathrm{C}$. 


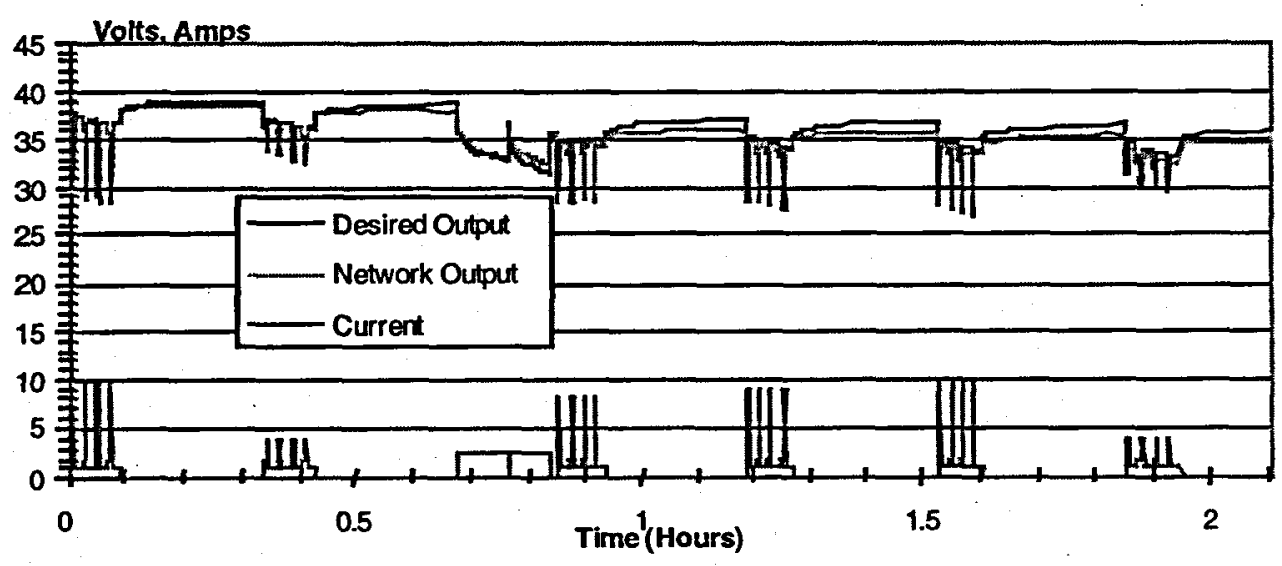

Figure 6.3. Net voltage response predictions on 2 hours of test $\mathbf{H}$ (gray) compared to measured cell voltage response (black). The input current pattern is shown at the bottom of the graphic (dark gray, bottom). The network was trained with the first 60 minutes of tests $B$ and $D$, and first 10 minutes of tests $\mathrm{H}$ and $\mathrm{J}$ (data representation one).

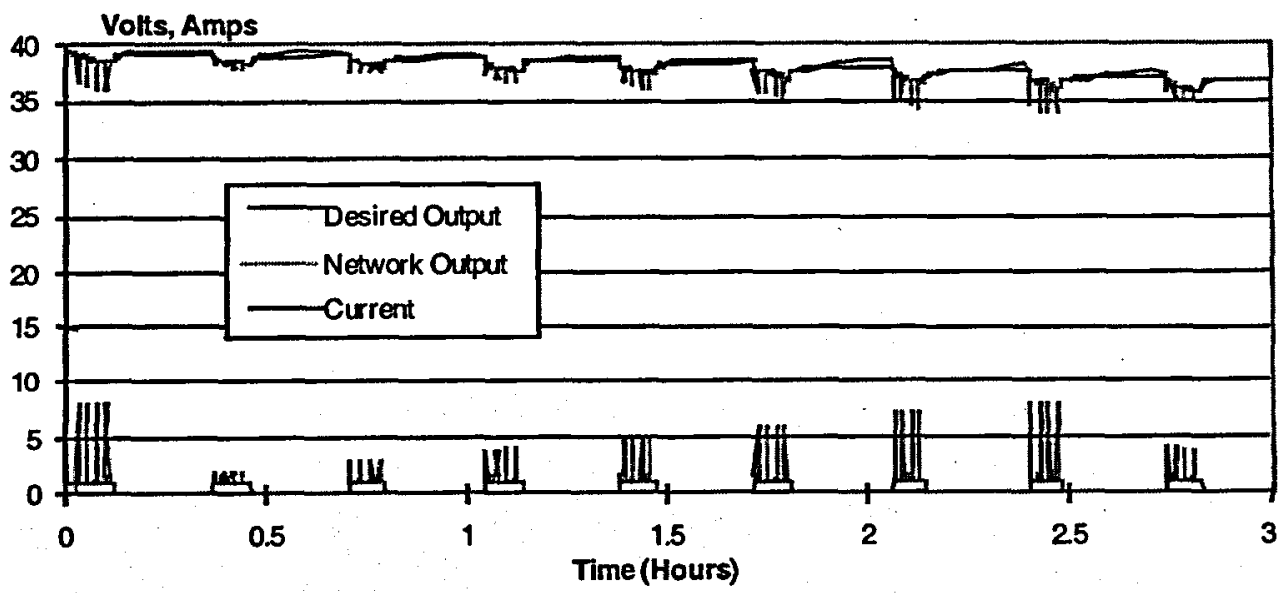

Figure 6.4. Net voltage response predictions on 2 hours of test $\mathrm{H}$ (gray) compared to measured cell voltage response (black). The input current pattern is shown at the bottom of the graphic (dark gray, bottom). The network was trained with the first 60 minutes of tests $B$ and $D$, and the first 10 minutes of tests $\mathrm{H}$ and $\mathrm{J}$ (data representation one). 


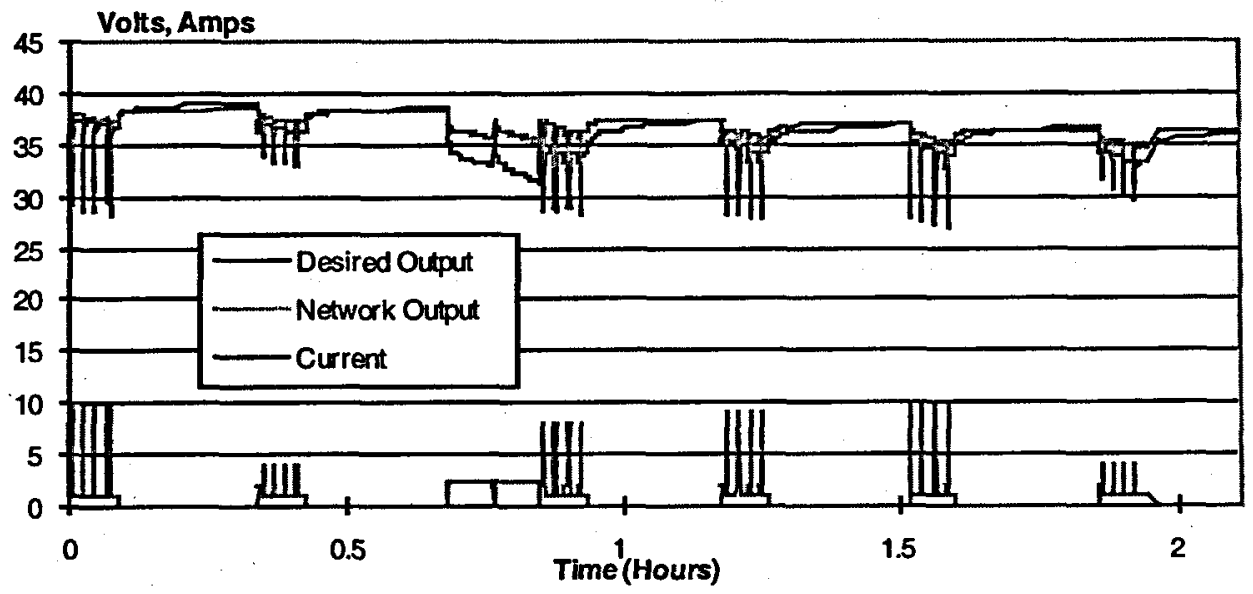

Figure 6.5. Net voltage response predictions on 2 hours of test $\mathrm{H}$ at $0^{\circ} \mathrm{C}$, and profile 2 - (gray) compared to measured cell voltage response (black). The input current pattern is shown at the bottom of the graphic (dark gray, bottom). The network was trained with the 120 minutes of tests test $\mathrm{B}$ (data representation one and $20^{\circ} \mathrm{C}$ ).

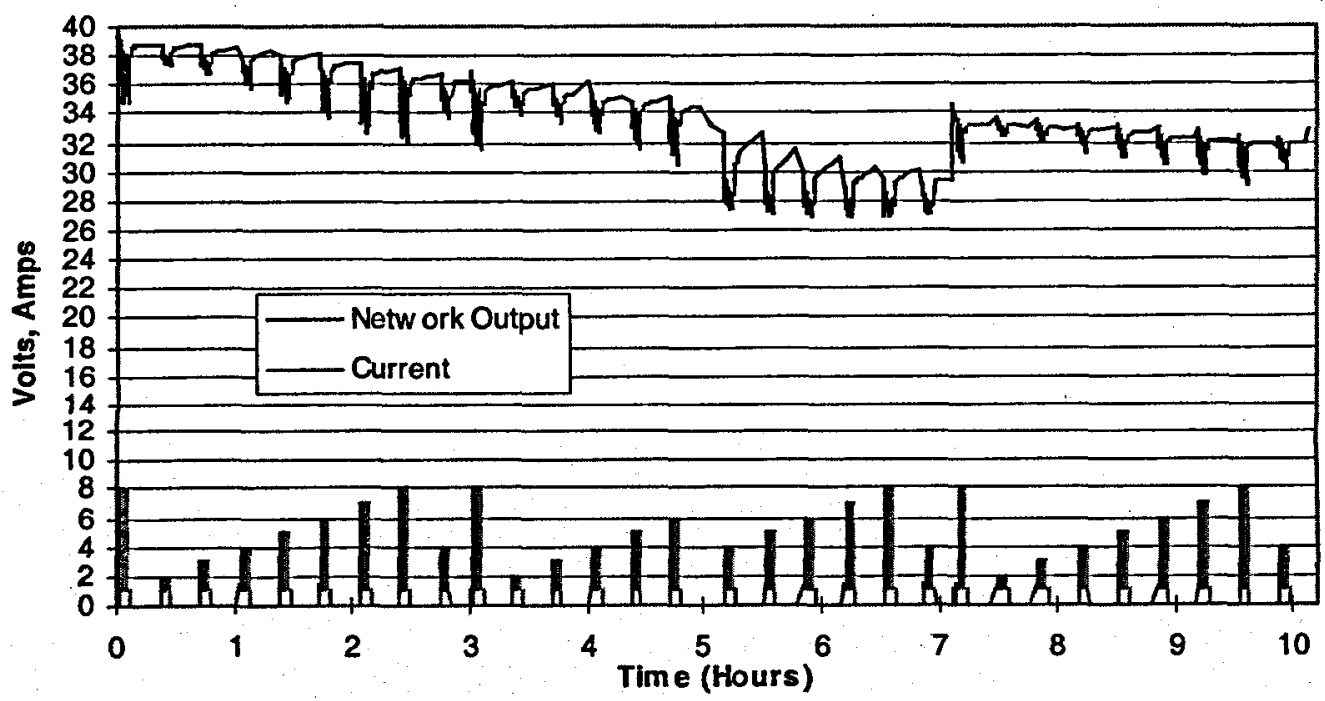

Figure 6.6. Simulated network voltage response (black) for an input excitation pattern as indicated (gray). The net was trained with tests $B, D, H$, and $J$ corresponding to profile characteristics 1 and 2 and temperatures 0,20 , and $40^{\circ} \mathrm{C}$. The results of the net were obtained by inputting a current pattern as test $\mathrm{B}$ but for which the temperature was artificially assigned as $20^{\circ} \mathrm{C}$ for the first 5 hours, $0^{\circ} \mathrm{C}$ for the 2 following hours and finally 3 hours at $40^{\circ} \mathrm{C}$. 


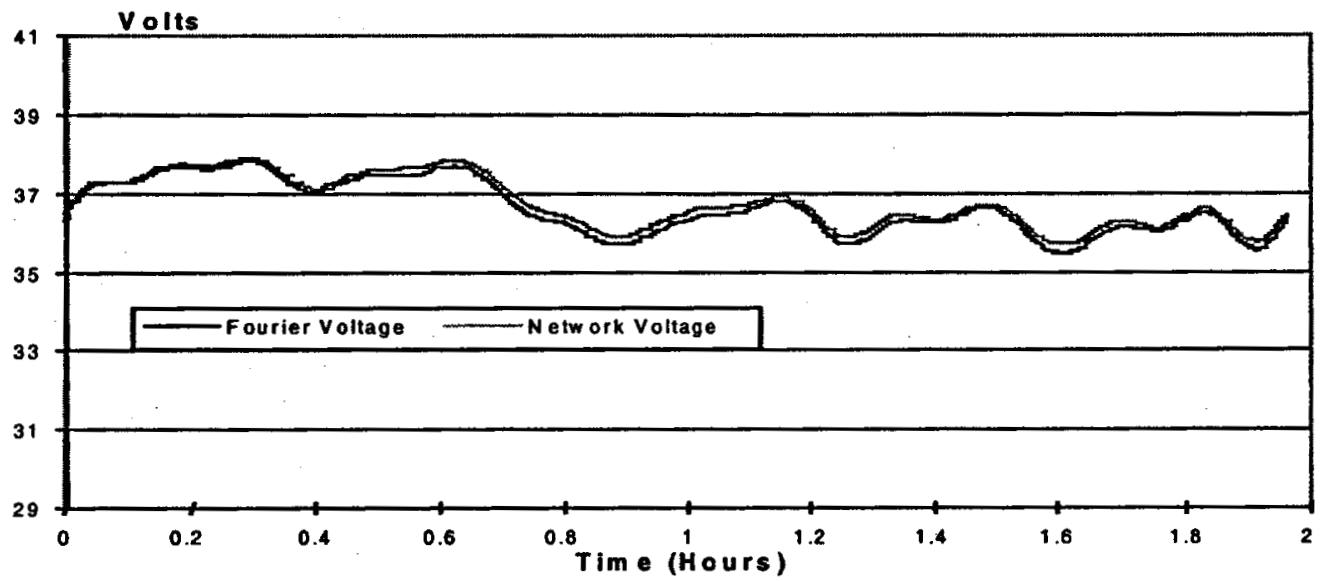

Figure 6.7. Fourier voltage and network voltage during a two hour test. The network was trained with Fourier coefficients (16) on the first 2 hours of test B (profile $1,20^{\circ} \mathrm{C}$ ); and tested with test $\mathrm{D}$ (profile $2,20^{\circ} \mathrm{C}$ ).

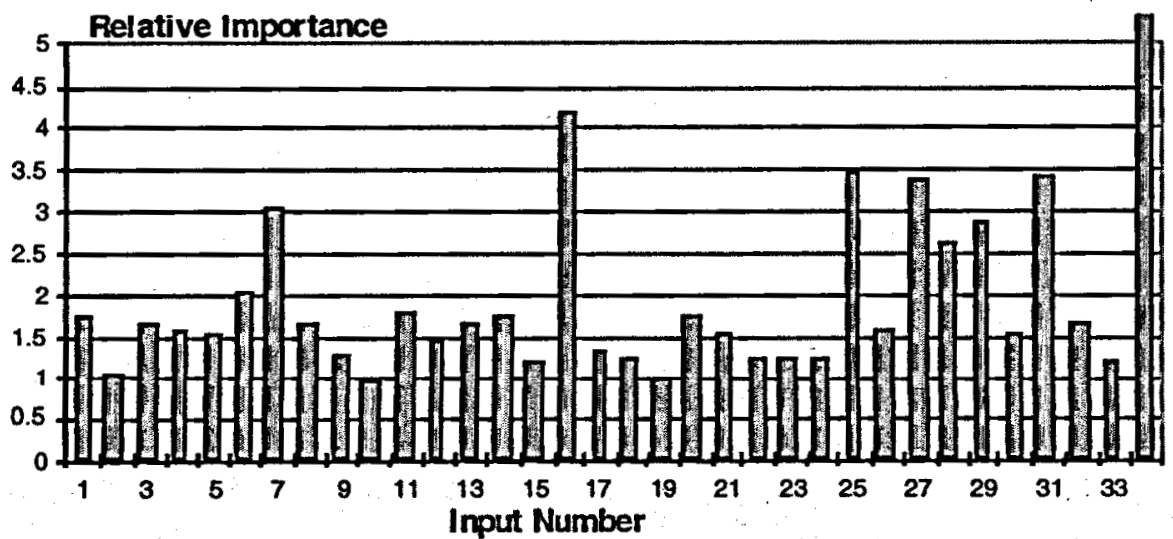

Figure 6.8. Relative importance of inputs for network trained with Fourier coefficients (16), test duration, and temperature. The net used during training was the first 2 hours of tests $\mathrm{B}, \mathrm{D}, \mathrm{H}$, and $\mathrm{J}$. 


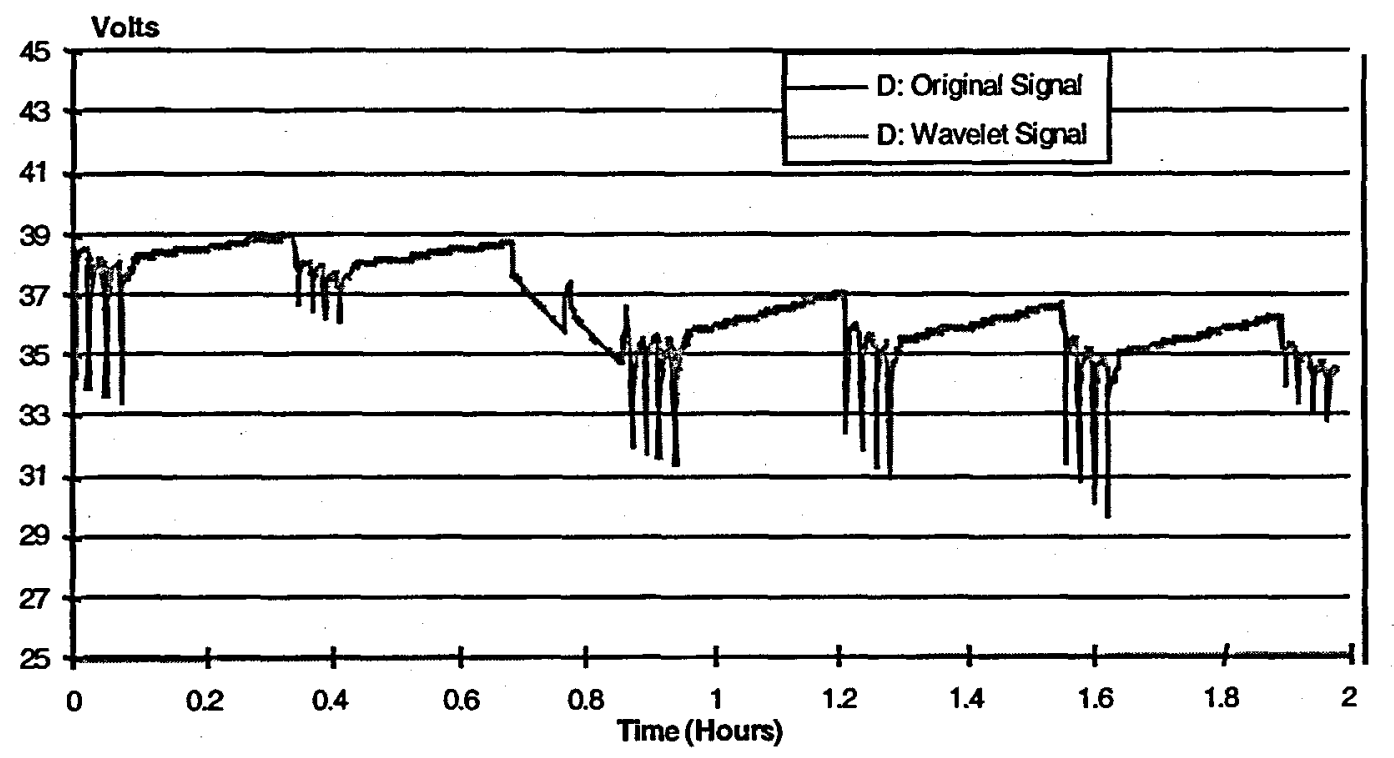

Figure 6.9. Original voltage signal from test D (black) compared to voltage signal produced by wavelet compression using 106 coefficients (gray). representation (106 coefficients) of test $\mathrm{J}$ (Profile 1 at $40^{\circ} \mathrm{C}$ ).

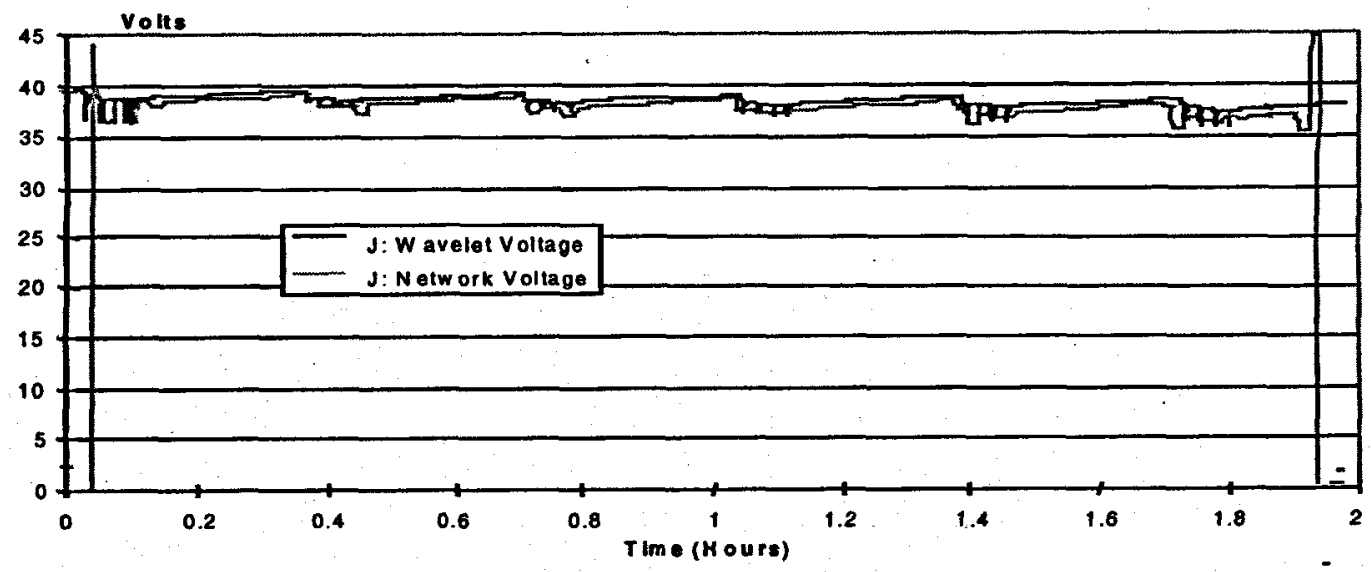

Figure 6.10. Voltage response network predictions (gray) compared to the measured voltage response (black). The net was trained using test $B$ (profile 1 at $20^{\circ} \mathrm{C}$ ) with only 106 coefficients extracted using a wavelet representation of the original signal. The net was tested using the wavelet representation (106 coefficients) of test $\mathrm{J}$ (profile 1 at $40^{\circ} \mathrm{C}$ ). 


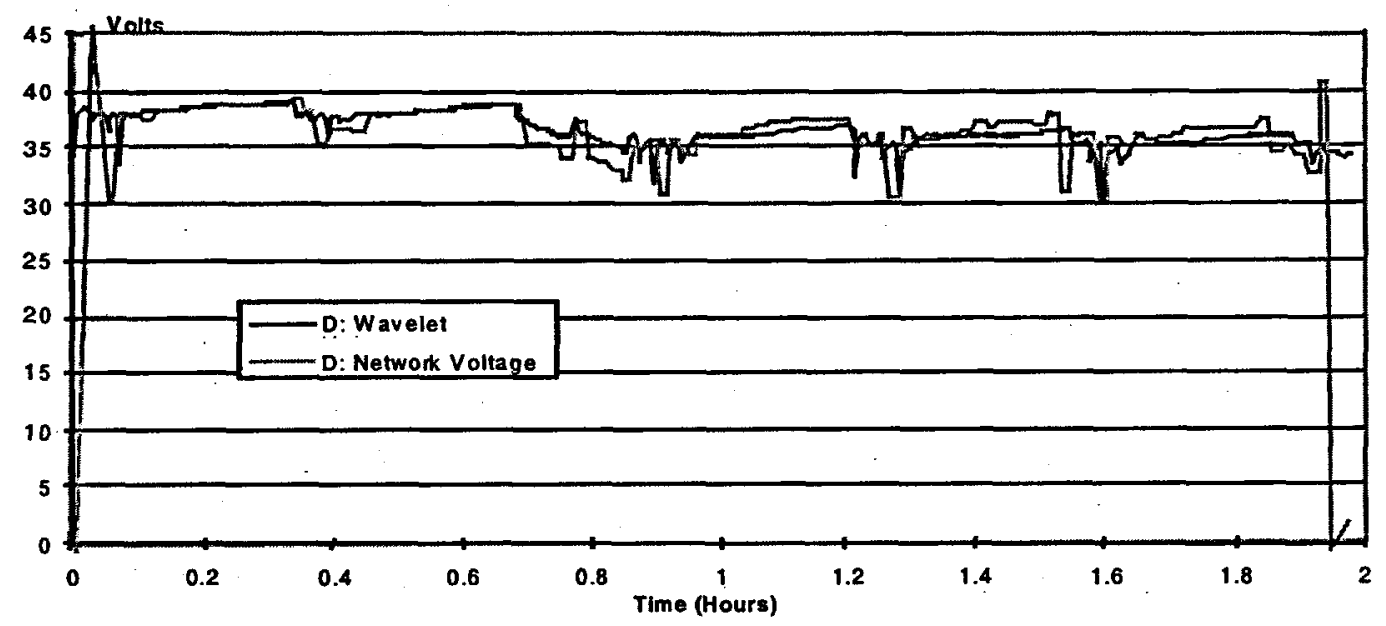

Figure 6.11. Voltage response network predictions (gray) compared to the measured voltage response (black). The net was trained using test B (profile 1 at $20^{\circ} \mathrm{C}$ ) with only 106 coefficients extracted using a wavelet representation of the original signal. The net was tested using the wavelet representation (106 coefficients) of test $\mathrm{D}$ (Profile 2 at $20^{\circ} \mathrm{C}$ ).

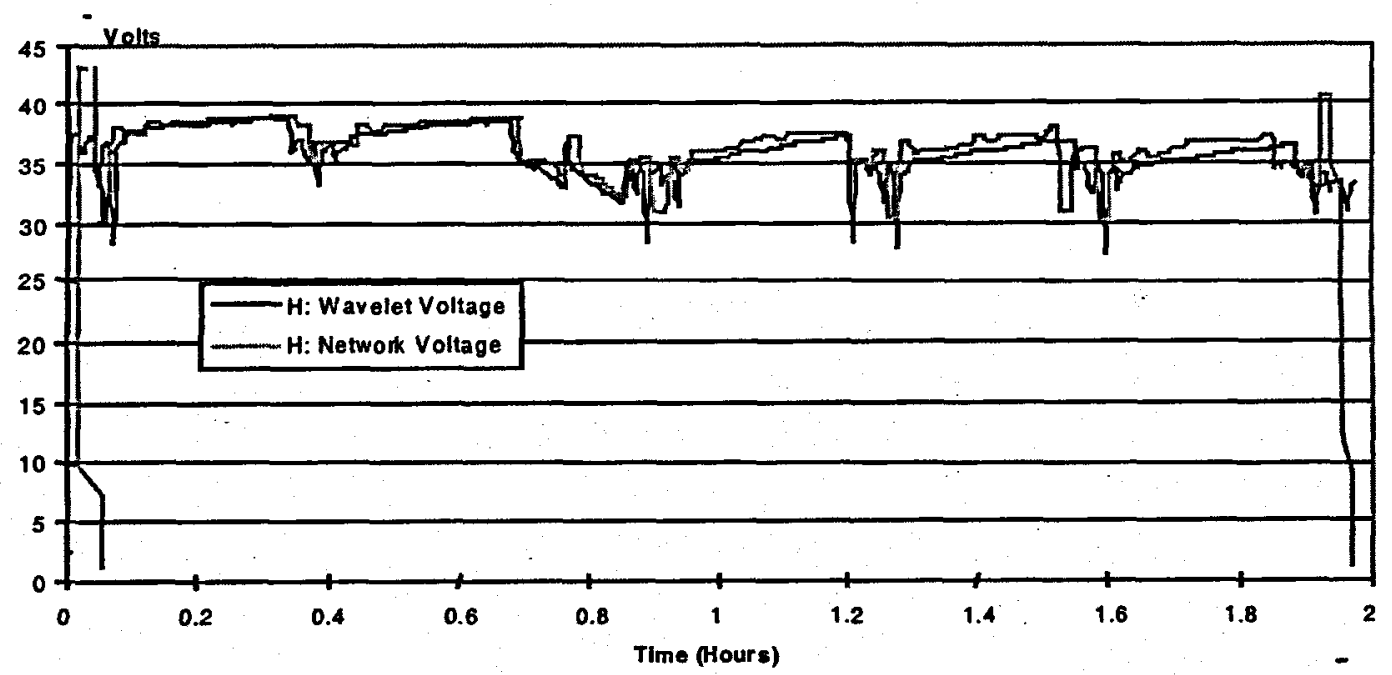

Figure 6.12. Voltage response network predictions (gray) compared to the measured voltage response (black). The net was trained using test $B$ (profile 1 at $20^{\circ} \mathrm{C}$ ) with only 106 coefficients extracted using a wavelet representation of the original signal. The net was tested using the wavelet representation (106 coefficients) of test $\mathrm{H}$ (profile 2 at $0^{\circ} \mathrm{C}$ ). 


\section{Chapter 7. Discussion}

Numerous new polyphosphazene solid electrolytes have been synthesized and the ionic conductivities of their complexes with dissolved salts (LiTriflate) have been measured. In designing polymer electrolyte materials, avoiding crystallinity, while maximizing the number of coordination sites, is of the utmost importance. The polymers bearing branched oligooxyethylene units are an improvement over MEEP, in that they have high ionic conductivities and are dimensionally stable enough to eliminate the need for radiation cross linking. Finally, the conductivity of MEEP has been dramatically improved by the addition of non-volatile plasticizers.

\section{Lithium Metal Anode/Polymer Interface}

The sensitive dilatometry results clearly show that irreversible processes, which lead to volume changes of the laminate, occur at the Li/Poly[bis(2,3-di(2methoxyethoxy)propoxy)phosphazene] interface during cycling. However, destructive analysis of the sample revealed no massive powdering of lithium at the Li/SPE interfaces. This explains the stable (constant) impedance throughout the entire cycling regimen. Interestingly, the impedance is found to be largely resistive, with no significant reactance being detected over the frequency $(\omega)$ range of $1 \mathrm{~Hz}$ to $10 \mathrm{kHz}$. At higher frequencies, reactance becomes significant, as shown by the increase in the phase angle (Figure 7.3). The lack of reactance for $\omega<10^{4} \mathrm{~Hz}$ also indicates that any geometric capacitance can be neglected. The density of lithium at $20^{\circ} \mathrm{C}$ is $0.535 \mathrm{~g} / \mathrm{cm}^{3}$ and the isotope-averaged atomic weight is $6.929 \mathrm{~g} / \mathrm{mol}$. The amount of lithium transferred from one side of the cell to the other during a cycle is $0.0029 \mathrm{~cm}$. Thus, the ratio of the lithium transferred to the thickness of the Li foil is 0.285 . Accordingly, one "turn" of lithium is transferred every 3.5 cycles, or 143 turns occur over the more than 500 cycles of a typical experiment.

The finding that the cell impedance is predominantly resistive is somewhat unusual in that previous [1,2], but not all [3], studies have demonstrated that the Li/SPE interface displays considerable reactance that may be attributed to parallel geometric, space charge, faradaic and mass transport phenomena. It might be postulated that the cell electrical properties reflect the development of a "soft" short due to the growth of lithium dendrites through the SPE. However, 
this explanation is considered to be unlikely for the following reasons: (i) the impedance displays reactance at sufficiently high frequency; (ii) the lower frequency resistive behavior occurs from the first cycle; (iii) the magnitude of the impedance does not change substantially over many cycles (Figures 7.1-7.6), although the scattered nature of the impedance precludes a definitive conclusion on this point; and (iv) the electrolyte film is thick (typically $300-400 \mu \mathrm{m}$ ), compared with that used in an actual battery (typically 30-50 $\mu \mathrm{m}$ ), and hence should be much less susceptible to dendrite penetration. Instead, we postulate that the resistive nature of the cell impedance for $\omega<10^{4} \mathrm{~Hz}$ reflects, firstly, the use of a thick electrolyte layer and secondly, the inherently resistive nature of interstitially-conducting reaction product films, as explored theoretically in this study. Finally, we note that the same resistive behavior has been found in more than 3 experiments of the type described in this report, representing a cumulative total of more than 1500 cycles.

The galvanostatic cycling performance of the Li/Poly[bis(2,3-di(2methoxyethoxy)propoxy)phosphazene] (SPE) interface has been explored by monitoring changes in the volume, impedance, and voltage drop across a $\mathrm{Li} / \mathrm{SPE} / \mathrm{Li}$ laminate as a function of cycle number. Cycling was performed at $25^{\circ} \mathrm{C}$ and at a current density of $6 \mathrm{~mA} / \mathrm{cm}^{2}$ for a charge "capacity" on each cycle of $6 \mathrm{~mA}-\mathrm{hr} / \mathrm{cm}^{2}$. The findings are as follows:

1. The volume of the laminate increases monotonically with cycle number, and reaches a steady-state after about 500 cycles. The increase in volume is attributed to the irreversible reaction of lithium with moisture and/or components of the electrolyte;

2. The measured laminate impedance was found to be resistive over a wide frequency range, and was found to be independent of cycle number (up to 1000 cycles maximum);

3. The pressure of the system increases monotonically with cycle number, as does the volume of the laminate, and reaches a steady state after about 500 cycles. The increase of the system is regarded as a result of both the absorption of water from the environment and the irreversible reaction at the interface;

4. No powdering of the lithium was detected;

5. No sudden increase in the laminate impedance, corresponding to "failure", was detected. 


\section{Intercalation Cathode}

The solid polymer electrolyte (SPE)/intercalation cathode (IC) interface appears to play a vital role in the degradation of this Li/SPE battery. The same cycling conditions were used in the $\mathrm{Li} / \mathrm{SPE}$ studies with one side of the cathode material $\left(\mathrm{MnO}_{2}\right.$, in this case) intercalated with $\mathrm{Li}^{+}$. Lithiated $\gamma-\mathrm{MnO}_{2}$ has been used in battery research for quite some time and is now available commercially. Because of the limited time available for this research, only a very restricted study of the SPE/C interface was possible.

Models has been developed to explain the behavior of the IC (intercalation cathode) DC and $\mathrm{AC}$-impedance data by assuming interstitial $\mathrm{Li}^{+}$conduction across the IC with subsequent penetration into the active material $\left(\mathrm{MnO}_{2}\right.$ particle) surface. This model, combined with percolation, appears to be capable of accounting for the slow degradation if the IC capacity with increasing cycle number as well as accounting for the catastrophic failure of the cathode.

AC impedance measurements for a cathode-polymer-cathode system were carried out, and the life cycle of the cathode, and cathode response to several parameters, was studied.

The galvanostatic cycling performance of the Li/SPE/C cell, and IC/SMEEP/IC' using Poly[bis(2,3-di(2-methoxyethoxy)propoxy)phosphazene]/LiTriflate as SPE, has been explored by monitoring changes in the volume, pressure, impedance, and voltage drop across the cells as a function of cycle number. Cycling was performed at $25^{\circ} \mathrm{C}$ and at a current density of 6 to 10 $\mathrm{mA}-/ \mathrm{cm}^{2}$ with charge/discharge cycles lasting $2 \mathrm{hrs}$ or $4 \mathrm{hrs}$., respectively. The findings are as follows:

1. Little volume change of the laminate IC/SEP/C' occurs under conditions where no failure has taken place;

2. The non-ohmic part of the measured laminate impedance was found to be dominated by the impedance of the polymer electrolyte, and was found to be independent of cycle number;

3. The processing method of IC is found to be critical to the performance of the IC, and hence, the Li/SPE/C battery. Pre-compression of the IC using MEEP as the binder results in superior cycling performance over conventionally cast cathodes using the same polymer or compressed structures employing $\operatorname{Teflon}^{\odot}$. An optimal 
battery processing method has been reported in order to achieve the maximum cycle life.

\section{Artificial Neural Network}

Data representation one produced good results when trained with portions of both types of current profiles and portions of tests at each temperature. The amplitude/time representation (data representation one) required a little less than half the number of elements per input vector (54 inputs) than the wavelet representation (data representation three, 106 inputs). However, while one vector. is used to train a net when representation two or three is used, representation one requires 1,416 different vectors to present to the network (each vector is 54 elements long, and it simulates two hours length sample), and training took longer. Representation one allowed the net to interpolate temperatures and patterns very well. But the net trained with representation one, when only one type of pattern and one temperature were used during the net training, had some problems extrapolating temperatures and pattern types (it underestimated them). The net showed good capabilities of extrapolating data over a period of two hours when trained for just minutes with all information about temperature and pattern. We had only data measured over two hours to compare with the net predictions. The net predictions obtained over 10 hours agreed with our expectations based on experience and data available. ${ }^{3}$ The net is capable of accurately predicting the output voltage with time for the lithium-ion battery.

Data representation two produced the correct voltage output for current patterns that it had not been trained with. However, the level of detail of the 1416 data point with 16 Fourier coefficients was not good enough to confirm that the net was capable of extrapolating behaviors (e.g., to predict temperatures outside the range of temperatures the net was trained with). The Fourier representation does not capture all the current spikes imposed on the cell, nor the voltage response spikes of the cell, but only a wave type response results. The Fourier representation did not require pre-processing of training data, as compared to data representation one. To better reproduce the original pattern, more Fourier coefficients would have to be used. The network should not experience any loss in performance in this case, but this increase in coefficients would mean an increase in input and output elements of the network. Another problem encountered with this representation was that the network could not be trained with part 
of a test and then tested with the rest of to same test, because the network had to be trained with Fourier coefficients from test segments of a uniform length.

The wavelet representation (representation three) was similar to the Fourier representation in the sense that it required no pre-processing of the data before presentation to the network, unlike the amplitude/time representation (representation one). The wavelet coefficient data representation experienced the same problem as the Fourier representation, since the wavelet coefficients also had to be generated from test segments of the same length (in this research we used two hours), i.e., the net can not be trained in one segment of a current/voltage signature and tested in another segment of the same signature. However, the wavelets, representation is more closely tuned to the current and voltage signatures. The spike behavior was easily captured; accordingly we could more easily assess the performance of the net trained with the wavelet representation than the net trained with the Fourier representation. The net trained with the wavelet representation performed much better than the net trained with the Fourier transform. Data representation three accurately reproduced the original voltage signal with a relatively small number of wavelet coefficients. Conversely, the discrete Fourier transform with 128 coefficients (including real and imaginary) did not reproduce more than small waves in response to steep voltage drops (spikes). In comparison with the previous two representations, the wavelet representation had the most powerful extrapolating capabilities; it captured well the temperature and pattern dependency response of the cell information embodied in the current/voltage temperature without the need to explicitly define temperature and pattern type.

This results appears to indicate that the response to a current pattern is a cell property. A well trained net will capture that mathematical function that correctly describes the cell's response to current patterns and temperature changes. That net will be able to extrapolate correctly the cell behavior. The net trained with the wavelet representation using only a given pattern and temperature predicted the response of the cell at different temperatures and current patterns imposed on the cells. The wavelet representation had the best extrapolation capabilities (and of course interpolation) when compared to the other representations. The wavelets data representation with (data representation three) looks very promising in predicting the cycling failure of batteries, because it appears to capture the hidden functions describing temperature dependency and effect of long current plateaus (instead of spikes). 
Coming back to the discussion of how many coefficients to choose to represent a given signature when Fourier or wavelet coefficients are chosen to represent the input current pattern, we can anticipate that if all of the sampling points were used, and more coefficients generated, greater detail in the signature would be produced, but at a cost of increasing the number of elements in the neural network. This increase in the number of elements is not a great concern, however, because although there may be many elements in an input vector, there will be only one input vector for each test used for training.

This paper does not represent an exhaustive study of the parameters that can affect the cycling life of a battery. We were limited to using only those parameters that were monitored during the used tests. If more information on variables were made available, a similar technique to the one described in this paper could be used. For example, none of these data representations had any input elements representing the capacity loss due to repeated recharge/discharge cycles. This capacity loss is difficult to measure for so few tests because it is expected to be very small. Since the tests were conducted at different temperatures it is difficult to decide whether to attribute capacity loss to temperature change or repeated cycling. If data were available from tests conducted for repeated rechärge/discharge cycles conducted at a constant temperature, an input element could be included to represent the previous cycles of the battery, and the network could learn the effects of repeated cycling on the output voltage. More extended databases are needed.

In each one of the cases presented, the network voltage predictions followed very closely the measured voltage pattern (when data were available to compare), and we can conclude that the predictive capabilities of the net trained with any of the three data representations are, as discussed, very good, making neural networks a very promising technique in predicting cycling life of batteries.

\section{References Chapter 7}

1. T. Momma, S. Kakuda, H. Yarimizu and T. Osaka, J. Electrochem. Soc., 142, No.6, p. 1766-1769, 1995.

2. D. Fauteux, Solid State Ionics, 17, p. 133-138, 1985.

3. S. Sloop and M. Lerner, J. electrochem. Soc., 143, p. 1292-1297, 1996. 


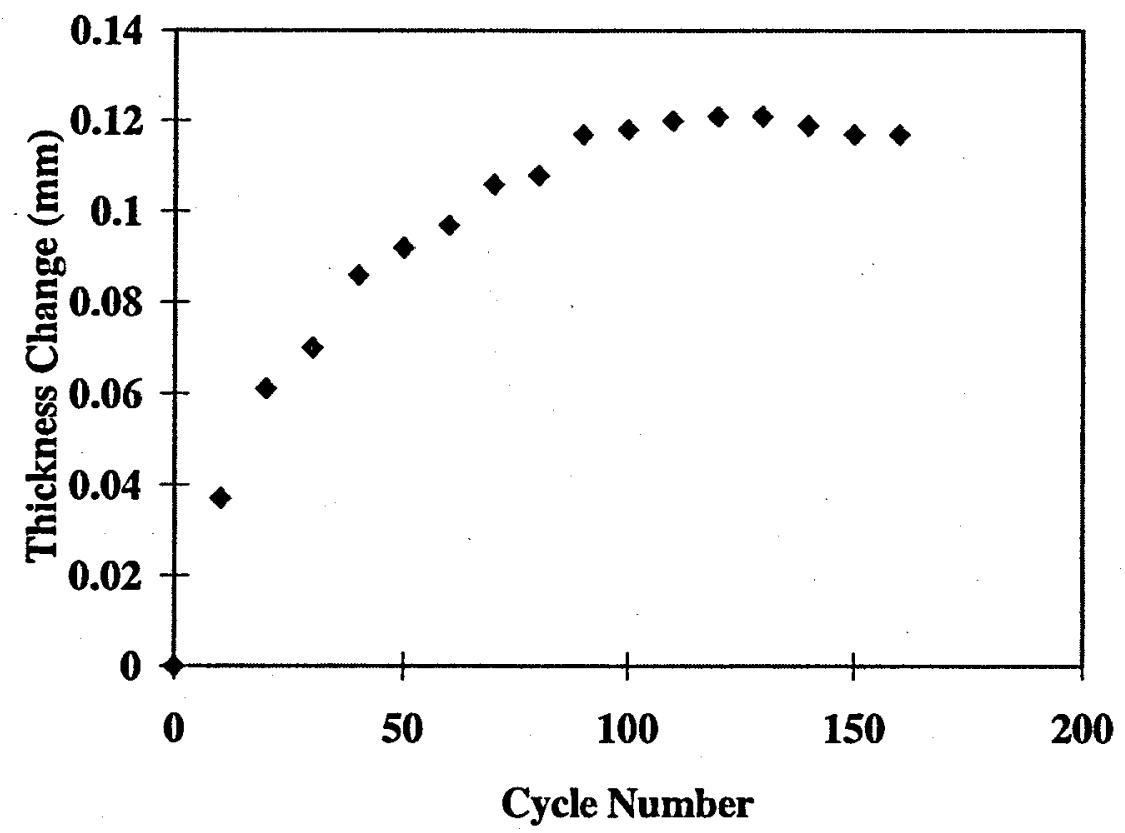

Figure 7.1. The change of $\mathrm{Li} / \mathrm{SPE} / \mathrm{Li}$ laminate thickness as a function of cycle number. Run \#1: Initial pressure $=0 \mathrm{psi}$

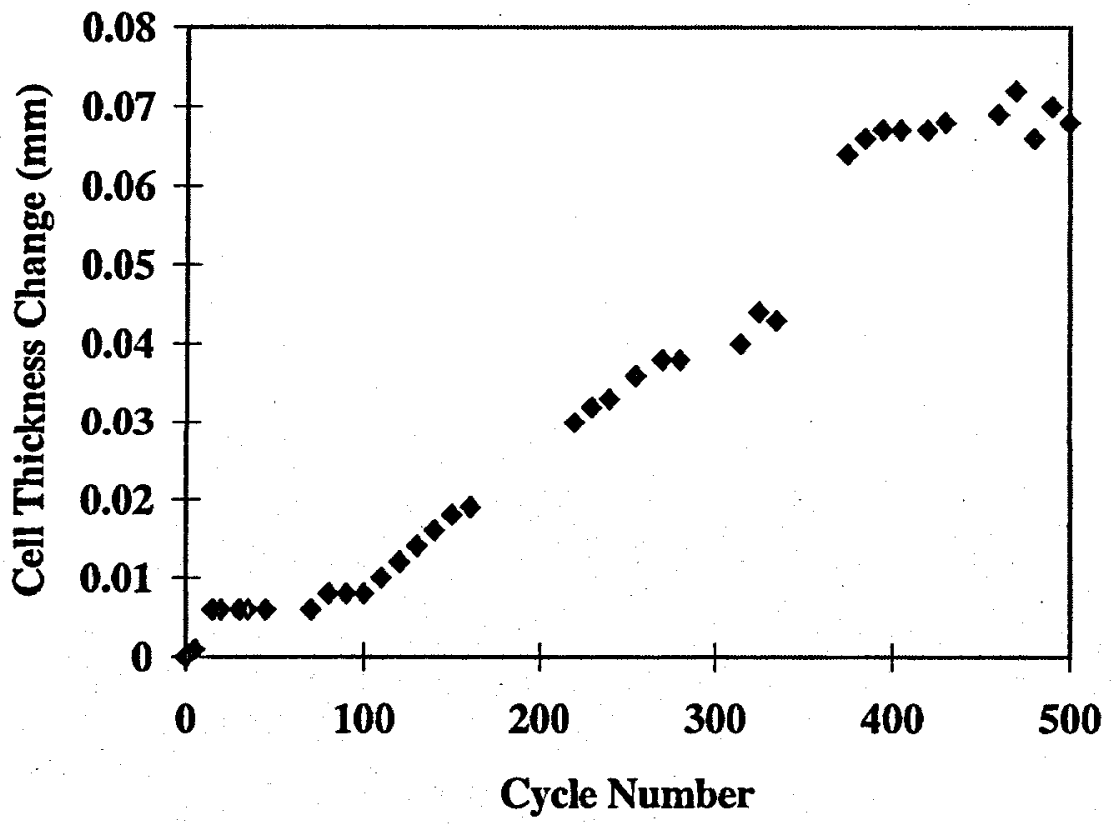

Figure 7.2. The change of $\mathrm{Li} / \mathrm{SPE} / \mathrm{Li}$ laminate thickness as a function of cycle number. Run \#4: Initial pressure $=135 \mathrm{psi}$. 


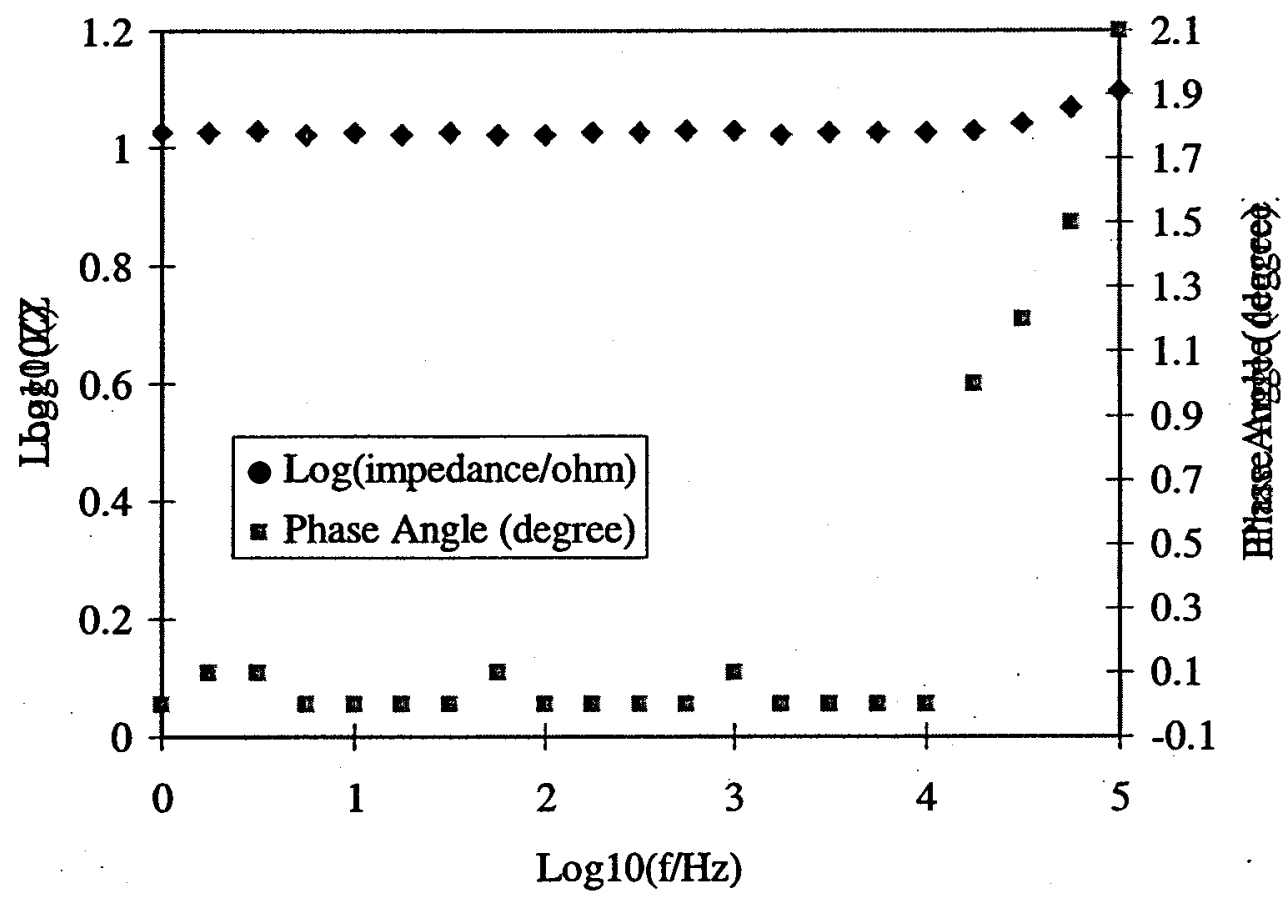

Figure 7.3. Typical Bode diagram for the $\mathrm{Li} / \mathrm{SPE} / \mathrm{Li}$ laminate demonstrating the resistive nature of the measured impedance.

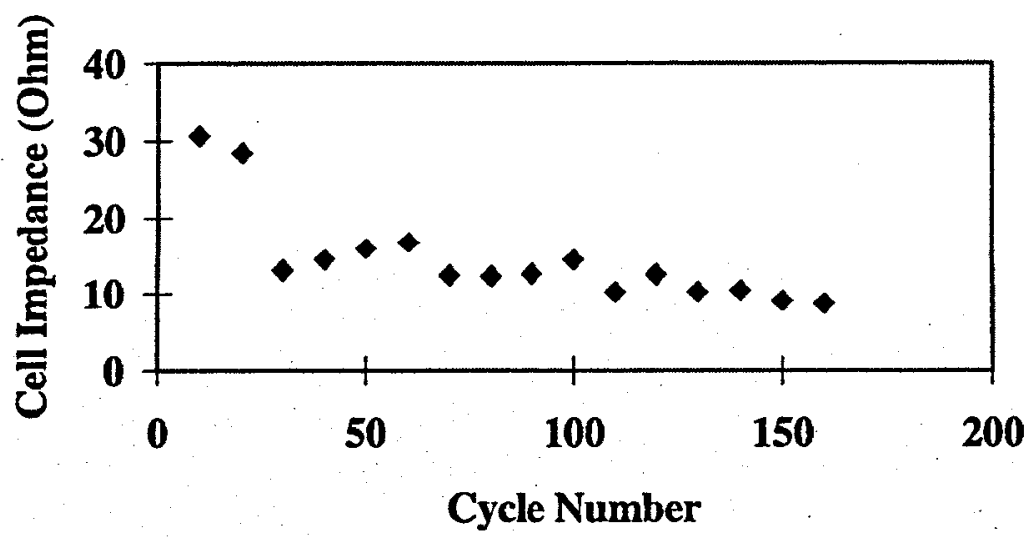

Figure 7.4. The measured impedance of the $\mathrm{Li} / \mathrm{SPE} / \mathrm{Li}$ laminate as a function of cycle number. Run \#1: Initial pressure $=0$ psi. 


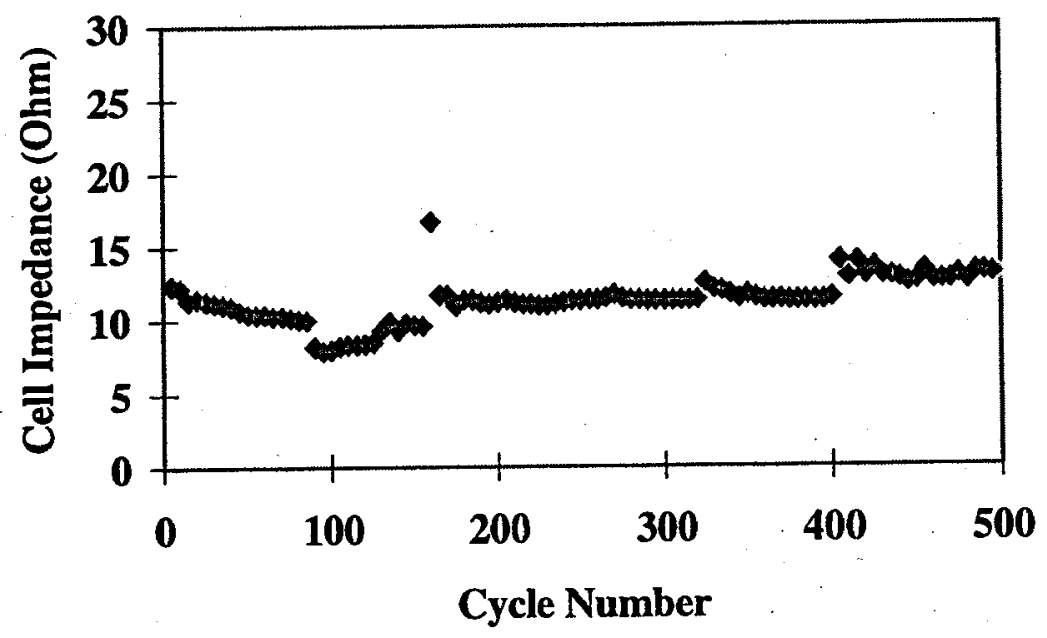

Figure 7.5. The measured impedance of the $\mathrm{Li} / \mathrm{SPE} / \mathrm{Li}$ laminate as a function of cycle number. Run \#3: Initial pressure $=46$ psi.

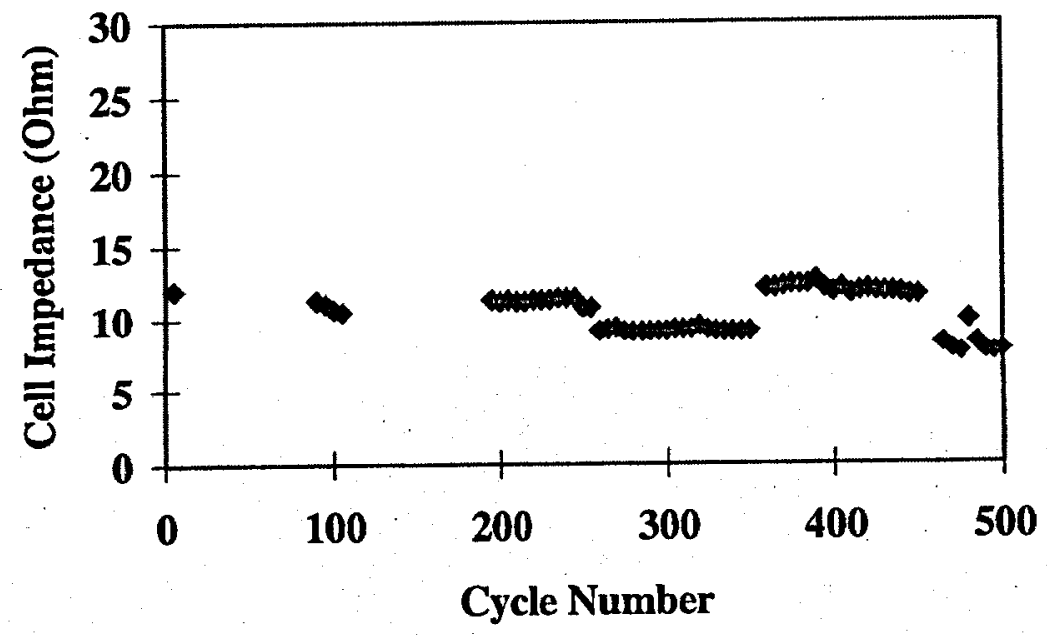

Figure 7.6. The measured impedance of the $\mathrm{Li} / \mathrm{SPE} / \mathrm{Li}$ laminate as a function of cycle number. Run \#4: Initial pressure $=135$ psi. 


\section{Appendix 1. List of Publications and Abstract Submitted for Publication or in Preparation}

Polyphosphazenes Bearing Branched and Linear Oligoethyleneoxy Side Groups as Solid Solvents for Ionic Conduction. Allcock, H. R.; O'Connor, S. J. M.; Olmeijer, D. L.; Napierala, M. E.; Cameron, C. G. Macromolecules 1996, 29, 7544.

Synthesis of Polyphosphazenes with Ethyleneoxy-Containing Side Groups: New Solid Electrolyte Materials. Allcock, H. R.; Kuharcik, S. E.; Reed, C. S.; Napierala, M. E.. Macromolecules 1996, 29, 3384.

Synthesis and Characterization of Ionically Conducting Alkoxy Ether/Alkoxy Mixed-Substituent Poly(organophosphazenzes) and Their Use as Solid Solvents for Ionic Conduction. Allcock, H. R.; Napierala, M. E.; Cameron, C. G.; O’Connor, S. J. M. Macromolecules 1996, $29,1951$.

Effect of Oligoethyleneoxy-cyclotriphosphazenes, Tetraglyme, and Other Small Molecules on the Ionic Conductivity of the Poly[bis(methoxyethoxyethoxy)-phosphazene] (MEEP) / Lithium Triflate System. Allcock, H. R.; Ravikiran, R.; O’Connor, S. J. M. Macromolecules (accepted)

Predicting Secondary Battery Failure Before it Happens. Mirna Urquidi-Macdonald and Neil A. Bomberger. The Electrochemical Meeting, Montreal, Canada, May 1-5, 1997 (accepted).

Characterization of Irreversible Processes at the Li/ Poly[bis(2,3-di-(2methoxyethoxy)propoxy)phosphazene] Interface on Charge Cycling. Gao, L.; Macdonald, D.D.. J. Electrochem. Soc. 1997, 144, 1174-1179.

Characterization of Irreversible Processes at the Li/ Poly[bis(2,3-di-(2methoxyethoxy)propoxy)phosphazene] Interface on Charge Cycling. Lei Gao, D.D. Macdonald. Battery/Energy Technology Joint General Session. 191st Meeting of the Electrochemical Society, Inc. Montreal, Quebec, Canada, May 5th, 1997 
Charge Cycling and Characterization of Polyphosphazene Solid Polymer Electrolyte-Manganese (IV) Oxide Intercalation Cathode Interface. Lei Gao, Digby D. Macdonald, Mirna UrquidiMacdonald, David L. Olmeijer, and Harry R. Allcock, Electrochim. Acta, in preparation (2001). 


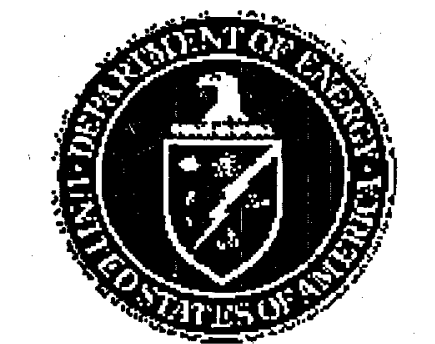

$\lambda$

Invention Information

Invention No S-87,858

Contract ID DE-FG02-93ER14387

Sub-Contract ID

Contractor No P00027

Docket No PSU-96-1660

Contractor Name PENNSYLVANIA STATE UNIVERSITY

Serial No

Patent No

OUTCNSL

PROSEC CP

OPCPRO MFL

Responsible

GOCO

Tech Class

E6.83

SIR APPL NO

Waiver No NO

ARB/ASAP

Foreign File NO Status AID

BYDO ID NP

BR Code $\quad \ldots$.

Action Due Date

11

Disclosure Date

10/17/1996

Invention Status Date

05/14/1999

Appl Forwarded to HQ

11

Application Filed

I I

Patent Issued

I I

Patent from Contractor

11

Assignment Lic to HQ

I I

Return Date

11

Agreement Type

Record Date

Reel/Frame

Inventors

OLMEIJER D L

ALLCOCK H R

\section{Description}

PHOSPHAZENES BEARING SULFONE OR SULFOXIDE GROUPS - 3/16/99 CR declines title. 5/14/99 AID insufficient novelty and information for patent application. 
05/15/2001

10:06:03 AM

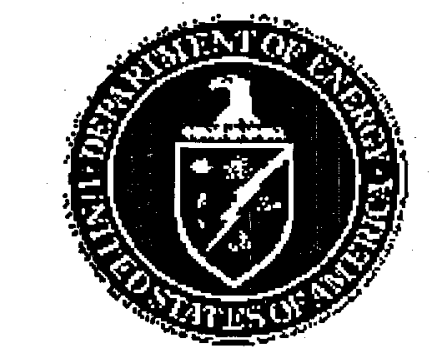

\section{Invention Information}

Invention No S-89,827

Contract ID DE-FG02-93ER14387

Sub-Contract ID

Contractor No P00027

Docket No PSU-97-1803

\section{Contractor Name PENNSYLVANIA STATE UNIVERSITY}

Serial No $\quad 917,069$

Patent No $\quad 5,914,388$

$\begin{array}{lll}\text { OUTCNSL } & \text { PROSEC }\end{array}$

OPCPRO JP Responsible

GOCO

Tech Class

C9.1

SIR APPL NO

Waiver No NO

Foreign File NO

Status LICREC

ARBIASAP

BYDO ID NP

BR Code

Action Due Date

11

05/27/1999

08/22/1997

$08 / 08 / 2000$

I I

03/04/1999
Disclosure Date

$09 / 29 / 1997$

Appl Forwarded to HQ / /

Patent Issued

$06 / 22 / 2000$

Assignment Lle to HQ / /

Agreement Type

Reel/Frame

$9807 / 0672$

\section{Inventors}

ALLCOCKHR

NELSON J M

PRIMROSE AP

HARTLE T J

PRANGE R

\section{Description}

SYNTHESIS OF POLYPHOSPHAZENES WITH CONTROLLED MOLECULAR WEIGHT AND POLYDISPERSITY (AS FILED) 9/22/97 CR elects title. 11/7/97 CONF LIC TO CR. 2/9/99 REQ FOR CONF LIC. 2/17/99 Cy Pat Appl \& exec Conf Lic. 3/4/99 Confirmatory License to PTO. 5/27/99 PTO Recordation memo. 8/8/00 Cy issued patent. 2/7/01 Cy issued patent.

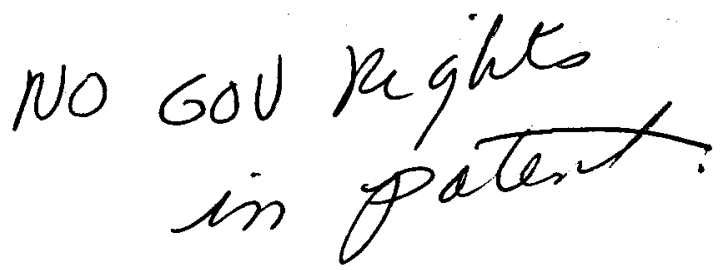

